Louisiana State University

LSU Digital Commons

1970

\title{
The Kinetics of Polymerization of Pentafluorostyrene.
}

Tzu-lee Huang

Louisiana State University and Agricultural \& Mechanical College

Follow this and additional works at: https://digitalcommons.Isu.edu/gradschool_disstheses

\section{Recommended Citation}

Huang, Tzu-lee, "The Kinetics of Polymerization of Pentafluorostyrene." (1970). LSU Historical

Dissertations and Theses. 1785.

https://digitalcommons.Isu.edu/gradschool_disstheses/1785

This Dissertation is brought to you for free and open access by the Graduate School at LSU Digital Commons. It has been accepted for inclusion in LSU Historical Dissertations and Theses by an authorized administrator of LSU

Digital Commons. For more information, please contact gradetd@lsu.edu. 
HUANG, Tzu-Lee, 1938-

THE KINETICS OF POLYMERIZATION OF

PENTAFLUOROSTYRENE.

The Louisiana State University and Agricultural and Mechanical College, Ph.D., 1970

Chemistry, organic

University Microfilms, Inc., Ann Arrbor, Michigan 
THE KİNETICS OF POLMERTZATION OF PENTAFLUOROSTYRENE

\author{
A Dissertation \\ Submitted to the Graduate Faculty of the \\ Louisiana State University and \\ Agricultural and Mechanical College \\ in partial fulfillment of the \\ requirements for the degree of \\ Doctor of Philosophy
}

in

The Department of Chemistry

by

Tzu-Lee Huang

B.S., Prov. Chung-Hsing University, 1960

Nay, 1970 
To Shiao Lung-Lung

Reproduced with permission of the copyright owner. Further reproduction prohibited without permission. 
ACKNOWLEDGEMENTS

Thise author would like to thank Professor William A.Pryor, whose heip ard inspiration led to the successful completion of this work. He would also like to thank Dr. R.A. Patsiga, Dr. T. Yamamota and Dr. W.:. Daly for their many helpful suggestions. His appreciation is extended to the members of Dr. Pryor's research group, especially Mr. Lynn D. Lasswel1 III; for their help in the completion of this work. He would like to thank the U.S. Army Research Office for a grant. He further acknowledges financial assistance from the . Charles I. Coates Memorial Fund, donated by George H. Coates, for preparation of this Ph.D. dissertation. Finally, he would like to thank his parents for their wholehearted support and encouragement. 
ACKNONLEDGEMENTS. . . . . . . . . . . . . . . . . II

IIST OF TABLES. . . . . . . . . . . . . . . . . . v

IIST OF FIGURES . . . . . . . . . . . . . . . . . .viI ABSTRACT. . . . . . . . . . . . . . . . . . . IX INTRODUCTION. . . . . . . . . . . . . . . . . . 1

Synthesis. . . . . . . . . . . . . . . . . 1

Kinetics of Polymerization . . . . . . . . . . . . 2

Mechanism of Thermal Initiation. . . . . . . . . . . 5

The Rotating Sector Method . . . . . . . . . . . 8

Copolymerization . . . . . . . . . . . . . . 13

The Q - e Scheme . . . . . . . . . . . . . 15

The 6 Factor . . . . . . . . ........... 17

HOMOPOLYMERIZZATION. . . . . . . . . . . . . . . . 19

I. EXPERTMENTAL SECTION . . . . . . . . . . . 19

II. RESULTS AND DISCUSSION . . . . . . . . . . . 24

Thermal Polymerization of PFS in Bulk at Different

Temperatures . . . . . . . . . . . . . . 24

Molecular Weight Determinations. . . . . . . . . 25

The Polymerization of PFS Initiated by AIBN at

Different Temperatures ............ . 32

Data on the Thermal Polymerization of PFS in

Solvents at 60\%............... 50

The Mechanism of Thermal Initiation. . . . . . . 54

The Measurement of the Rate of Initiation for PFS. . . . 81

The Determination of Radical Lifetime (The Rotating

Sector Method) ................. . 83

COPOLYMERIZATION. . . . . ............... . . 98

I. EXPERIMENTAL SECTION . . . . . . . . . . . . 98

II. RESULTS AND DISCUSSION . . . . . . . . . . . . . 99

Copolymerization of PFS and Styrene Initiated by AIBN. . 99

Copolymerization of PFS and Methyl Methacrylate

Initiated by AIBN. . . . . . . . . . . 100

iii 
Therinal Copolymerization of PFS and Styrene. . . . . 102

Thermal Copolymerization of PFS and Methyl.

Methacrylate .................... 103

Copolymerization of PFS and Styrene in Solvents. . . . . 103

HETEROPOLYMERIZATION. . . . . . . . . . . . . . . . . 115

I. EXPERIMENTAL SECTION ................. 115

II. RESULTS AND DISCUSSION . . . . . . . . . . . 115

Variation of $\mathrm{R}_{\mathrm{P}}$ and $\overline{\mathrm{P}}$ with Monomer Concentration . . . . 115

Variation of $R_{P}$ with Initiator Concentration . . . . 117

SUMMARY . . . . . . . . . . . . . . . . . . 124

REFERENCES. . . . . . . . . . . . . . . . . . . . . 127

APPENDICES. ....................... 136

VITA. . . . . . . . . . . . . . . . . . 144

iv

Reproduced with permission of the copyright owner. Further reproduction prohibited without permission. 


\section{LIST OF TABLES}

TABLE

PAGE

1. Thermal Polymerization of PFS in Bulk at Different Temperatures. . . . . . . . . . . . . . . . 26

2. The Polymerization of PFS Initiated by AIBN $-{ }^{3} \mathrm{H}$ at $60^{\circ} \mathrm{C}$. 30

3. The Polymerization of PFS Initiated by AIBN at $60^{\circ}$. . . 36

4. The Polymerization of PFS Initiated by AIBN at $30^{\circ}$. . . . 38

5. The Polymerization of PFS Initiated by AIBN at $40^{\circ}$. . . . 40

6. The Polymerization of PFS Initiated by AIBN at $60^{\circ}$.

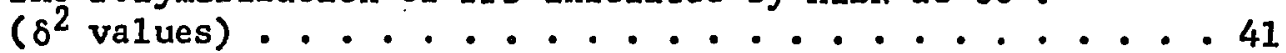

7. The Polymerization of PFS Initiated by AIBN at $30^{\circ}$ and

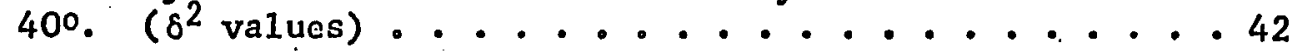

8. Thermal Polymerization of PFS in Solvents at $60^{\circ}$. . . . 63

9. Thermal Polymerization of PFS in Mixed Solvents Consisting of THF and Third Component. . . . . . . . . . . 66

10. Thermal Polymerization of Styrene in Solvents at $60^{\circ}$. . . 69

11. A Comparison of the Transfer Constants for PFS and Styrene Toward Several Solvents at $60^{\circ}$............. 72

12. The Order in Monomer for Thermal Polymerization of PFS and Styrene in Solvents at $60^{\circ}$............ 73

13. The Activation Energies for Thermal and Initiated Polymerization of Some Vinyl Monomers . . . . . . . . . 74

14. DPPH Disappearance in PFS - Solvent Mixtures at $80^{\circ}$. . . 84

15. Determination of Average Lifetime of PFS Radical at $30^{\circ}$. 90

16. The Photopolymerization of. PFS at $30^{\circ},[\mathrm{ACHN}]=3.00 \times 10^{-3} \mathrm{M}_{0} .92$

17. Theoretical Values of $R_{P} / R_{P_{8}}$ as a Function of $m$ and $z$ for

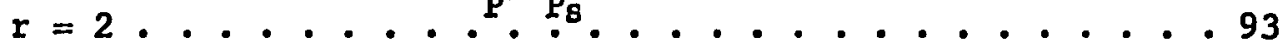

18. A Comparison of Absolute Rate Constants for Substituted Styrenes....................... 95

19. A Comparison of Radical Reactivities for PFS and Styrene. 96

20. Copolymerization of $\mathrm{PFS}\left(\mathrm{M}_{2}\right)$ and Styrene $\left(M_{1}\right)$ at $60^{\circ}$. . .106

21. Copolymerization of $\mathrm{PFS}\left(\mathrm{M}_{2}\right)$ and Methyl Methacrylate $\left(\mathrm{M}_{1}\right)$

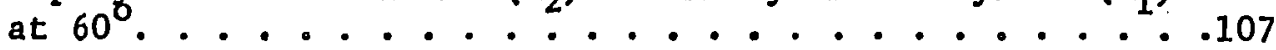

22. Copolymerization Parameters for Several Monomers with Styrene and Methyl Methacrylate . . . . . . . . . 108 
23. A Summary of the Copolymerization Parameters for PFS. . . . 109

24. - Values of the Cross-Termination Constant \$. ........ 110

25. Thermal Copolymerization of $\mathrm{PFS}\left(\mathrm{M}_{2}\right)$ and Styrene $\left(\mathrm{M}_{1}\right)$ at $60^{\circ}$........................................ 11

26. Thermal Copolymerization of PFS $\left(M_{2}\right)$ and styrene $\left(M_{1}\right)$ in

Solvents....................... . 112

27. Thermal Copolymerization of RFS $\left(M_{2}\right)$ and Methyl

Methacrylate $\left(M_{1}\right)$ at $60^{\circ}$......................... 113

28. The Polymerization of PFS in Methanol Initiated by AIBN.

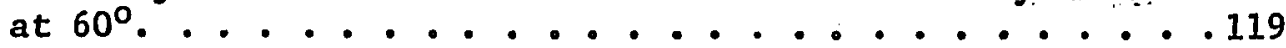

vi. 


\section{LIST OF FIGURES}

\section{FIGURE}

1. Arrhenius P1ot for Thermal Polymerization of PFS in Bulk. - 27

2. Plot of $\log \bar{M}_{\mathfrak{n}}$ vs. $\log R_{\mathrm{P}, \mathrm{th}}$ for Thermal Polymerization of PFS in Bulk ...... ............. 28

3. Plot of $\log \overline{\mathrm{P}}_{\mathrm{n}}$ vS。 $1 / \mathrm{T}$ for Thermal Polymerization of PFS in Bulk . . . . . . . . . . . . . . . . . 29

4. Intrinsic Viscosity in MIBK at $30^{\circ}$ for Poly-PFS vs. Molecular Weight. . . . . . . . . . . . . 31

5. Graph of Equation 10 for the AIBN-Initiated Polymerization of PFS at $60^{\circ}$. . . . . . . . . . . . . . 43

6. Graph of $\left(\overline{\mathrm{P}} \times R_{\mathrm{p}}\right)^{-1}$ for the Polymerization of PFS

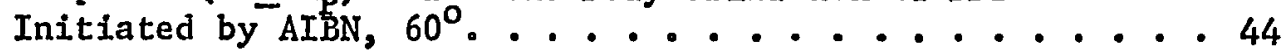

7. Graph of Equation 10 for the AIBN-Initiated Polymerization of PFS at $30^{\circ}$. . . . . . . . . . . . . . 45

8. Graph of Equation 13 for the AIBN-Initiated Polymerization

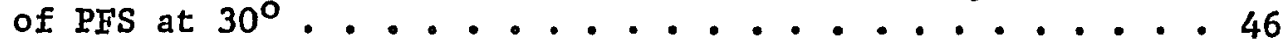

9. Graph of Equation 10 for the AIBN-Initiated Polymerization

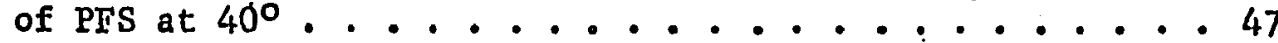

10. Graph of Equation 13 for the AIBN-Initiated Polymerization of PFS at $40^{\circ}$. . . . . . . . . . . . . . 48

11. Graph of $\log \left(1 / \delta^{2}\right)$ vs. $1 / T$ for the AIBN-Initiated Polymerization of PFS in Bulk . . . . . . . . . 49

12. Transfer to Fluorobenzene, Hexafluorobenzene, Benzotrifluoride, and Benzonitrile by PFS at $60^{\circ}$. . . . 75

13. Transfer to THF, MIPK and MIBK by PFS, and to THF by Styrene . ................. 76

14. Transfer to Cumene, Ethylbenzene and Toluene by PFS at $60^{\circ}$ in the Presence of the Cosolvent THF. . . . . . . . 77

15. Transfer to MIPK, MIBK, Fluorobenzene, Benzonitrile, Hexafluorotenzene and Benzotrifluoride by Styrene at $60^{\circ}$. 78

16. Graph of $\log R_{P}$ vs. $\log [M]$ for Thermal Polymerization of PFS in Solvents at $60^{\circ}$................ 79

17. Graph of $\log R_{P}$ vs. $\log [M]$ for Thermal Polymerization of Styrene in Solvents at $60^{\circ}$. . . . . . . . . . . 80

18. DPPH Disappearance in PFS-PhCN Mixtures at $80^{\circ}$. . . . 85 vii 
19. Graph of \% Conversion vs. Time for the Polymerization of PFS in the Presence of AIBN and DPPH. . . . . . . . 86

a. Graph of \% Conversion vs. Time for the Polymerization of PFS in the Presence of AIBN and Benzoquinone . . . 87

20. Determination of the Average Lifetime of Poly-PFS Radicals. . . . . . . . . . . . . . . . 97

a. Relationship Between Copolymer and Feed Compositions for PFS-Styrene and PFS-MMA Systems . . . . . . . 114

21. Graph of $\log R_{p}$ vs. $\log [M]$ for the Polymerization of PFS in Methanol at $60^{\circ}$, [AIBN] $=1.85 x 10^{-4} \mathrm{M} \ldots . . . . .121$

22. Graph of $\log R_{p}$ vs. $\log$ [AIBN] for the Polymerization of PFS in Methanol at $[\mathrm{M}]=1.83 \mathrm{M}$ and at $[\mathrm{M}]=0.611 \mathrm{M} . . .122$

23. Graph of $\overline{\mathrm{P}}_{\mathrm{n}}$ vs. [M] for the Polymerization of PFS in Methanol at $[\mathrm{AIBN}]=1.85 \times 10^{-4} \mathrm{M} \ldots . . . . . . .123$ 


\section{ABSTRACT}

Thermal polymerization of pentafluorostyrene (PFS) was carried out in bulk and in the presence of solvents. Comparison of molecular weights determined osmometrically with those obtained using tritium-labeled AIBN indicates that termination occurs exclusively by combination. Molecular weights may be calculated from intrinsic viscosities using the equation $\bar{M}_{n}=8.50 \times 10^{5}[\eta]^{1.36}$. The solubility of poly-PFS was studied in a number of solvents. Values of $2 \mathrm{k} d \mathrm{~d} / \delta^{2}$ were obtained for AIBN-initiated polymerization in bulk and in several solvents. From these values and molecular weight data, values of $f$ and $\delta^{2}$ were calculated, where $\delta^{2}=2 \mathrm{k}_{t} / \mathrm{k}_{\mathrm{p}}^{2}$. Both $\mathrm{f}$ and $\delta^{2}$ show some solvent dependence. The thermal polymerization of PFS has a rate which is similar to that of styrene, and has an activation energy of thermal initiation which ís nuch lower than that of styrene. These observations are difficult to explain in terms of the most accepted mechanism for styrene's thermal polymerization; that is, one which involves an atom-transfer reaction between a Diels-Alder dimer and another molecule of styrene. If this mechanism were to apply to PFS, a fluorine atom would have to be transferred. The transfer constant to PFS is zero; this fact also is relevant to the speculation on the mechanism of thermal initiation. Transfer to THF, fluorobenzene, methyl isobuty1 ketone, methyl isopropyl ketone, benzonitrile, benzotrifluoride, hexafluorobenzene and some non-solvents were studied with or without a third solvent. Photopolymerization of PFS both in 
bulk and in solvents were studied and the radical lifetime was measured by the rotating sector method. Both thermal and AIBN-initiated copolymerization of PFS-styrene and PFS-methyl methacrylate (MMA) were studied. For PFS-styrene, the values of $\dot{r}_{2}, e_{2}$ and $Q_{2}$ for PFS are $0.22,0.74$ and 0.69 ; for PFS-MMA, the values of these parameters are $0.91,0.75$ and 0.87 . From the data obtained from chain transfer, absolute rate constant and copolymerization experiments, it is concluded that poly-PFS radical is more reactive than polystyryl radical but that the monomer is less reactive. The kinetics of copolymerization were studied also: for PFS-styrene, $\phi$ is 7.2 and for MMA it is 5.3. The kinetics of heteropolymerization of PFS were examined in the presence of methanol. It was shown that typical occlusion phenomena are operative in this system. 


\section{INTRODUCTION}

Synthesis. The monomer 2,3,4,5,6-pentafluorostyrene (PFS) was synthesized for the first time in 1959 by Wall ${ }^{1}$ in the United States and by Nield et al., 2 in England. Pentafluorobromobenzene is obtained as one of the products from the synthesis of hexafluorobenzene by the pyrolysis of tribromofluoromethane. ${ }^{1}$. It is then reacted as shown below:

$$
\mathrm{C}_{6} \mathrm{~F}_{5} \mathrm{Br} \stackrel{\mathrm{Mg}}{\longrightarrow} \mathrm{C}_{6} \mathrm{~F}_{5} \mathrm{MgBr} \stackrel{\mathrm{CH}_{3} \mathrm{CHO}}{\longrightarrow} \mathrm{C}_{6} \mathrm{~F}_{5}-{\underset{\mathrm{OH}}{\mathrm{CHCH}}}_{3} \frac{\mathrm{Al}_{2} \mathrm{O}_{3}}{350^{\circ}} \mathrm{C}_{6} \mathrm{~F}_{5} \mathrm{CH}_{2} \mathrm{CH}_{2}
$$

An alternate route to pentafluorobromobenzene lutilizes bromination of pentafluorobenzene in $65 \%$ oleum. ${ }^{3}$. Recently, Wa $11^{4}$ reported a third method of preparation of PFS: With vinyl lithium, prepared from 0.1 inole of $\mathrm{PhLi}$ and 0.025 mole of tetravinyltin, 0.1 mole of hexafluorobenzene gave $20 \%$ PFS. Pure PFS is a colorless liquid having b.p. $141-142^{\circ}(760 \mathrm{~mm})^{1,2}$ and $\mathrm{n}_{\mathrm{D}}^{20} 1.4410-1.4420$. Commercial PFS usua11y contains $0.5 \%$ t-butylcatecho1 as inhibitor.

This monomer is interesting because its structure is similar to styrene and yet it has 5 fluorine atoms on the ring. Furthermore, PFS polymer might be expected to have greater stability than polystyrene in the same way that Teflon is more stable than polyethylene. Indeed, Wall ${ }^{5,6}$ reported that PFS polymer (poly-PFS) has greater thermal stability and better radiation-resistance than polystyrene. The purpose of this study is to investigate the kinetics of polymerization of this interesting monomer. 
Kinetics of Polymerization: The kinetic symbolism used In this study is In conformity with American conventions in polymerization kinetics. ${ }^{7}$ (See Appendix I.) There are four basic equations involved in a radical induced polymerization:

$\begin{array}{ll}I \longrightarrow 2 R^{\prime} & \frac{\text { Rate }}{2 k_{d} f[I]} \\ R \cdot+M \longrightarrow M \cdot & k_{i}[R \cdot][M] \\ M \cdot+M \longrightarrow M \cdot & k_{p}[M \cdot][M] \\ 2 M \bullet \longrightarrow P & 2 k_{t}[M \cdot]^{2}\end{array}$

where $I$ is initiator, $R \cdot$ the primary radical, $M$ the monomer, $M$ a polymer radical regardless of chain length, and $P$ a polymer molecule. Note that in Equation 4, a factor of 2 is introduced for the rate of disappearance of radicals. (See Appendix I.) When solvent is present in a polymerization system, two more steps may be added:

$$
\begin{array}{ll}
M \bullet+S \longrightarrow P+S \cdot & k_{t r}[M \cdot][S] \\
S \cdot+M \longrightarrow M \cdot & k_{a}[S \cdot][M]
\end{array}
$$

where $\mathrm{S}$. is the solvent radical, and $\mathrm{S}$ the solvent molecule. In order to derive useful kinetic expressions, it is assumed that (a) all rate constants are independent of chain length, so that $M_{\mathfrak{n}}=M_{n+1}=M^{*}$ as implied In Equation 3; (b) the rates of formation and destruction of free radicals are equal (the steady state assumption); (c) the solvent radical formed in Equation 5 immediately initiates a new chain by Equation 6, $1 . . e$. , there is no degradative chain transfer. 8 If the 
polymer chain length is very large, the monomer disappearance is predominantly due to the propagation reaction, and the overall rate of polymerization can be replaced by the rate of propagation.

$$
-d[M] / d t=R_{P}=k_{p}[M \cdot][M]
$$

By the steady state assumption, the rate of initiation of radicals is equal to the rate of their destruction:

$$
R_{i}=R_{t}
$$

or

$$
2 k_{d} f[I]=2 k_{t}[M \cdot]^{2}
$$

Combining Equations 7 and 9,

$$
R_{P}=[M] \frac{R_{i}^{0.5}}{\delta}=\frac{\left(2 k_{d} f\right)^{0.5}}{\delta}[M][I]^{0.5}
$$

where $\delta=\left(2 k_{t}\right)^{0.5} / k_{p}$.

The degree of polymerization, defined as the number of monomer units in the average polymer molecule, can be formalized as follows :

$$
\overline{\mathbf{P}}=\frac{-\mathrm{d}[\mathrm{M}] / \mathrm{dt}}{\mathrm{d}[\mathrm{P}] / \mathrm{dt}}
$$

where $d[P] / d t$ represents the rate of production of polymer, and $-d[M] / d t$ the rate of consumption of monomer. If the growing radicals are terminated by mutual combination, as well as by transfer, then

$$
\frac{d[P]}{d t}=k_{t}[M \cdot]^{2}+k_{t r, M}[M \cdot][M]+k_{t r, S}[M \cdot][S]+k_{t r, I}[M \cdot][I]+\cdots
$$


By rearrangement of Equation 11 and combining with Equations 7-10, 12, we obtain

$$
\frac{1}{\mathrm{P}}=\frac{\delta^{2}}{2[\mathrm{M}]^{2}} \mathrm{R}_{\mathrm{P}}+\mathrm{C}_{\mathrm{M}}+\mathrm{C}_{\mathrm{S}} \frac{[\mathrm{S}]}{[\mathrm{M}]}+\mathrm{C}_{I} \frac{[\mathrm{I}]}{[\mathrm{M}]}+\cdots
$$

where $C_{M}=\frac{k_{t r}, M}{k_{p}}, C_{S}=\frac{k_{t r}, S}{k_{p}}$, and $C_{I}=\frac{k_{t r}, I}{k_{p}}$ are called the transfer constants to monomer, solvent and initiator, respectively. If $R_{P}$ is taken to be constant and in the absence of initiator, Equation 13 becomes the Mayo equation for transfer to solvent ${ }^{9}$

$$
\frac{1}{\mathrm{P}}=\frac{1}{\overline{\mathrm{P}}_{0}}+\mathrm{C}_{\mathrm{S}} \frac{[\mathrm{S}]}{[\mathrm{M}]}
$$

where $1 / \overline{\mathrm{P}}_{0}$ is the inverse of the degree of polymerization for bulk monomer (no solvent case), and the $1 / \overline{\mathrm{P}}_{0}$ value is dependent on the monomer and the temperature of the polymerization but 1 , is independent of solvent. One way of measuring $\mathrm{C}_{S}$ is to use thermal initiation and Equation 14. A graph of $1 / \overline{\mathrm{P}}$ against $[\mathrm{S}] /[\mathrm{M}]$ should give a straight line with slope $C_{S}$. In another method, an Initiator is used and the $\mathrm{C}_{\mathrm{S}}$ value may be calculated from Equation 13. Value of $k_{\mathrm{d}} \mathrm{f}$ and $\delta^{2}$ can be determined by plotting $R_{P}$ against $[M][I]^{0.5}$, and $1 / \bar{P}$ against $R_{P}$, as seen from Equations 10 and 13, respectively. The mechanism of radical termination, combination or disproportionation must be known before calculating transfer constants, $R_{i}$ values. Equations 12 and 13 are true only when growing chains are terminated by mutual combination. If polymer radicals are terminated by disproportionation, Equations 12 
and 13 should be replaced by

$\frac{d[P]}{d t}=2 k_{t}[M \cdot]^{2}+k_{t r, M}[M \cdot][M]+k_{t r, S}[M \cdot][S]+k_{t r, I}[M \cdot][I]+\cdots$

and

$$
\frac{1}{\overline{\mathrm{P}}}=\frac{\delta^{2}}{[\mathrm{M}]^{2}} \mathrm{R}_{\mathrm{P}}+\mathrm{C}_{\mathrm{M}}+\mathrm{C}_{S} \frac{[\mathrm{S}]}{[\mathrm{M}]}+\mathrm{C}_{I} \frac{[I]}{[\mathrm{M}]}+\cdots
$$

Mechanism of Thermal Initiation. It has been observed that rigorously purified styrene and some other olefins gave reproducible polymerization rates in the dark and in the absence of initiators. 119,120 This indicates that impurities which might act as initiators are not responsible for the thermal initiation. Flory ${ }^{120}$ reported that the overall thermal polymerization is second order in styrene, and he suggested a bimolecular initiation mechanism involving a diradical intermediate:

$$
2 \mathrm{PhCH}=\mathrm{CH}_{2} \longrightarrow \mathrm{Ph}-\stackrel{\dot{\mathrm{CHCH}}}{2} \mathrm{CH}_{2} \stackrel{\bullet}{\mathrm{CH}}-\mathrm{Ph}
$$

However, some evidence ${ }^{12 d}$ against the formation of diradical in the initiation step has since been reported. Mayo, 28 from studies of the amounts of low- and high-molecular-weight polymers formed in the styrene-bromobenzene system, concluded that the overall rate is actually 2.5 order in styrene. To explain this, Mayo ${ }^{109,110}$ suggested a termolecular initiation mechanism which involves a Diels-Alder type dimer as an intermediate and the reaction of this adduct with a third 
styrene molecule in a molecule-induced homolysis step:

$$
\text { (AH }+\mathrm{M} \longrightarrow{ }_{\mathrm{PhCHCH}_{3}}
$$

Mayo's mechanism is substantiated by the isolation of 1-phenyltetraline (and other derivatives) from heaced styrene, 51,61 by kinetic analysis, $^{118}$ and by kinetic isotope effect studies. $121,122,127,128$ Pure styrene decolorizes diphenylpicrylhydrazyl (DPPH), and this would seem to indicate that radicals are formed. However, the DPPH' disappears faster than radicals are calculated to be produced based on the rate of appearance of thermal polymer. ${ }^{69}$ This can be explained 62 by postulating that the $\mathrm{DPPH}$ reacts with the dimer to oxidize it:

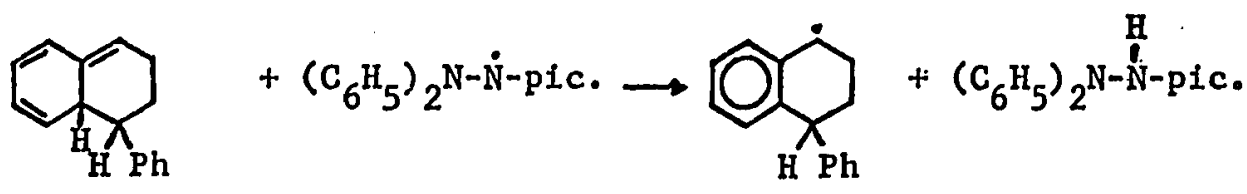

(AH)

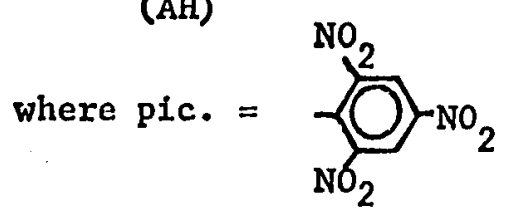

The activation energy for this reaction is found to be $23 \mathrm{kcal} / \mathrm{mole}$ 
close to that of thermal polymerization of pure styrene $\left(21.0 \mathrm{kcal} / \mathrm{mole} \mathrm{e}^{28}\right)$. However, Lasswel1 ${ }^{126}$ found that the DPPH disappears rapidly in vinylmesttylene, stilbene, cyclohexane and all other solvents except benzene. Thus the reaction of DPPH appears to be much more complicated than what one would expect; the DPPH may react with the monomer and the solvent as well as the dimer. oxygen $^{62}$ also spontaneously reacts with styrene with an activation energy of $24 \mathrm{kcal} / \mathrm{mole}$. Apparently oxygen also undergoes a molecule-induced horiolysis reaction with the adduct.

$$
\mathrm{AH}+\mathrm{O}_{2} \longrightarrow \mathrm{O}_{\mathrm{H} \mathrm{Yh}_{\mathrm{h}}}+\mathrm{HO}_{2}
$$

This mechanism for spontaneous autoxidation of styrene is substantiated by the identification of 4-phenyl-tetralone in styrene which reacted with oxygen in the presence of inhibitors to prevent extensive autoxidation: 123
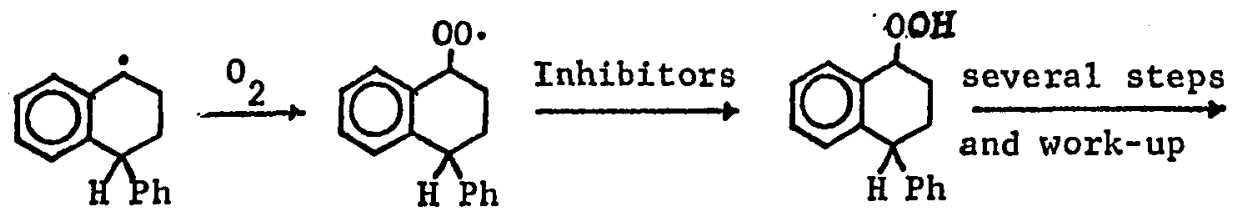<smiles>O=C1CCC(c2ccccc2)c2ccccc21</smiles>

Mayo's mechanism may be valid for styrene as well as other vinyl monomers such as 2-vinylfuran, 2-vinylthiophene. 58 . However, a recent study by Brown 117 indicates that a more extended reaction scheme for the thermal polymerization of styrene involving both the Diels-Alder dimer and the diradical intermediate may be needed. More 
discussion will be given later in the section on the thermal initiation mechanism of PFS (see p.54).

The Rotating Sector Method. In the case of photopolymerization, primary free radicals are produced from the decomposition of initiator excited by the absorption of light (usually in the ultraviolet region). The rate of production of these radicals is proportional to the intensity of the absorbed light, $I_{a b s .}$

$$
R_{i}=2 f \cdot I_{\text {abs }}
$$

where $I_{a b s .}$ is the quanta absorbed in moles/liter/sec, and $f$ the efficiency of chain initiation. (Usually $f$ is less than 1 due to cage reactions). Beer's law states that:

$$
I_{\text {abs. }}=I_{0}\left(1-e^{-\epsilon[S] \cdot \ell}\right) \approx I_{0} \cdot \epsilon \cdot[S] \cdot \ell
$$

where $I_{0}$ is the intensity of incident light, $\epsilon$ the extinction coefficient of the initiator, [S] the sensitizer concentration, and \& the optical path length. Eq.17 then gives:

$$
R_{i}=2 f \cdot I_{0} \cdot \epsilon \cdot l \cdot[S]
$$

When steady state conditions are reached,

$$
\frac{d[M \cdot]}{d t}=0=2 f \cdot I_{0} \cdot \epsilon \cdot l \cdot[S]-2 k_{t}[M \cdot]^{2}
$$

and Equation 19 may be substituted into Equation 7, yielding

$$
R_{P}=k_{P}[M]\left\{\frac{2 f \cdot I_{0} \cdot \epsilon \cdot l \cdot[S]}{2 k_{t}}\right\} 0.5
$$


Thus, the rate of polymerization is proprotional to the square root of light intensity and photosensitizer concentration.

Equations 19 and 20 are valid when the steady state of radical concentration is reached, but they are not valid at the start of the irradiation. The study of this non-steady state condition is the basis of the rotating sector technique, which at present appears to be the most accurate and dependable method of determining the rate constants in polymerization processes. ${ }^{10}$ A concept of the average lifetime of a growing polymer chain, $\tau_{s}$, is introduced in the rotating sector method. This quantity is defined as the ratio of radical concentration at the steady state to the rate of disappearance of radicals

$$
T_{s}=\frac{[M \cdot]_{s}}{2 k_{t}[M \cdot]_{s}^{2}}=\frac{1}{2 k_{t}[M \cdot]_{s}}
$$

Recalling Equation 7, a relationship between $k_{p}$ and $k_{t}$ is obtained:

$$
\tau_{s}=\frac{k_{p}[M]}{2 k_{t}} \frac{R_{P_{s}}}{R_{1}}
$$

Equations 10 and 22 contain only two variables, and therefore individual values of $k_{p}$ and $k_{t}$ may be obtained. The theory of non-steady state kinetics and the evaluation of radical lifetime, ' $S$, by intermittent illumination, is discussed by Melville and Burnett ${ }^{10}$ in detail. Only the results will be mentioned here. A sector is driven by a synchronous motor through a set of gears so as to give 
varying rotation speeds. (See Appendix II). The light can be flickered at chosen intervals depending on the sector speed and the dark to light ratio, $r$, of the sector. This causes the radical production to be started and stopped at the chosen interval. For example, consider a sector with $r=I$ (i.e., dark and light area equal). When the sector rotates very slowly, the radical concentration will be able to reach the steady state level during the light period and drop completely to zero during the dark period. In this extreme case, the rate of photo-polymerization will be

$$
\mathrm{R}_{\mathrm{P}_{\text {avg }}}=\frac{1}{\mathrm{r}+1} \mathrm{R}_{\mathrm{P}_{\mathrm{s}}}=0.5 \mathrm{R}_{\mathrm{Ps}_{\mathrm{g}}}
$$

where $R_{P_{s}}$ denotes the rate of polymerization under steady light. This is the so-called "lower limit" for the polymerization rate. If, on the other hand, the sector rotates very fast, the effect is the same as steady'light, but the light intensity will be. reduced by a factor of $r+1=2$. Since the rate of polymerization is proportional to the square root of the light intensity, the rate in this case will be

$$
\mathrm{R}_{\text {avg }}=\left(\frac{1}{1+r}\right)^{0.5} \mathrm{R}_{\mathrm{Ps}_{\mathrm{g}}}=0.708 \mathrm{R}_{\mathrm{Ps}}
$$

This is called the "upper limit" for the photopolymerization rate. Now, if we choose a sector speed between these two extreme limits, the rate will lie between the upper and lower limits, $1 . e_{0}$, $\frac{1}{\mathrm{r}+1} \mathrm{R}_{\mathrm{PS}_{\mathrm{S}}}<\mathrm{R}_{\mathrm{P}_{\text {avg }}}<\left(\frac{1}{\mathrm{r}+1}\right)^{0.5} \mathrm{R}_{\mathrm{P}_{\mathrm{S}}}$ or $0.5 \mathrm{R}_{\mathrm{P}_{\mathrm{S}}}<\mathrm{R}_{\mathrm{P}}<0.708 \mathrm{R}_{\mathrm{P}_{\mathrm{S}}}$. In this case, the radical concentration will not reach the steady state value but will lie between the two extreme values of $[M \cdot]$. An 
experimental curve is obtained by measuring the polymerization rates at different sector speeds, $R_{p}$, comparing with those obtained at steady light, $R_{P_{S}}$, and plotting the ratio $R_{P} / R_{P_{S}}$ against $\log \lambda$, where $\lambda$ is the flash time measured by stop watch. Theoretical curves for different $r$ values can be constructed (by plotting $R_{P} / R_{P_{S}}$ vs. $100 \mathrm{~m}$ ) using the following equations: 10

$$
\begin{aligned}
& \frac{R_{\mathrm{P}}}{R_{P_{s}}}=\frac{1}{r+1}\left\{1+\frac{1}{m} \ln \left[\frac{r m}{1+R_{P_{s}} / R_{P_{2}}}+1\right]\right\} \\
& \frac{R_{P_{2}}}{R_{P_{g}}}=\frac{r m \tanh m+\left[r^{2} m^{2} \tanh ^{2}+4(r m+\tanh m) \tanh m\right]^{0.5}}{2(r m+\tanh m)} \\
& \tau_{s}=\frac{\lambda}{m}
\end{aligned}
$$

where $m$ is the ratio of time of flash to the lifetime of kinetic chain. Substitution of Equation 24 in 23 will give the values of $R_{P} / R_{P s}$ in terms of $m$ and $r$ only. Burnett and Melville $e^{10}$ tabulated the values of $R_{P} / R_{P_{s}}$ as function of $m$ for various values of $r$. The $T_{\mathbf{s}}$,value can be calculated from the difference between the theoretical and experimental curves as implied by Equation 25. Usually an average value is taken and is called the "average lifetime". The above discussion is based on three important assumptions: (1) The thermal (dark) rate is negligible, (2) the transition from light to dark conditions is" sharp, and (3) termination occurs by only one mechanism. If the thermal rate is not negligible, the two curves (experimental and theoretical) will not met at the lower (slow sector 
speed) region. In this case in constructing theoretical curve, it 1s necessary to allow for $t$ ermal rate as given by Equations 26-28:

$$
\begin{aligned}
& \frac{R_{P}}{R_{P_{s}}}=\frac{1}{r+1}\left\{1+z x+\frac{1}{m} \ln \left[\frac{1+R_{P_{1}} / R_{P_{s}}}{1+R_{P_{2}} / R_{P_{s}}}\right]\left[\frac{1+z^{-1} R_{P_{2}} / R_{P_{s}}}{1+z^{-1} R_{P_{1}} / R_{P_{s}}}\right]\right] \\
& \frac{R_{P_{2}}}{R_{P_{8}}}=\frac{\left[R_{\mathrm{P}_{1}} / R_{\mathrm{P}_{s}}\right]+\tanh m}{1+\left[\mathrm{R}_{\mathrm{P}_{1}} / \mathrm{R}_{\mathrm{Ps}_{\mathrm{g}}}\right] \tanh \mathrm{m}} \\
& \frac{R_{P_{1}}}{R_{P_{S}}}=-\left(1-z^{2}\right) \tanh z \text { rm tanh } m+\left\{\left(1-z^{2}\right)^{2} \tanh ^{2} z \text { rm } \tanh ^{2} m\right. \\
& \frac{\left.+4(\tanh z r m+z \tanh m)\left(z \tanh m+z^{2} \tanh z r m\right)\right\}^{\frac{3}{2}}}{2(\tanh 2 r m+z \tanh m)}
\end{aligned}
$$

where $z$ is the ratio of the thermal to overall photochemical rates. $\mathrm{R}_{\mathrm{P}_{1}}$ and $\mathrm{R}_{\mathrm{P}_{2}}$ are proportional to radical concentrations at the beginning and end of the light flash, respectively. The computation is complicated, and a computer program has been written by Mr. H. Streiffer (Department of Chemistry, Louisiana State University) and was used in this study. Table 17 lists some theoretical values of $R_{P} / R_{P_{s}}$ computed by this program. These data allow for thermal corrections from $z=0.01$ to 0.04 and they are not available in the 1iterature. Dainton 11 showed that assumption (2) is usually valid except at very low sector speeds. Assumption (3) is usually satisfied for the polymerization of styrene. Most experimental evidence ${ }^{12}$ has shown that the termination reaction between two polystyryl radicals is an exclusive combination process for temperatures up to $80^{\circ} \mathrm{C}$. Experiments using a labeled 
inftiator were used to show that PFS also undergoes termination by combination; these data have been published ${ }^{13}$ and will be present in this thesis also. If first order radical termination as well as mutual termination (combination or/and disproportionation) occurs, two curves (experimental and theoretical) will not meet at the upper (high sector speed) region, and a special calculation ${ }^{10}$ will be required to account for this. However, if both the dark rate and more than one radical termination mechanism become important at the same time, they tend to compensate each other and normal curves are obtained.

Copolymerization. In the copolymerization of two types of monomers, four chain propagating reactions and three termination steps are involved:

\section{Propagation}

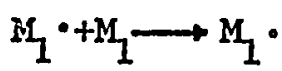

$\mathrm{M}_{1} \cdot+\mathrm{M}_{2} \rightarrow \mathrm{M}_{2} \cdot$

$M_{2} \cdot M_{1} \rightarrow M_{1} \cdot$

$\mathrm{M}_{2} \cdot \mathrm{M}_{2} \rightarrow \mathrm{M}_{2} \cdot$

\section{Rate}

$$
k_{11}\left[M_{1} \cdot\right]\left[M_{1}\right]
$$$$
k_{12}\left[M_{1} \cdot\right]\left[M_{2}\right]
$$$$
k_{21}\left[\mathrm{M}_{2} \cdot\right]\left[\mathrm{M}_{1}\right]
$$$$
k_{22}\left[\mathrm{M}_{2} \cdot\right]\left[\mathrm{M}_{2}\right]
$$

\section{Termination}

$$
\begin{array}{ll}
M_{1} \cdot+M_{1} \cdot \rightarrow M_{1}-M_{1} & 2 k_{t 11}\left[M_{1} \cdot\right]^{2} \\
M_{1} \cdot+M_{2} \cdot \rightarrow M_{1}-M_{2} & 2 k_{t 12}\left[M_{1} \cdot\right]\left[M_{2} \cdot\right] \\
M_{2} \cdot+M_{2} \cdot \rightarrow M_{2}-M_{2} & 2 k_{t 22}\left[M_{2} \cdot\right]^{2}
\end{array}
$$

where $M_{1}=$ monomex $1, M_{2}=$ monomer $2, M_{1}$ is a polymer radical having monomer 1 at the chain end, $\mathrm{M}_{2} \cdot$ is a polymer radical having monomer 
2 unit at the chain end, $k_{12}$ is the rate constant for reaction of polymer radical having monomer 1 at the end of chain with monomer 2 , and so on. Here again, some assumptions have to be made in order to obtain useful kinetic expressions: (1) velocity coefficients are independent of radical size, (2) the chain length is great and total rate of monomer consumption may be taken to be that in propagating reactions, and (3) a steady state in radical concentrations exists. Using these simplifications, one can easily show that

$$
\frac{d\left[M_{1}\right]}{d\left[M_{2}\right]}=\frac{\left[M_{1}\right]}{\left[M_{2}\right]} \cdot \frac{r_{1}\left[M_{1}\right]+\left[M_{2}\right]}{\left[M_{1}\right]+r_{2}\left[M_{2}\right]}
$$

where $r_{1}=k_{11} / k_{12}$, and $r_{2}=k_{22} / k_{21} \cdot r_{1}, r_{2}$ are called "monomer reactivity ratios". Equation 36 is called the "copolymerization equation", and it was first introduced by Alfrey and Goldfinger. 14 Evaluation of monomer reactivity ratios can be made by different methods. 7 In this study, the Fineman-Ross method ${ }^{15}$ is adopted. By using the definitions $\mathrm{f}=\mathrm{d}\left[\mathrm{M}_{1}\right] / \mathrm{d}\left[\mathrm{M}_{2}\right]$ and $\mathrm{F}=\left[\mathrm{M}_{1}\right] /\left[\mathrm{M}_{2}\right]$, Equation 36 can be transformed to

$$
\frac{F}{f}(f-1)=r_{1} \frac{F^{2}}{f}-r_{2}
$$

The $F$ value is known from the monomer composition and $f$ can be determined by the analyses of the copolymer formed. Thus, a plot of $\frac{F}{f}(f-1)$ against $\frac{F^{2}}{f}$ gives slope $=r_{1}$ and intercept $=-r_{2} \cdot$ Reactivity ratios are characteristic of each monomer pair, and they are independent of the type of initiation. The actual initiator used affects the rate 
but not the composition of the copolymer formed. On the other hand, It is necessary to indicate the, temperature at which the copolymerization is carried out because reactivity ratios are temperature dependent; $\underline{i} . \underline{e} \cdot$, the two rate constants comprising the reactivity ratios do not, in general, have the same activation energy. There is some evidence indicating that solvents have no detectable effect on reactivity ratios; Mayo ${ }^{16}$ found identical reactivity ratios for the styrene-MMA system in benzene and acetonitrile (solvents of low and high dielectric constant, respectively) and in methanol (a solvent from which the polymer precipitates).

The $Q-e$ Scheme. In addition to their obvious use in predicting the composition of a resulting copolymer, the monomer reactivity ratios can be used in a quantitative discussion of monomer and radical reactivity. The best known and the most widely used repactivity correlation is known as the Alfrey-Price Q - e scheme. 17 This scheme expresses each propagation rate constant in terms of four parameters representing the basic reactivities and polarities of the two species concerned. If the polarity of the monomer and of its corresponding radical are assumed to be the same, then the following equations can be derived:

$$
\begin{aligned}
& k_{11}=P_{1} Q_{1} \exp \left(-e_{1}^{2}\right) \\
& k_{12}=P_{1} Q_{2} \exp \left(-e_{1} e_{2}\right) \\
& k_{22}=P_{2} Q_{2} \exp \left(-e_{2}^{2}\right) \\
& k_{21}=P_{2} Q_{1} \exp \left(-e_{1} e_{2}\right)
\end{aligned}
$$


where $P$ and $Q$ are proportional to the basic reactivities of the radical and monomer respectively, and $\mathrm{e}$ is proportional to the charge on the monomer unit. Thus, by recalling the definition of $\mathbf{r}_{1}$ and $\mathbf{r}_{2}$

$$
\begin{aligned}
r_{1} & =\frac{Q_{1}}{Q_{2}} \exp \left[-e_{1}\left(e_{1}-e_{2}\right)\right] \\
r_{2} & =\frac{Q_{2}}{Q_{1}} \exp \left[-e_{2}\left(e_{2}-e_{1}\right)\right] \\
r_{1} x_{2} & =\exp \left[-\left(e_{1}-e_{2}\right)^{2}\right]
\end{aligned}
$$

Upon rearrangement,

$$
\begin{aligned}
& e_{2}=e_{1} \pm\left(-\ln r_{1} r_{2}\right)^{0.5} \\
& Q_{2}=\frac{Q_{1}}{r_{1}} \exp \left[-e_{1}\left(e_{1}-e_{2}\right)\right]
\end{aligned}
$$

Clearly, a standard reference monomer is needed in the assignment of Q, e values. Styrene has been chosen for this purpose, and the scheme has been found to be self-consistent when $Q_{1}=1.0, e_{1}=-0.80$ for styrene. The factor $Q$ is a measure of general reactivity of the monomer and its corresponding radical. Resonance stabilization affects both monomer and radical, but the effect on the radical is usually greater. Therefore, the greater the $Q$ value, the greater will be the relative resonance stabilization of the radical produced from the monomer, and the higher will be the reactivity of the monomer. The greater the $Q$ of a monomer, the less reactive will be its corresponding polymer radical. The factor $e^{\prime}$ is a measure of polarity 
of the monomer and the corresponding radical (assumed to be of equal polarity in the Q.- e scheme). The more positive the e value, the more electropositive (electron-poor) will be the reaction site (usually at the vinyl double bond of a monomer); the more negative the e vaiue, the more electron-rich will be the monomer.

The 6 Factor. The $\phi$ factor, another important parameter in copolymerization, can be derived from the kinetic measurements.

While the composition of the copolymer is governed largely by four propagation rate constants in terms of $r_{1}$ and $r_{2}$ values, the rate of copolymerization depends on the rates of initiation, termination, and propagation. According to the steady state assumption, the rate of initiation is equal to the rate of termination, $\underline{1} \cdot \underline{e} .:$

$$
R_{1}=2 k_{t 11}[M \cdot]^{2}+2 k_{t 12}\left[M_{1} \cdot\right]\left[M_{2} \cdot\right]+2 k_{t 22}\left[M_{2} \cdot\right]^{2}
$$

The over-ail rate of copolymerization is given by

$$
R_{P}=\frac{-d\left(\left[M_{1}\right]+\left[M_{2}\right]\right)}{d t}=k_{11}\left[M_{1} \cdot\right]\left[M_{1}\right]+2 k_{12}\left[M_{1} \cdot\right]\left[M_{2}\right]+k_{22}\left[M_{2} \cdot\right]\left[M_{2}\right]
$$

By combining Equations 43 and 44, it can be shown that

$$
R_{P}=\frac{\left\{r_{1}\left[M_{1}\right]^{2}+2\left[M_{1}\right]\left[M_{2}\right]+r_{2}\left[M_{2}\right]^{2}\right\} R_{1}^{0.5}}{\left\{r_{1}^{2} \delta_{1}^{2}\left[M_{1}\right]^{2}+2 \phi r_{1} r_{2} \delta_{1} \delta_{2}\left[M_{1}\right]\left[M_{2}\right]+r_{2}^{2} \delta_{2}^{2}\left[M_{2}\right]^{2}\right\}^{0.5}}
$$

where $r_{1}=\frac{k_{11}}{k_{12}}, r_{2}=\frac{k_{22}}{k_{21}}, \delta_{1}^{2}=\frac{2 k_{t 11}}{k_{11}^{2}}, \delta_{2}^{2}=\frac{2 k_{t 22}}{k_{22}^{2}}$ and $\phi=\frac{k_{t 12}}{2\left(k_{t 11} k_{t 22}\right)^{0.5}}$ 
The factor $\phi$ is a measure of the importance of cross-termination in copolymerization. Usually $6>1$ means that radicals of different polarities terminate with each other (cross-termination) in preference to the termination of the same kind of radicals. The value of $\phi$ Indicates that the cross-termination step in copolymerization pairs is quite important. It is a qualitative fact that 6 is largest in those systems in which the propagation processes show a tendency towards alternation $\left(r_{1} r_{2}\right.$ small). 
HOMOPOLYMERIZATION

I. EXPERTMENTAI SECTION

Purification of Monomer. PFS was purchased from the Imperial Smelting Corp. of England as a light yellow liquid containing 0.5\% t-butylcatechol as inhibitor. Purification was accomplished by prepolymerization at $60^{\circ}$ for $6 \mathrm{hr}$ followed by distiliation under nitrogen at $34^{\circ}(25 \mathrm{~mm})$. The cycle was repeated until a constant rate of thermal polymerization was reached. The correct thermal rate was found to be $5.70 \times 10^{-7} \mathrm{M} \mathrm{sec}-1$ at $60^{\circ} \mathrm{C}$. The pure monomer has b.p. $141-142^{\circ}(760 \mathrm{~mm})^{1,2}$ and $n_{D}^{20} 1.4410-1.4420$, and it is colorless. Isolation of the Polymer. Polymer was isolated by a modification of the freeze-dry technique developed by Lewis and Mayo for styrene ${ }^{19}$; the modifications were necessary since poly-PFS is insoluble in benzene, and the freezing point of the solvent tetrahydrofuran $\left(-65^{\circ}\right)$ precludes its use in freeze-drying. The contents of ampoules were washed into a $125 \mathrm{ml}$.flask with 50-100 ml of THF, the solvent was evaporated under a moderate vacuum, $50 \mathrm{ml}$ of benzene was added, the suspension was frozen in Dry Ice-acetone, and the benzene was allowed to sublime off under full vacuum. The cycle was repeated unt11 constant weight was obtained.

In the runs where tritium-labeled azobisisobutyronitrile (AIBN) was used as initiator, the polymer was dissolved in $15 \mathrm{ml}$ of 
THF and precipitated from $250 \mathrm{ml}$ of cold methanol $\left(-30^{\circ}\right)$, filtered Immediately and washed with cold methanol. This cycle was repeated three times. A typical control was as follows: $1 \mathrm{ml}$ of PFS was polymerized to $20.3 \%$ conversion using $4.57 \times 10^{-4} \mathrm{M}$ AIBN-t at $60^{\circ}$. The polymer isolated after three precipitations showed a weight loss of about $5 \%$. A mixture of $4.6 \leq 10^{-5} \mathrm{~mol}$ of AIBN-t and $0.052 \mathrm{~g}$ of inactive poly-PFS was prepared in PFS monomer and purified in the same way; the isolated polymer had an apparent activity of about $10 \mathrm{dpm}$. Similar controls at Iower AIBN-t molarities had proportionally less activity in the recovered polymer.

\section{Molecular Weight Determinations. A Hewlett-Packard Mode1}

501 membrane osometer was used to measure molecular weights. Conditions were $30^{\circ}, S \& S$ 0-8 membrane, and methyl isobutyl ketone (MIBK) as solvent. Molecular weights also were measured by counting polymer prepared with tritium-labeled AIBN as initiator and by assuming that each polymer molecule contains one entire AIBN molecule. The radioactive polymer was dissolved in $8 \mathrm{ml}$ of counting solution prepared by diluting $20 \mathrm{ml}$ of Packard concentrated scintillation solution to $500 \mathrm{ml}$ with fluorobenzene as a solvent. Counting was done with a Packard Tri-Carb Mode1 3003 Iiquid scintillation spectrometer. Efficiencies were determined using the external standard of this instrument, calibrated against acetone-quenched standards. The AIBN-t used was prepared by Dr. T.R. Fiske using method of Thiele and Heuser, ${ }^{20,21}$ and had a specific activity of 3.047 x $10^{9} \mathrm{dpm} / \mathrm{mol}$. Viscosity Measurements. Viscosities were measured at $30^{\circ}$ using Cannon-Ubbelohde viscometers and concentrations of $0.05-0.07 \mathrm{~g} / 25 \mathrm{ml}$ 
of MIBK. Intrinsic viscosities were determined by extrapolation of specific viscosities to Infinite dilution. Intrinsic viscosities could also be calculated using the following equation

$$
[\eta]=\frac{\left[1+2.08 \eta_{s p}\right]^{\frac{1}{2}}-1}{0.75 c_{v}}
$$

at $30^{\circ}$ and in MIBK as solvent, where $C_{v}$ is the polymer concentration in grams per $100 \mathrm{ml}$ of solution at $30^{\circ}$ and $\eta_{\mathrm{sp}}=\left(t / t_{0}\right)-1$, where $t$ and $t_{0}$ are the flow times for solution and pure solvent, respectively.

Kinetics. Rates of thermal (uncatalyzed) and catalyzed polymerizations were followed by using either a $10 \mathrm{ml}$ dilatometer or by an ampoule technique. The density of PFS was found to $1.414 \mathrm{~g} / \mathrm{ml}$ at $30^{\circ}, 1.388 \mathrm{~g} / \mathrm{ml}$ at $46.2^{\circ}$, and $1.366 \mathrm{~g} / \mathrm{ml}$ at $60^{\circ}$. The plot of $\%$ polymer in monomer (i..e., \% conversion) vs. density is linear to about $25 \%$ conversion, the highest calibration point. The data at $60^{\circ}$ give the relation $\%$ conversion $=(0.1040)(\%$ contraction $)$. This relation is similar to that for other substituted styrenes. $22-24$ The density measurements on polymex-monomer mixtures extrapolate to give $1.5921 \mathrm{~g} / \mathrm{ml}$ for the density of poly-PFS at $100 \%$ conversion. The density of polymer was measured by pressing it under 90,000 psi, placing it in a pycnometer which was then filled with mercury and heated to $120^{\circ}$ for $3 \mathrm{hr}$, cooled, again filled with mercury and heated to $60^{\circ}$. The experimental value for the polymer density by this procedure is $1.5499 \mathrm{~g} / \mathrm{ml}$. This density of solid polymer is about $2.6 \%$ less than that calculated for an infinitely concentrated solution of polymer in its own monomer. Similar behavior has teen reported for 
styrene. 25,26

Solubility. Poly-PFS is souble in methyl ethyl ketone (MEK), MIBK, THF, ethyl acetate, ethyl propionate, fluorobenzene, benzotrifluoride, hexafluorobenzene; slowly soluble or slightly soluble in pyridine, acetone, methyl isopropyl ketone, methyl acetate, benzonitrile, chlorobenzene, and acetophenone; and insoluble in benzene, toluene, ethylbenzene, cumene, bromobenzene, iodobenzene, carbon tetrachloride, chloroform, carbon disulfide, methanol, ethanol, ether, tetralin, dioxane, decalin, cyclohexane, hexane, heptane, ㅇ-dichlorobenzene, benzyl alcohol, phenyl ether, methyl benzoate, ethyl benzoate, benzophenone, anisole, N, N-dimethylformamide (DMF), ethylene glycol, aniline, nitrobenzene, $\mathrm{p}^{\text {-chloroanisole, bromo- }}$ cyclohexane and benzotrichloride.

Determination of Absolute Rate Constants. Radical 1ifetimes were measured by the rotating sector technique. ${ }^{10}$ The set-up was as follows: The reaction cell was irradiated by the light from a 100-watt Genera1 Electric U1traviolet Mercury Quartz lamp with a U.V. transmitting filter (Corning C.S. 0-52) to give maximum transmittance at $366 \mathrm{~m}$. The light was collimated by three lenses to produce a parallel beam through the reaction cell in a $30^{\circ} \mathrm{C}$ bath. Two $60^{\circ}$ sectors $(x=2)$ were cut from a disc made from a blackened sheet of aluminum. This disc was driven by a Bodine synchronous motor through a set of gears which could be varied so as to give rotation speeds ranging from 60 to $0.06 \mathrm{r} \cdot \mathrm{p} \cdot \mathrm{m}$. The light intensity was practically constant throughout the experiment since a check of 
the plot of the rate vs. the square root of the sensitizer concentration (Eq,20) always give an excellent lineạr relationship (See Appendix I). Azocyclohexanecarbonttrile (ACHN), purchased from Koch-Light Laboratories Ltd. of England, was recrystallized twice from methanol and melted at $114-115^{\circ}$. AIBN was purified by the same procedure and melted at 103-104\%. In all runs, ACHN was used as a photosensitizer whereas AIBN was used as an initiator for all thermal (dark) runs. The reaction was followed with a $10 \mathrm{ml}$ dilatometer, and the densities of poly-PFS-monomer solutions were determined at $30^{\circ} \mathrm{C}$ with' a pycnometer. The data of $30^{\circ}$ give the relation: $\%$ converston $=(0.0950)$ (\% contraction).

The thermal rate of polymerization in the dark was measured in each run, and the treatment allowing for thermal rate ${ }^{10}$ was employed in the calculation of radical lifetime, $\tau$. The rates of initiation were calculated from the rates measured dilatometrically, and values of $\delta^{2}=2 k_{t} / k_{p}^{2}$ were obtained from runs with AIBN as initiator.

DPPH Scavenging Experiments. In experiments in which the disappearance of diphenylpicrylhydrazyl (DPPH) was followed by absorption measurements, the reaction vessels were cells which were optically matched at $520 \mathrm{~m} \mu$, and the change in absorption was followed at this wavelength with a Beckman DK Spectrophotometer. The DPPH concentrations used were 9.79 × $10^{-5} \mathrm{M}$. An electrically heated cell holder was used, and the temperature was regulated to within $\pm 1^{\circ}$ during the reaction times. 


\section{II. . RESULTS AND DISCUSSION}

\section{Thermal Polymerization of PFS in Bulk at Different Temperatures.}

The purified monomer gave reproducible rates of uninitiated polymerization in the dark at different temperatures. Table 1 gives the data. An Arrhenius plot of $\log R_{P}$ againtst $1 / T$ shows a good linear relationship (Figure 1), and the thermal rate of PFS, therefore, can be expressed by the following equation:

$$
\mathrm{R}_{\mathrm{P}, \mathrm{th}}(\% / \mathrm{hr})=\left(2.37 \times 10^{9}\right) \exp (-16,800 / \mathrm{RT})
$$

For thermal polymerization of styrene, the equation is $:^{29}$

$$
R_{\mathrm{P}, \mathrm{th}}(\% / \mathrm{hr})=\left(3.55 \underline{\mathrm{x}} 10^{11}\right) \exp (-19,100 / \mathrm{RT})
$$

Figure 2 is a plot of $\log \bar{M}_{n}$ against $\log R_{p}$ using the data from Table 1. It can be seen that there is a good reciprocal relation. existing between rate and molecular weight for PFS thermal polymerization. This is, of course, an evidence for the validity of Equation 13 in this particular polymerization. This oberservation is true for styrene also. ${ }^{29 c}$ An Equation relating $\overline{\mathrm{P}}$ to temperature may be derived from Equation $11:^{30,57 e}$

$$
\overline{\mathrm{p}}=\frac{-\mathrm{d}[\mathrm{M}] / \mathrm{dT}}{\mathrm{d}[\mathrm{P}] / \mathrm{dT}}=\frac{\mathrm{k}_{\mathrm{P}}[\mathrm{M} \cdot][\mathrm{M}]}{\left.\mathrm{k}_{\mathrm{t}}[\mathrm{M} \cdot]^{2}+\mathrm{k}_{\mathrm{tr}, \mathrm{M}}[\mathrm{M} \cdot] \Gamma \mathrm{M}\right]}
$$

In the absence of initiator, by assuming chain transfer reactions are negligible, and by introducing $k=A e^{-E / R T}$ and $[M \cdot]=\left[\frac{R_{1}}{2 k}\right]_{t}^{\frac{3}{2}}$ where 
$R_{i}=k_{i}(M)^{a}$ with a a constant, it is shown that

$$
\frac{d 1 n \vec{P}_{n}}{d T}=\left(E_{p}-E_{t} / 2-E_{i, t h} / 2\right) / R T^{2}
$$

If, on the other hand, transfer reactions are controlling the molecular weight, the following equation is obtained: $57 \mathrm{e}$

$$
\frac{d \ln \bar{p}_{n}}{d T}=\left(E_{P}-E_{t r, M}\right) / R r^{2}
$$

where $E_{t r, M}$ is the activation energy for chain transfer to monomer; $E_{t}$, termination; $E_{p}$, propagation; and $E_{i, t h}$ thermal initiation. In the thermal polymerization of PFS, as can be seen from Figure 3, a plot of $\log \overline{\mathrm{P}}$ vs $1 / \mathrm{T}$ does give a good linear relationship which is expected from both Equations 46 and 47.

Molecular Weight Determinations. The polymerization of PFS was carried out under a number of experimental conditions (thermal and catalyzed) as shown in Tables 1 to 3 . The molecular weight of the isolated polymers was determined by osmometry and by counting polymer prepared in the presence of tritium-labeled AIBN (AIBN- ${ }^{3} \mathrm{H}$ ) assuming that termination is entirely by combination (i.e.., one mole of initiator is incorporated into each mole of polymer). Figure 4 shows the relationship between the number-average molecular weight, $\bar{M}_{n}$, and the intrinsic viscosity. The agreement between two methods (see Figure 4) shows that termination is entirely by combination within the accuracy of the molecular weight measurements. The line shown in 
Table 1

Thermal Polymerization of PFS in Bulk at Different Temperatures

\begin{tabular}{|c|c|c|c|c|c|c|c|c|c|}
\hline${ }^{\circ} \mathrm{C}$ & Hours & \% Conv. & $R_{P, t h} x 10^{2^{a}}$ & {$[\eta]^{b}$} & $\overline{\mathrm{p}} \times 10^{-4^{c}}$ & $\overline{\mathrm{M}}_{\mathrm{n}} \mathrm{x} 10^{-6^{\mathrm{d}}}$ & $1 / T \times 10^{3}$ & {$[\mathrm{M}]^{\mathrm{e}}$} & $R_{p} x 10^{6^{f}}$ \\
\hline 129 & 8.5 & 16.9 & 199 & 3.02 & 1.97 & 3.82 & 2.49 & 6.47 & 35.8 \\
\hline 129 & 8.5 & 15.5 & 182 & 3.15 & 2.09 & 4.06 & 2.49 & 6.47 & 32.7 \\
\hline 119 & 5 & 4.55 & 91.2 & $-\cdots$ & --- & ---- & 2.55 & 6.55 & 16.6 \\
\hline 100 & 24 & 9.71 & 40.4 & 4.82 & 3.69 & 7.16 & 2.68 & 6.70 & 7.52 \\
\hline 100 & 17.4 & 8.83 & 50.7 & 3.78 & 2.68 & 5.18 & 2.68 & 6.70 & 9.44 \\
\hline 100 & 19.5 & 5.68 & 29.1 & 4.25 & 3.13 & 6.08 & 2.68 & 6.70 & 5.42 \\
\hline 80 & 100.8 & 6.88 & 6.82 & 6.58 & 5.68 & 11.02 & 2.83 & 6.87 & 1.30 \\
\hline 80 & 48 & 2.98 & 6.21 & 5.79 & 4.76 & 9.24 & 2.83 & 6.87 & 1.19 \\
\hline 60 & 160 & 4.82 & 3.01 & 5.94 & 4.95 & 9.84 & 3.00 & 7.04 & 0.589 \\
\hline 60 & 160 & 4.50 & 2.81 & 7.23 & 6.45 & 12.52 & 3.00 & 7.04 & 0.570 \\
\hline
\end{tabular}

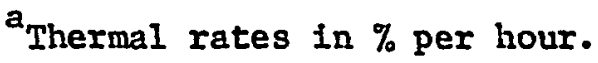

b Intrinsic viscosities measured in MIBK at $30^{\circ}$.

${ }^{c}$ Calculated by using Equation 48.

$\mathrm{d}_{\bar{M}_{\mathrm{n}}}=(194.1) \overline{\mathrm{P}}$.

Monomer concentration calculated from density measurements, in mole/1.

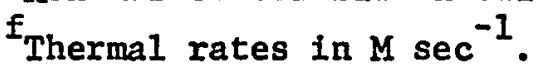




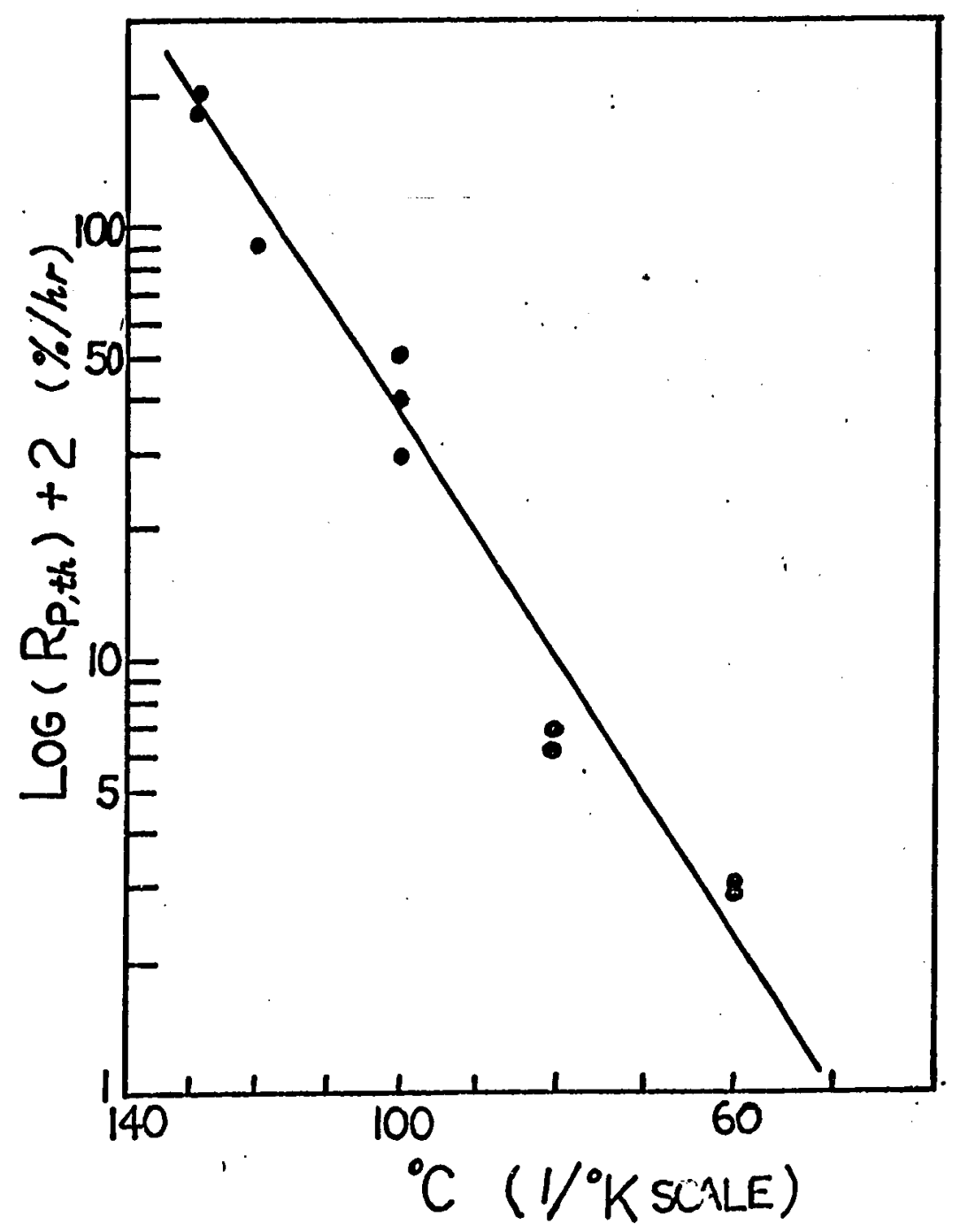

Figure 1. Arrhenius Plot for Thermal Polymerization of PFS in Bulk. 


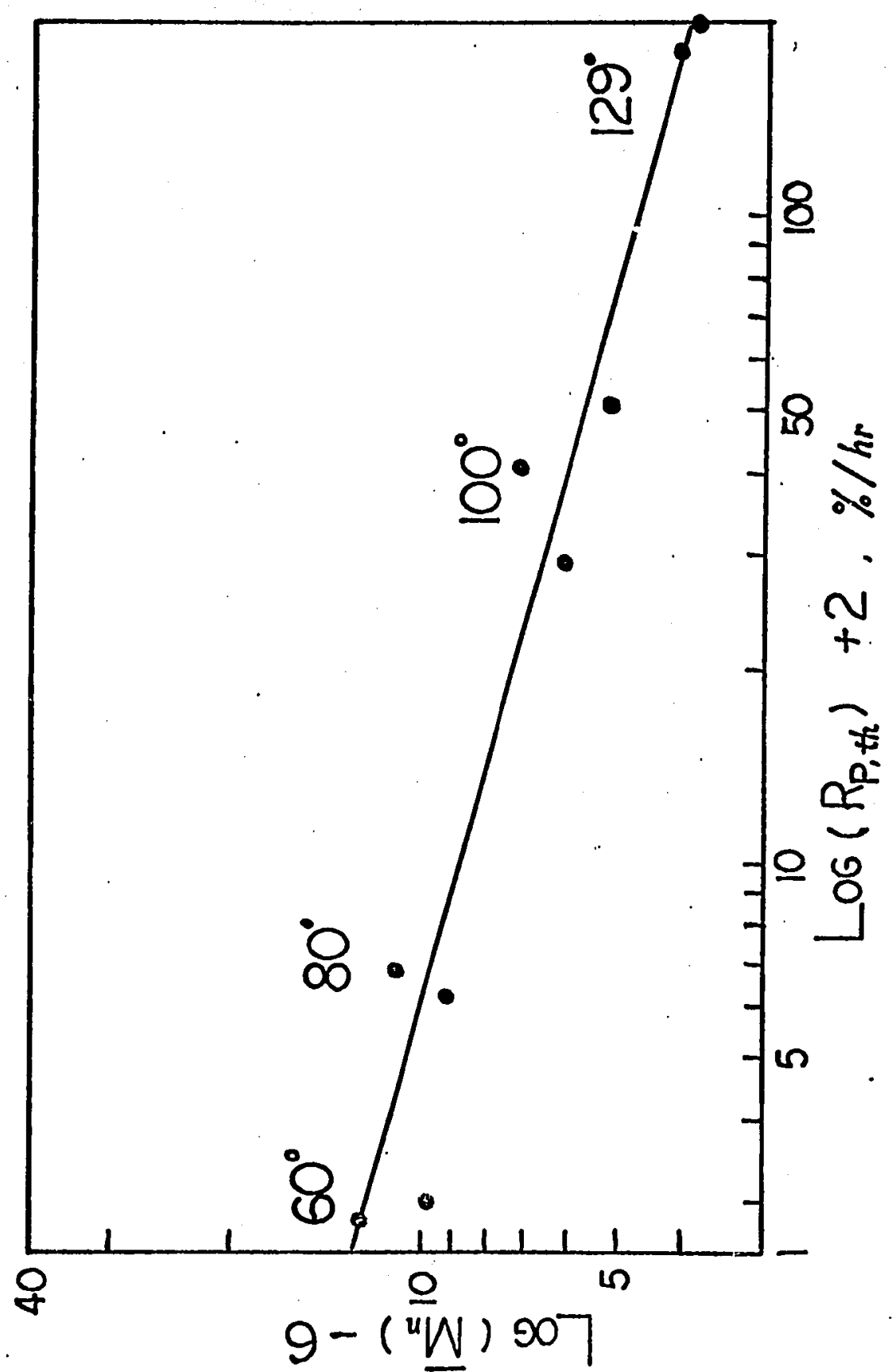

Figure 2. Plot of $\log \bar{M}_{n}$ vs. $\log R_{P, t h}$ for Thermal Polymerization of PFS in Bulk. 


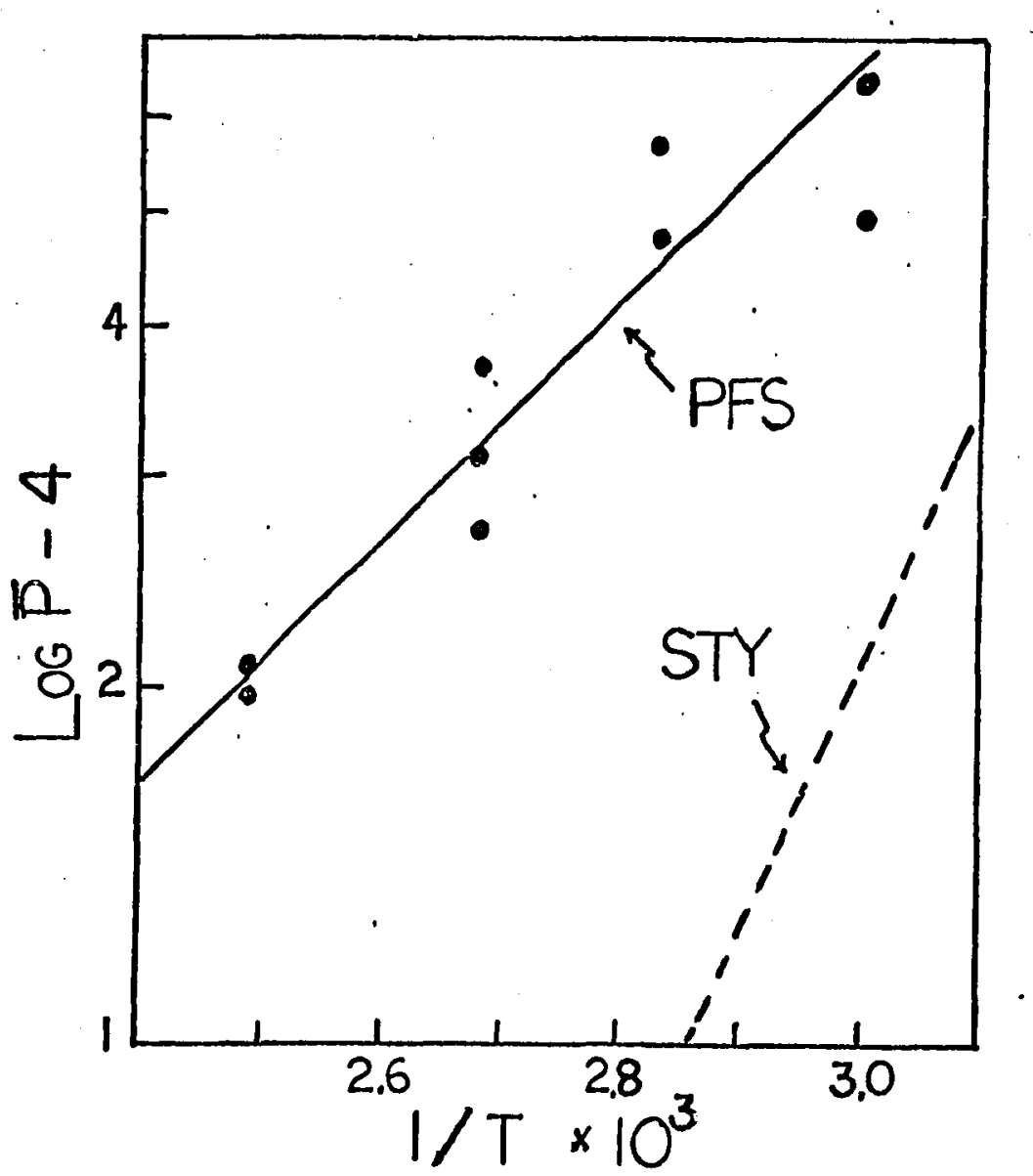

Figure 3. Plot of $\log \overline{\mathrm{P}}$ vs. $1 / T$ for Thermal Polymerization of PFS in Bulk. Dotced line shows the corresponding plot for styrene and with $\overline{\mathrm{P}}$ calculated from Table 3-1 of Ref.12a. 
Table 2

The Polymerization of PFS Initiated by AIBN- ${ }^{3}$ H at $60^{\circ} \mathrm{C}$

\begin{tabular}{|c|c|c|c|c|c|c|c|}
\hline $\begin{array}{c}{\left[\mathrm{AIBN}-{ }^{3} \mathrm{H}\right]} \\
\times 10^{2}\end{array}$ & $\begin{array}{l}\text { Time, hr } \\
\text { (at } 60^{\circ} \text { ) }\end{array}$ & $\begin{array}{c}\text { Convn. } \\
\%\end{array}$ & $\begin{array}{l}\text { Dpm in Polymer } \\
\text { corrected }^{a}\end{array}$ & $\begin{array}{l}\text { Moles } \frac{M}{b} \\
\times 10^{4^{b}}\end{array}$ & $\begin{array}{l}\text { Moles I } \\
\times 10^{7^{c}}\end{array}$ & $\bar{M}_{n} x 10^{5^{d}}$ & {$[\eta]^{e}$} \\
\hline 4.57 & 1.5 & 15.1 & 970 & 2.65 & 3.16 & 1.63 & 0.31 \\
\hline 2.74 & 3.6 & 26.2 & 909 & 2.99 & 2.96 & 1.96 & 0.37 \\
\hline 1.83 & 4 & 19.9 & 567 & 2.57 & 1.86 & 2.68 & 0.39 \\
\hline 1.37 & 5 & 25.7 & 567 & 2.60 & 1.85 & 2.74 & 0.45 \\
\hline 0.915 & 5.5 & 21.3 & 472 & 2.78 & 1.55 & 3.47 & 0.47 \\
\hline 0.457 & 9 & 27.7 & 385 & 3.72 & 1.25 & 5.77 & 0.69 \\
\hline 0.366 & 11 & 27.6 & 343 & 4.17 & 1.12 & 7.26 & 0.83 \\
\hline 0.229 & 14 & 26.9 & 201 & 2.76 & 0.660 & 8.11 & 0.95 \\
\hline 0.137 & 17 & 24.7 & 230 & 4.28 & 0.747 & 11.1 & 1.14 \\
\hline 0.0915 & 18.1 & 22.3 & 129 & 2.54 & 0.423 & 11.7 & 1.42 \\
\hline 0.0457 & 22 & 20.3 & 111 & 4.84 & 0.364 & 25.8 & 1.78 \\
\hline
\end{tabular}

${ }^{a}$ Corrected dpm in polymer $=(d p m$ in polymer measured $) / 84 \%$, where dpm in polymer $=(\mathrm{cpm}$ observed $\times 100) /$ $\%$ efficiency.

boles $M=$ (gm. polymer used for counting) $/ 194.1$.

cMoles $I=\left(\right.$ dpm in polymer corrected)/sp. activity of AIBN- ${ }^{3}$. . Specific activity of AIBN- ${ }^{3}$ H 18 3.047 x $10^{9} \mathrm{dpm} / \mathrm{mole}$.

$\mathrm{d}_{\bar{M}_{\mathrm{n}}}=(194.1)$ (moles $\left.\mathrm{M}\right) /($ moles $I)$.

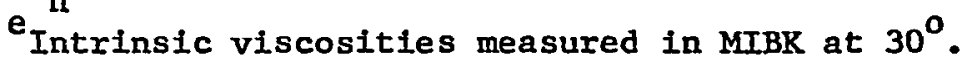




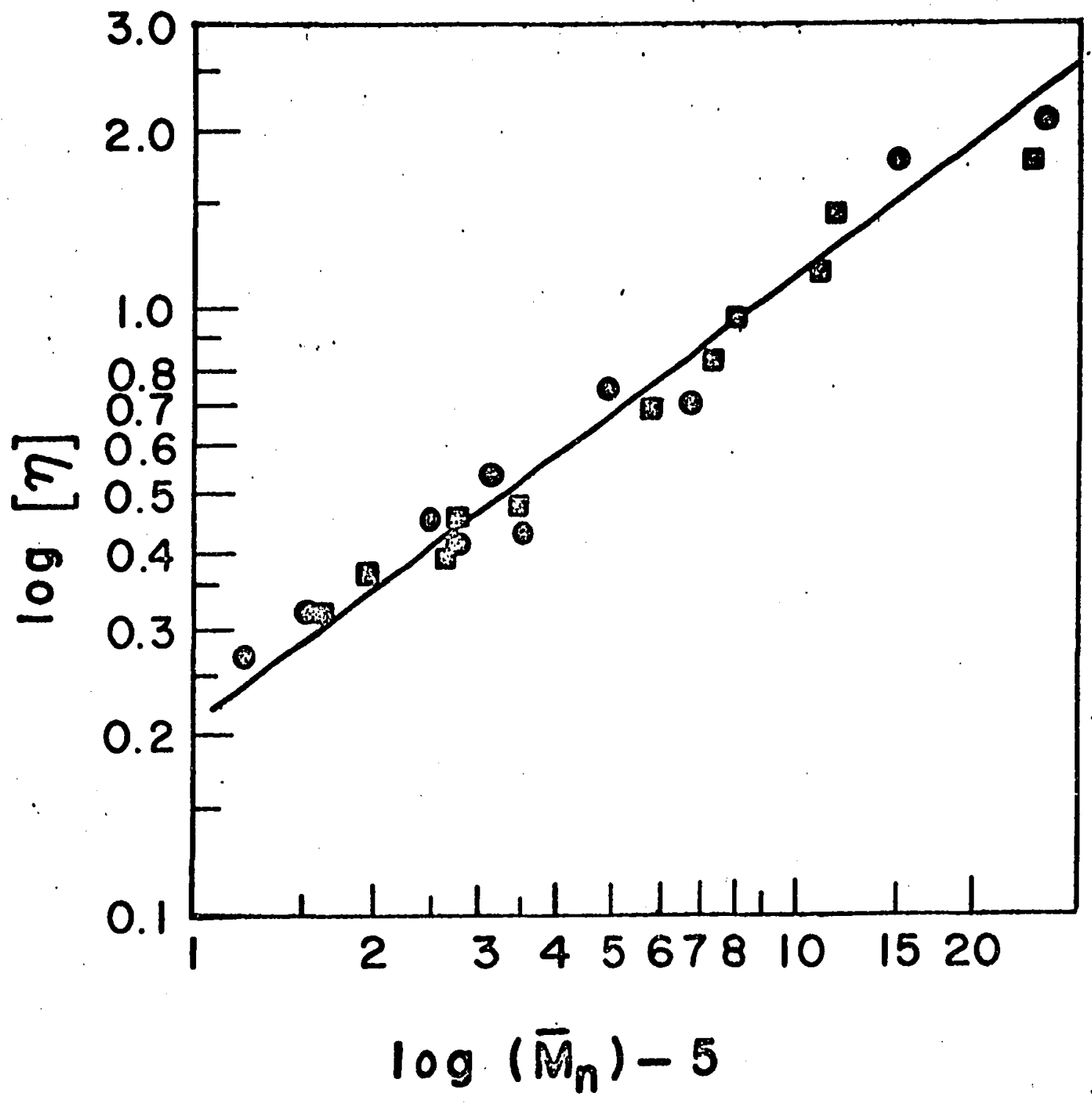

Figure 4. Intrinsic Viscosity in MIBK at $30^{\circ}$ for Poly-PFS vs. Molecular Weight: - Data obtained by osmometry; 0 Data obtained using tritiated AIBN and assuming that termination is entirely by combination. 
Figure 4 yields the equations

$$
[\eta]=4.37 \times 10^{-5} \bar{M}_{n}^{0.736} \text {, or, } \bar{M}_{n}=8.50 \times 10^{5}[\eta]^{1.36}
$$

Methyl isobutyl ketone (MIBK) is nearly a $\theta$ solvent at $30^{\circ}$ for poly-PFS and is convenient for osmometry and viscosity measurements. The number-average degree of polymerization, $\overline{\mathrm{P}}_{n}$, of poly-PFS is higher than that of polystyrene by about three times at $60^{\circ}$ to about 13 times at $129^{\circ}$ (see Figure 3). This observation can be explained if the chain transfer to monomer for PFS is of minor importance in the chain termination step. 45

The Polymerization of PFS Initiated by AIBN at Different Temperatures. Tables 3,4 and 5 give data for the AIBN-initiated polymerization of PFS at $60^{\circ}, 30^{\circ}$ and $40^{\circ} \mathrm{C}$, respectively. Figures 5 , 7 and 9 show these data plotted in the form of Equation 10; the - slopes of the lines yield values of $2 k \mathrm{~d} f / \delta^{2}$ (see the second column of Table 6). Figures 8 and 10 show the data at $30^{\circ}$ and $40^{\circ}$ plotted in the form of Equation 13; the slopes of the lines yield values of $\delta^{2} / 2[\mathrm{M}]^{2}$, and values of $\delta^{2}$ can be calculated using known values of [M]. The values of $\delta^{2}$ calculated in this way are given in Table 7 for $30^{\circ}$ and $40^{\circ}$. An alternate way to calculate $\delta^{2}$ is provided by the so-called molecular weight. ${ }^{46}$ since termination is by combination, the kinetic chain length, $v$, equals $\vec{p} / 2$, and since $v=R_{P} / R_{i}{ }^{47}$

$$
R_{1}=2 R_{p} / \ddot{p}=2 k_{d} \mp[I]
$$

The data in Table 3 can be plotted in the form $2 R_{p} / \bar{p}$ vs. [AIBN] and 
the result is a straight line with a slope equal to $2 k_{d}$. For example, in pure PFS, the slope gives $R_{1}=11.8 \times 10^{-6}$ [AIBN] $\mathrm{sec}^{-1}$. If the value of $1.13 \times 10^{-5} \mathrm{sec}^{-1}$ is taken for $k_{d}$ at $60^{\circ}, 37$ then a value of $f$ for AIBN can be calculated from these slopes; for example, . In pure PFS, $f$ is found to be 0.52 . This is in satisfactory agreement with other values in the Iiterature; for example, the $f$ value of AIBN in p-fluorostyrene, obtained by inhibitor method, is $0.550^{48}$ Table 6 gives values of $f$ for AIBN calculated by this method for mixtures of PFS and a number of solvents. By using these values of $f$, and the literature value of $\mathrm{k}_{\mathrm{d}}, 37$ apparent values of $\delta^{2}$ can be calculated. These data are shown in the last column of Table 6. The solvent dependence of $\delta^{2}$ is quite clearly observed for PFS as well as styrene. 49,50 In the absence of solvent, if the \% polymerization is low, Equation 13 may be simplified as

$$
\frac{1}{\bar{p}}=\frac{\delta^{2}}{2[M]^{2}} R_{P}+C_{M}+C_{I} \frac{[I]}{[M]}
$$

If $C_{I}$ is not negligible, a plot of $\left(\overline{\bar{p}} \underline{x} R_{P}\right)^{-1}$ vs. $R_{P}^{-1}$ should give a straight line with a slope equal to $\left\{\mathrm{C}_{\mathrm{M}}+\mathrm{C}_{\mathrm{I}} \frac{[\mathrm{I}]}{[\mathrm{M}]}\right\}$. This relationship can be easily seen from a transformation of Equation 50:

$$
\frac{1}{\bar{P} \frac{x}{P}}=\left\{C_{M}+C_{I[M]} \frac{[I]}{R_{P}}+\frac{1}{2[M]^{2}}\right.
$$

Figure 6 is a graph of Equation 50a for the polymerization of PFS initiated by AIBN by using the data in Table 3. A straight line 
relationship is observed. Least square treatment yields slope $=-4.54 \underline{x}$ $10^{-6}$; intercept $=6.56$. Since a negative slope is not ailowed by theory, It is concluded that the slope is essentially equal to zero.within the limits of the experimental error. (The standard deviation in the slope is $\pm 6.56 \times 10^{-6}$ and in the intercept is $\pm 2.61 \times 10^{-1}$. The probable error in the slope is $4.42 \times 10^{-6}$ and in the intercept is $1.76 \times 10^{-1}$. The maximum slope allowed is $2 \times 10^{-6}$. If $C_{I}=0$, then $C_{M}$ is 40 times sma1ler than that of styrene). This means that both $C_{M}$ and $C_{I}$ must be zero also. In contrast with $\mathrm{PFS}$, styrene has a $\mathrm{C}_{\mathrm{M}}$ of $8 \times 10^{-5}$ at $60^{\circ} .32$ If the rate constants in $\delta^{2}=\mathrm{k}_{\mathrm{p}}^{2} /\left(2 \mathrm{k}_{\mathrm{t}}\right)$ are expressed in terms of Arrhenius type equations, then we obtain: $57 c^{\prime}$

$$
k_{p}^{2} /\left(2 k_{t}\right)=\left(A_{p}^{2} / A_{t}\right) e^{-\left(2 E_{p}-E_{t}\right) / R I}
$$

where $A_{p}, A_{t}$ are the collision frequency factors for propagation and termination, respectively, and $E_{p}, E_{t}$ are the energy of activation for propagation and termination, respectively。 By plotting $\log \left(1 / \delta^{2}\right)$ against $1 / T, 2 E_{p}-E_{t}$ and $A_{p}^{2} / A_{t}$ can be evaluated. Such a plot for AIBN-initiated polymerization of PFS is shown in Figure 11 using the data in Tables 6 and 7. An excellent linear relationship is observed indicating that the two methods employed in the calculation of $\delta^{2}$ are self-consistent. The following equation is obtained from the least squares fit:

$$
1 / \delta^{2}=4.01 \times 10^{4} \exp (-11,300 / \mathrm{RT})
$$


Tobolsky and offenbach ${ }^{52}$ obtained the corresponding equation for styrene:

$$
1 / \delta^{2}=1.74 \underline{x} 10^{5} \exp (-12,740 / \mathrm{RT})
$$

Since In an initiated polymerization, $R_{P}$ is proportional to $k_{p}\left(k_{d} / k_{t}\right)^{0.5}$ (see Equation 10), the observed over-all activation energy, $E$, can be shown $30,57 c$ to be

$$
E \cdot=\left(E_{p}-E_{t} / 2\right)+E_{d} / 2
$$

where $E_{d}$, the activation energy for spontaneous decomposition of the Initiator, is about $30 \mathrm{kcal} / \mathrm{mole}$ for AIBN or benzoyl peroxide. 53 From Equation $52, E_{p}-E_{t} / 2=\frac{11.3}{2}=5.6 \mathrm{kcal} / \mathrm{mole}$, and the over-a11 activation energy for AIBN-initiated polymerization of PFS is therefore $E=5.6+\frac{30}{2}=20.6 \mathrm{kcal} / \mathrm{mole}$. This value corresponds to a two- to three-fold increase in rate for a $10^{\circ} \mathrm{C}$ temperature change. The corresponding value of $E$ for styrene is $21.4 \mathrm{kcal} / \mathrm{mole}$. Many other polymerization reactions have $\mathrm{E}$ of $20-21 \mathrm{kcal} / \mathrm{mole}$. Note that Equation 52 refers only to the ratio of rate constants $k_{p}^{2} /\left(2 k_{t}\right)$ and does not include the effect of temperature on the rate of initiation. In photo-polymerization, where the rate of initiation is independent of temperature, Equation 52 represents the complete activation energy. The value of $1 / \delta=k_{p} /\left(2 k_{t}\right)^{0.5}$ gives the polymerizability of the monomer. Comparable values at $60^{\circ}$ are PFS, 0.0385 ; styrene, 52 0.0333 ; methyl methacrylate, ${ }^{38} 0.147$; vinyl acetate, ${ }^{54} 0.430$. A comparison between the reactivities of poly-PFS and polystyryl radicals will be given after the section on absolute rate constants. 
Table 3

The Polymerization of PFS Initiated by AIBN at $60^{\circ}$

\begin{tabular}{|c|c|c|c|c|c|c|c|c|c|}
\hline Third Solvent ${ }^{a}$ & {$[M]^{b}$} & $\begin{array}{l}\text { [AIBN] } \\
\underline{x} 10^{4}\end{array}$ & {$[M][I]^{0.5}$} & $\begin{array}{l}\text { Time, hr } \\
\left(\text { at } 60^{\circ} \text { ) }\right.\end{array}$ & $\begin{array}{c}\text { Convn. } \\
\%\end{array}$ & $\begin{array}{l}R_{P, \text { obsd }} \\
\times 10^{5 c}\end{array}$ & $R_{P} \times 10^{5^{d}}$ & {$[\eta]$} & $10^{4} / \overline{\mathrm{P}}$ \\
\hline None & 6.69 & 185 & 0.910 & 3 & 17.6 & 12.0 & 12.0 & 0.37 & 8.80 \\
\hline None & 6.44 & 92.5 & 0.617 & 6 & 24.3 & 8.25 & 8.25 & 0.42 & 7.43 \\
\hline None & 6.36 & 37.0 & 0.385 & 11 & 26.5 & 4.91 & 4.91 & 0.75 & 3.37 \\
\hline None & 6.42 & 9.24 & 0.194 & 20 & 24.9 & 2.53 & 2.53 & 1.38 & 1.47 \\
\hline None & 6.60 & 1.85 & 0.0898 & 42 & 20.0 & 0.971 & 0.970 & 2.69 & 0.594 \\
\hline None & 7.00 & 185 & 0.952 & 1.5 & 9.20 & 12.5 & 12.5 & 0.40 & 7.92 \\
\hline None & 7.01 & 92.5 & 0.674 & 2 & 8.84 & 8.99 & 8.99 & 0.49 & 5.94 \\
\hline None & 7.03 & 37.0 & 0.427 & 3 & 8.22 & 5.58 & 5.58 & & \\
\hline None & 7.10 & 9.25 & 0.216 & 5 & 6.44 & 2.62 & 2.62 & & \\
\hline Fluorobenzene & 3.56 & 502 & 0.799 & 1 & 5.46 & 5.55 & 5.55 & & \\
\hline Fluorobenzene & 3.36 & 185 & 0.457 & 5 & 16.6 & 3.38 & 3.38 & 0.24 & 15.8 \\
\hline Fluorobenzene & 3.21 & 92.5 & 0.309 & 10 & 24.5 & 2.49 & 2.49 & & \\
\hline Fluorobenzene & 3.09 & 37.0 & 0.188 & 9 & 31.2 & 1.66 & 1.66 & 0.42 & 7.43 \\
\hline Fluorobenzene & 3.40 & 9.24 & 0.103 & 24 & 14.6 & 0.621 & 0.618 & 0.83 & 2.94 \\
\hline THF & 3.28 & 660 & 0.894 & 0.5 & 9.91 & 10.1 & 10.1 & & \\
\hline THF & 3.19 & 177 & 0.425 & 5 & 25.8 & 5.26 & 5.26 & 0.28 & 12.9 \\
\hline THF & 3.18 & 88.4 & 0.299 & 7 & 26.2 & 3.81 & 3.81 & 0.32 & 10.8 \\
\hline
\end{tabular}


Table 3 (Continued)

\begin{tabular}{|c|c|c|c|c|c|c|c|c|c|c|}
\hline Third & $\begin{array}{c}\text { Solvent } \\
\vdots\end{array}$ & {$[\mathrm{M}]^{\mathrm{b}}$} & $\begin{array}{l}\text { [AIBN] } \\
\times 10^{4}\end{array}$ & {$[M][I]^{0.5}$} & $\begin{array}{l}\text { Time,hr } \\
\text { (at } 60^{\circ} \text { ) }\end{array}$ & $\begin{array}{c}\text { Convn. } \\
\%\end{array}$ & $\begin{array}{l}R_{\mathrm{P}, \text { obsd }} \\
\times 10^{\mathrm{c}}\end{array}$ & $R_{P} \times 10^{5 d}$ & {$[\eta]$} & $10^{4} / \bar{P}$ \\
\hline THF & & 3.30 & 9.24 & 0.100 & 20 & 19.9 & 1.01 & 1.01 & 0.57 & 4.89 \\
\hline THF & . & 3.27 & 3.70 & 0.0629 & 30 & 21.6 & 0.731 & 0.728 & 0.63 & 4.28 \\
\hline THF & . & 3.35 & 1.85 & 0.0455 & 40 & 17.0 & 0.432 & 0.428 & 0.70 & 3.70 \\
\hline \multicolumn{2}{|c|}{ Pyridine } & 3.03 & 531 & 0.703 & 3 & 34.4 & 11.7 & 11.7 & & \\
\hline \multicolumn{2}{|c|}{ Pyridine } & 3.19 & 531 & 0.735 & 3 & 25.9 & 8.80 & 8.80 & & \\
\hline \multicolumn{2}{|c|}{ Pyridine } & 3.09 & 177 & 0.411 & 6 & 31.2 & 5.41 & 5.41 & & \\
\hline \multicolumn{2}{|c|}{ Pyridine } & 3.30 & 88.4 & 0.310 & 4 & 19.6 & 4.99 & 4.99 & & \\
\hline \multicolumn{2}{|c|}{ Pyridine } & 3.44 & 9.24 & 0.104 & 20 & 12.1 & 0.614 & 0.611 & & \\
\hline \multicolumn{2}{|c|}{ Pyridine } & 3.37 & 1.85 & 0.0458 & 40 & 15.9 & 0.405 & 0.401 & & \\
\hline
\end{tabular}

a Solutions consist of PFS and AIBN plus the third component listed. Solvents are $50 \%$ by volume. $b_{\text {PFS }}$ in moles per liter--the molarities shown are average molarities which have been corrected for $\%$ conversion.

Cobserved rate of polymerization in $\mathrm{M} \mathrm{sec}^{-1}$.

$\mathrm{d}_{\mathrm{R}_{\mathrm{P}}}=\left[\mathrm{R}_{\mathrm{P}, \mathrm{obsd}}^{2}-\mathrm{R}_{\mathrm{P}, \mathrm{th}}^{2}\right]^{\frac{1}{2}} ; \mathrm{R}_{\mathrm{P}, \mathrm{th}}=0.570 \underline{10^{-6} \mathrm{M} \mathrm{sec}} \mathrm{s}^{-1}$. 
Table 4

The Polymerization of PFS Initiated by AIBN at $30^{\circ}$

\begin{tabular}{|c|c|c|c|c|c|c|c|}
\hline Third Solvent ${ }^{a}$ & $\begin{array}{l}{[A I B N]} \\
x 10^{4}\end{array}$ & {$[\mathrm{M}][\mathrm{I}]^{0.5}$} & $\begin{array}{l}\text { Time, hr } \\
\text { (at } 30^{\circ} \text { ) }\end{array}$ & $\begin{array}{c}\text { Convn. } \\
\%\end{array}$ & $R_{P} \times 10^{5^{b}}$ & {$[\eta]$} & $10^{4} / \overline{\mathrm{P}}^{\mathrm{c}}$ \\
\hline None & 177 & 0.968 & 7.5 & 3.50 & 0.950 & 0.74 & 3.42 \\
\hline None . & 177 & 0.968 & 9 & 5.06 & 1.14 & 0.67 & 3.90 \\
\hline None & 44.2 & 0.484 & 13 & 3.13 & 0.490 & 1.29 & 1.61 \\
\hline None & 17.7 & 0.303 & 13 & 2.29 & 0.358 & --- & --- \\
\hline Fluorobenzene & 177 & 0.484 & 8 & 3.56 & 0.453 & 0.45 & 6.75 \\
\hline Fluorobenzene & 177 & 0.484 & 8 & 4.62 & 0.588 & 0.37 & 8.95 \\
\hline Fluorobenzene & 44.2 & 0.242 & 14.5 & 4.13 & 0.289 & 0.59 & 4.67 \\
\hline Fluorobenzene & 17.7 & 0.153 & 20.5 & 5.16 & 0.256 & 0.96 & 2.41 \\
\hline Benzonitrile & 177 & 0.484 & 8 & 6.66 & 0.847 & 0.60 & 4.67 \\
\hline Benzonitrile & 88.4 & 0.342 & 11 & 7.29 & 0.674 & 0.64 & 4.18 \\
\hline Benzonitrile & 44.2 & 0.242 & 14.5 & 4.85 & 0.340 & 1.29 & 1.62 \\
\hline Benzonitrile & 17.7 & 0.153 & 20.5 & 5.54 & 0.275 & 1.65 & 1.15 \\
\hline Benzotrifluoride & 177 & 0.484 & 8 & 6.00 & 0.763 & 0.30 & 12.0 \\
\hline Benzotrifluoride & 88.4 & 0.342 & 11 & 4.75 & 0.439 & 0.43 & 7.14 \\
\hline Benzotrifluoride & 17.7 & 0.153 & 20.5 & 3.95 & 0.197 & 0.86 & 2.81 \\
\hline
\end{tabular}


Footnotes to Table 4

a Solutions consist of PFS and AIBN plus the third component listed. Solvents are 50\% by volume, i.e., $[M]=3.64 \mathrm{M}$ for all 50:50 mixtures.

${ }^{b}$ Corrected for thermal polymerization rate.

${ }^{\mathrm{C}}$ Calculated from Equation 48. 
Table 5

The Polymerization of PFS Initiated by AIBN at $40^{\circ}$

\begin{tabular}{|c|c|c|c|c|c|c|}
\hline $\begin{array}{l}\text { [AIBN] } \\
\times 10^{4}\end{array}$ & {$[M][I]^{0.5}$} & $\begin{array}{l}\text { Time, hr } \\
\text { (at } 40^{\circ} \text { ) }\end{array}$ & $\begin{array}{c}\text { Convn. } \\
\%\end{array}$ & $R_{P} \times 10^{5}$ & {$[\eta]$} & $10^{4} / \overline{\mathrm{p}}$ \\
\hline 177 & 0.958 & 3.5 & 4.78 & 2.78 & 0.48 & 6.28 \\
\hline 177 & 0.958 & 3 & 4.48 & 3.04 & $-\cdots$ & $-\cdots$ \\
\hline 88.4 & 0.677 & 5 & 5.06 & 2.06 & 0.65 & 4.1 .4 \\
\hline 44.2 & 0.479 & 7 & 4.38 & 1.27 & 0.94 & 2.49 \\
\hline 17.7 & 0.303 & 9 & 3.45 & 0.779 & 1.61 & 1.19 \\
\hline
\end{tabular}

${ }^{a}$ See footnotes under Table 3. 
Table 6

The Polymerization of PFS Initiated by AIBN at $60^{\circ}$

\begin{tabular}{lccc}
\hline $\begin{array}{l}\text { Solvent } \\
\text { a }\end{array}$ & $\left(2 \mathrm{k} f / \delta^{2}\right) \times 10^{8^{b}}$ & $f^{c}$ & $\begin{array}{c}\text { Apparent } \\
\delta^{2^{d}}\end{array}$ \\
\hline None & 1.74 & $0.52^{c}$ & 675 \\
Fluorobenzene & 0.548 & $0.25^{\mathrm{e}}$ & $1030^{\mathrm{e}}$ \\
THF & 1.42 & $0.28^{\mathrm{e}}$ & $446^{\mathrm{e}}$ \\
Pyridine & 1.74 & & \\
Styrene & & $0.55^{\mathrm{f}}$ & \\
MMA & & $0.50^{8}$ &
\end{tabular}

${ }^{a}$ Solvents are $50 \%$ by volume.

${ }^{b}$ Calculated from the slopes of graphs like Figure 5 .

${ }^{c}$ Calculated from plots of Equation 49 and the value $1.13 \times 10^{-5}$ for $k_{d}$. dcalculated from column 2 and 3.

${ }^{e}$ Corrected for chain transfer and high conversion.

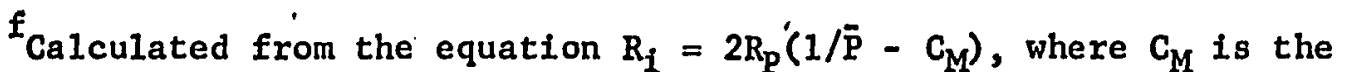
average of the transfer constants for styrene and PFS; $1 . e ., 4 \times 10^{-5}$. Values of $\overline{\mathrm{P}}$ were measured for the copolymer by osmometry and the same technique as described in the Experimental Section for Poly-PFS.

${ }^{8}$ Calculated by assuming termination occurs $50 \%$ by combination. 
Table 7

The Polymerization of PFS Initiated by AIBN at $30^{\circ}$ and $40^{\circ}$

\begin{tabular}{lcc}
\hline Solven $t^{a}$ & \multicolumn{2}{c}{$\delta^{2^{b}}$} \\
\cline { 2 - 3 } None & $30^{\circ}$ & $40^{\circ}$ \\
Fluorobenzene & 3710 & 2070 \\
Benzonitrile & 4000 & $\ldots$ \\
Benzotrifluoride & 1530 & $\ldots$ \\
\hline
\end{tabular}

${ }^{a}$ Solvents are $50 \%$ by volume.

${ }^{b}$ Calculated from the slopes of Figure 8 and 10 . 


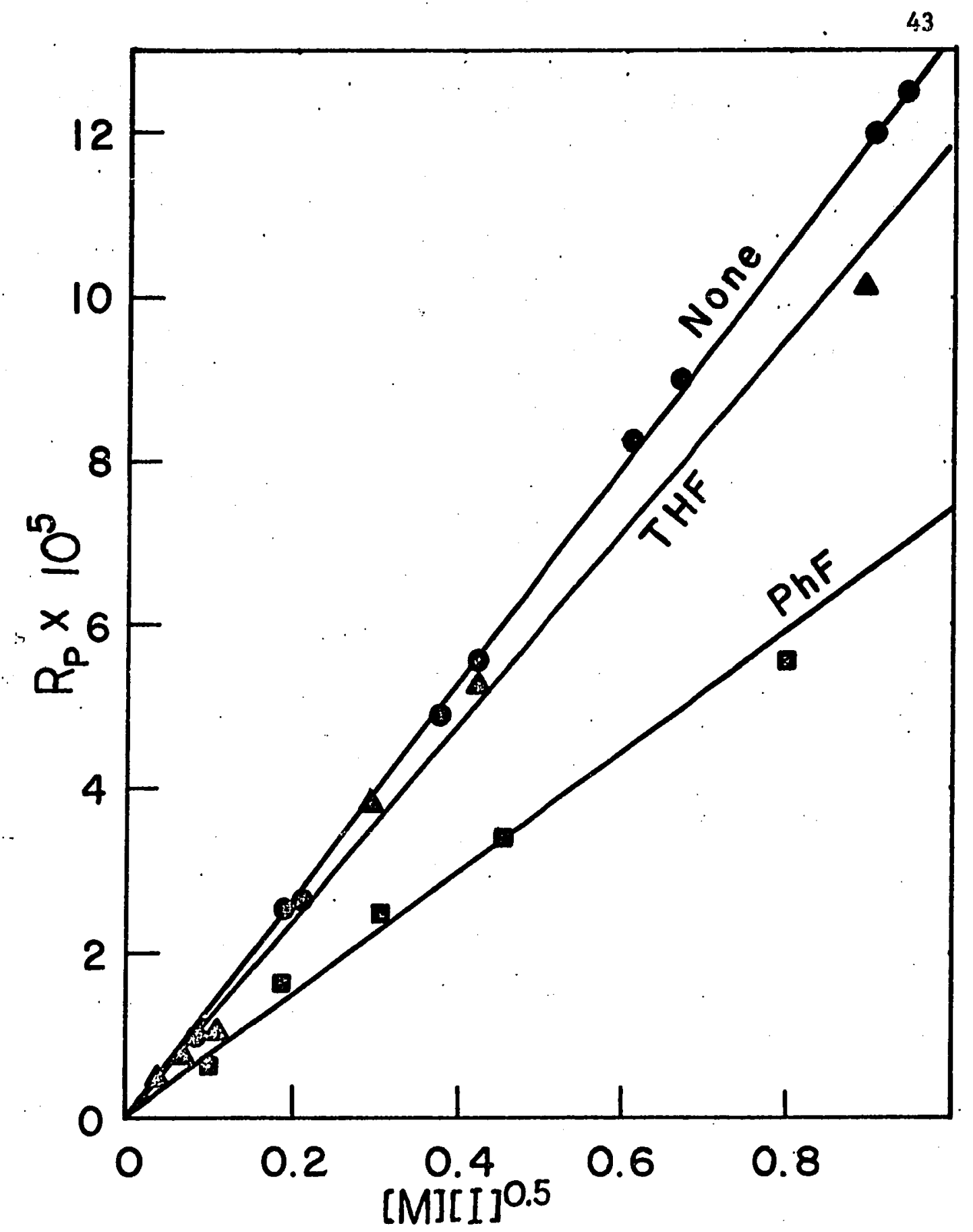

Figure 5. Graph of Equation 10 for the AIBN-Initiated Polymerization of PFS at $60^{\circ}$. Solvents ( $50 \%$ by volume) are coded as follows: - None; $\Delta$, THF; $\boldsymbol{\Delta}$, Fluorobenzene. Data for Pyridine as Solvent are not shown; they lie very near the Line for Pure PFS. 


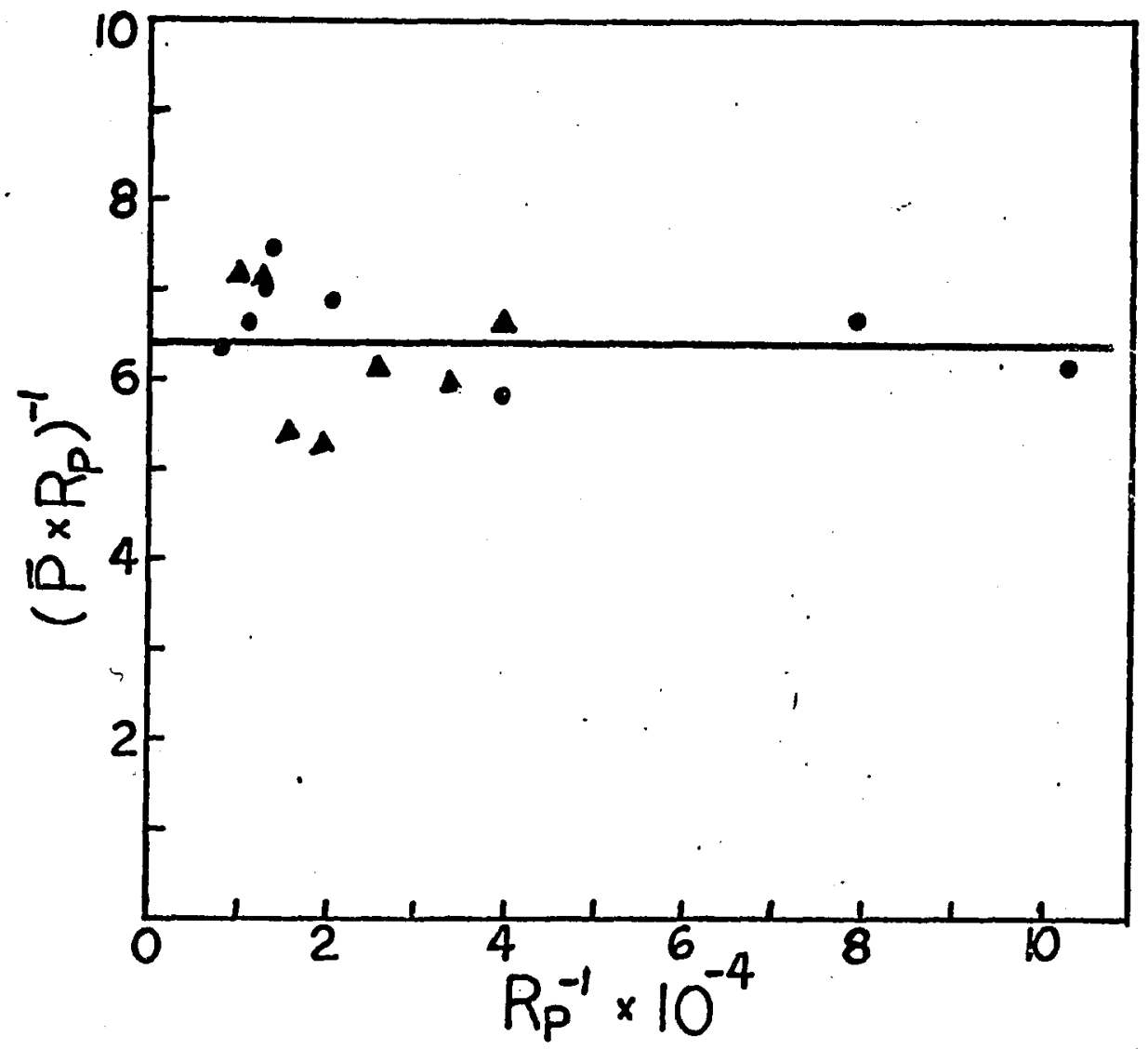

Figure 6. Graph of $\left(\overline{\mathrm{P}} \underline{\mathrm{x}} \mathrm{R}_{\mathrm{P}}\right)^{-1}$ vs. $\mathrm{R}_{\mathrm{P}}^{-1}$ for the Polymerization of PFS Initiated by $\operatorname{AIBN}(\bullet)$, and by $\operatorname{AIBN}-{ }^{3} \mathrm{H}(\mathrm{A}), 60^{\circ}$. 


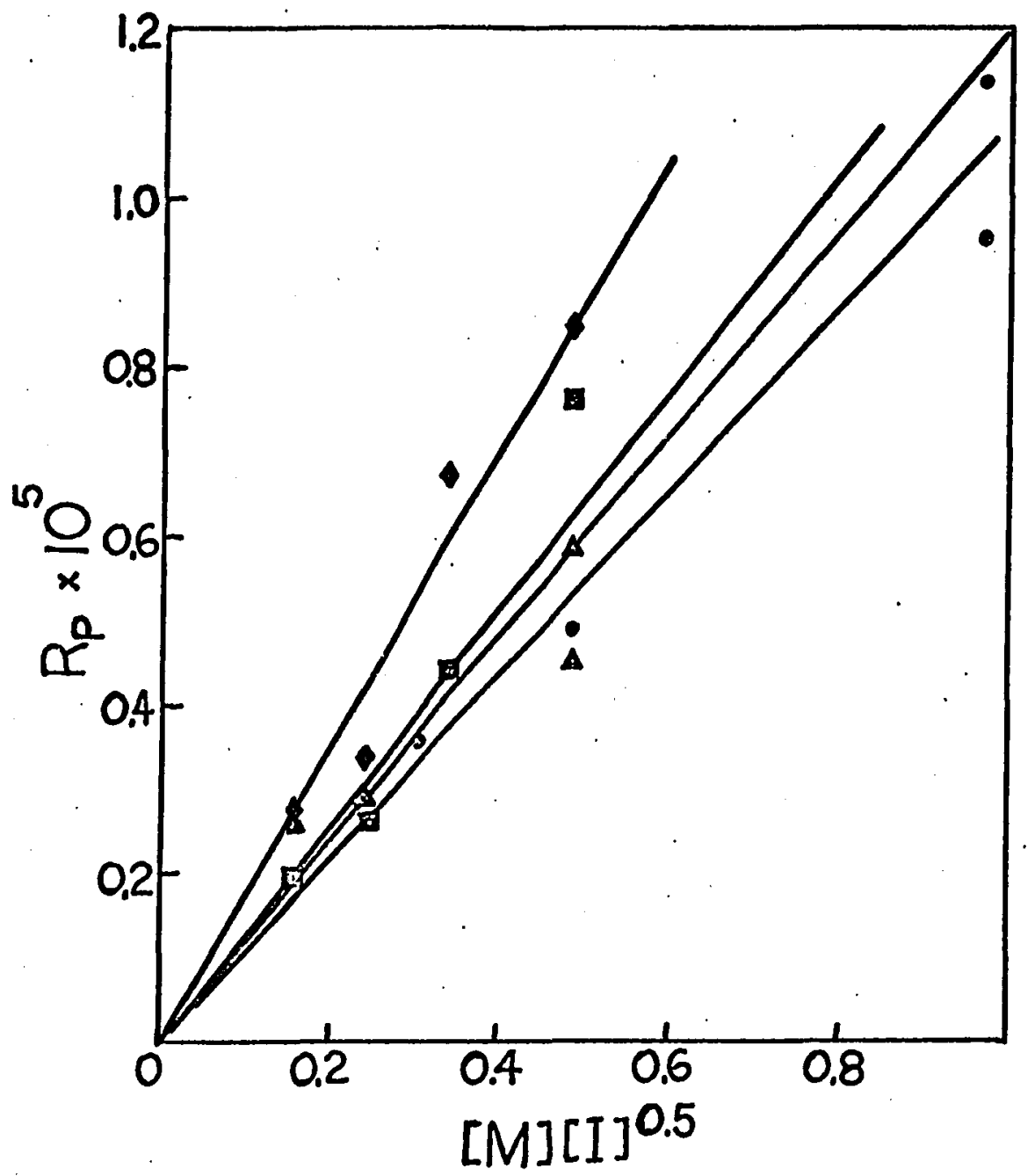

Figure 7. Graph of Equation 10 for the AIBN-Initiated Polymerization of PFS at $30^{\circ}$. Solvents ( $50 \%$ by volume) are coded as follows: $\boldsymbol{\theta}$, None; $\Delta$, Fluorobenzene; $\boldsymbol{\theta}$, Benzotrifluoride; $\checkmark$, Benzonitrile. 


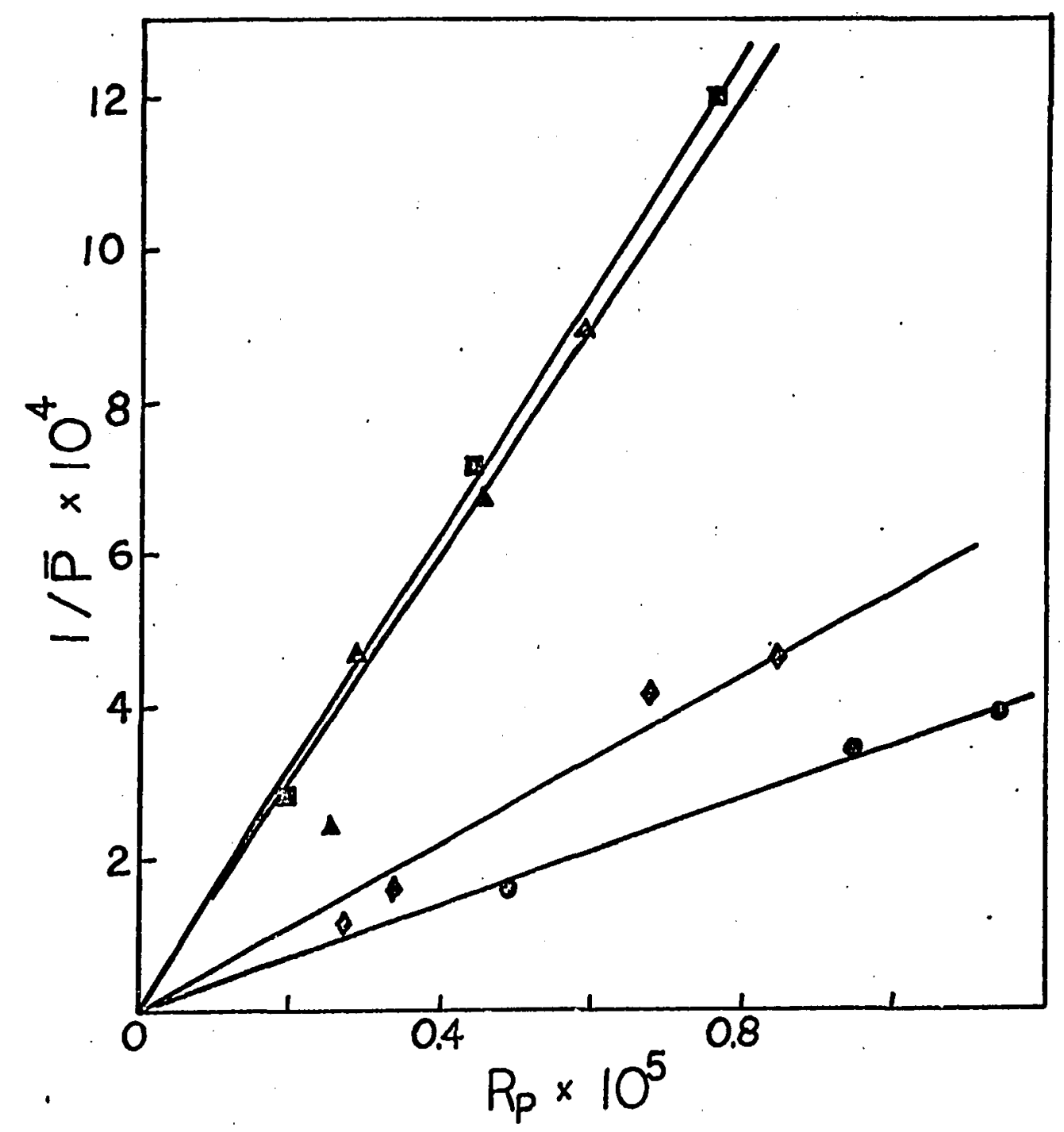

Figure 8. Graph of Equation 13 for the AIBN-Initiated Polymerization of PFS at $30^{\circ}$. Solvents (50\% by volume) are coded as follows: 0 , None; $\Delta$, Fluorobenzene; Benzotrifluoride; , Benzonitrile. 


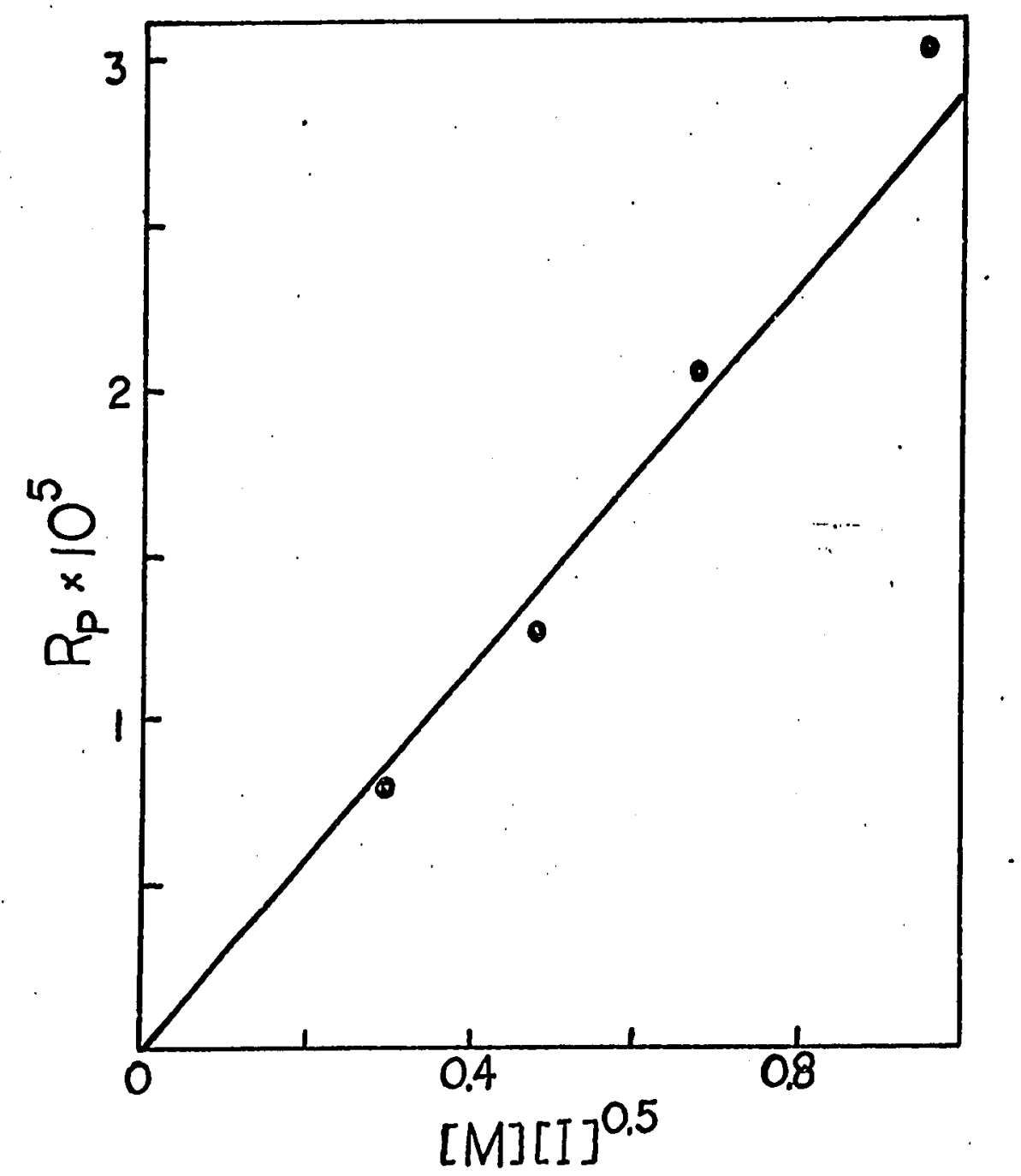

Figure 9. Graph of Equation 10 for the AIBN-Initiated Polymerization of PFS at $40^{\circ}$. 


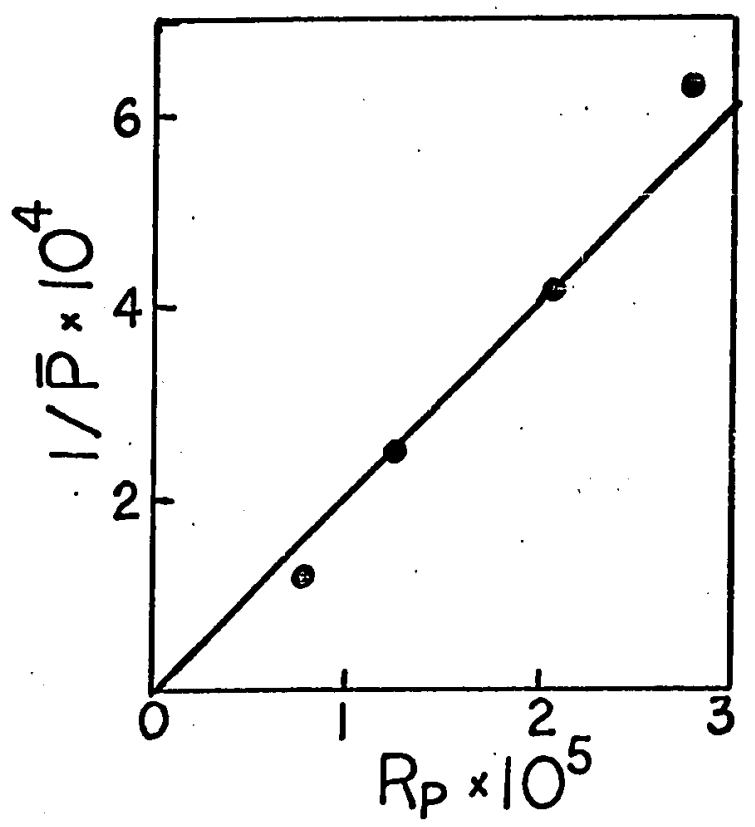

Figure 10. Graph of Equation 13 for the AIBN-Initiated Polymerization of PFS at $40^{\circ}$. 


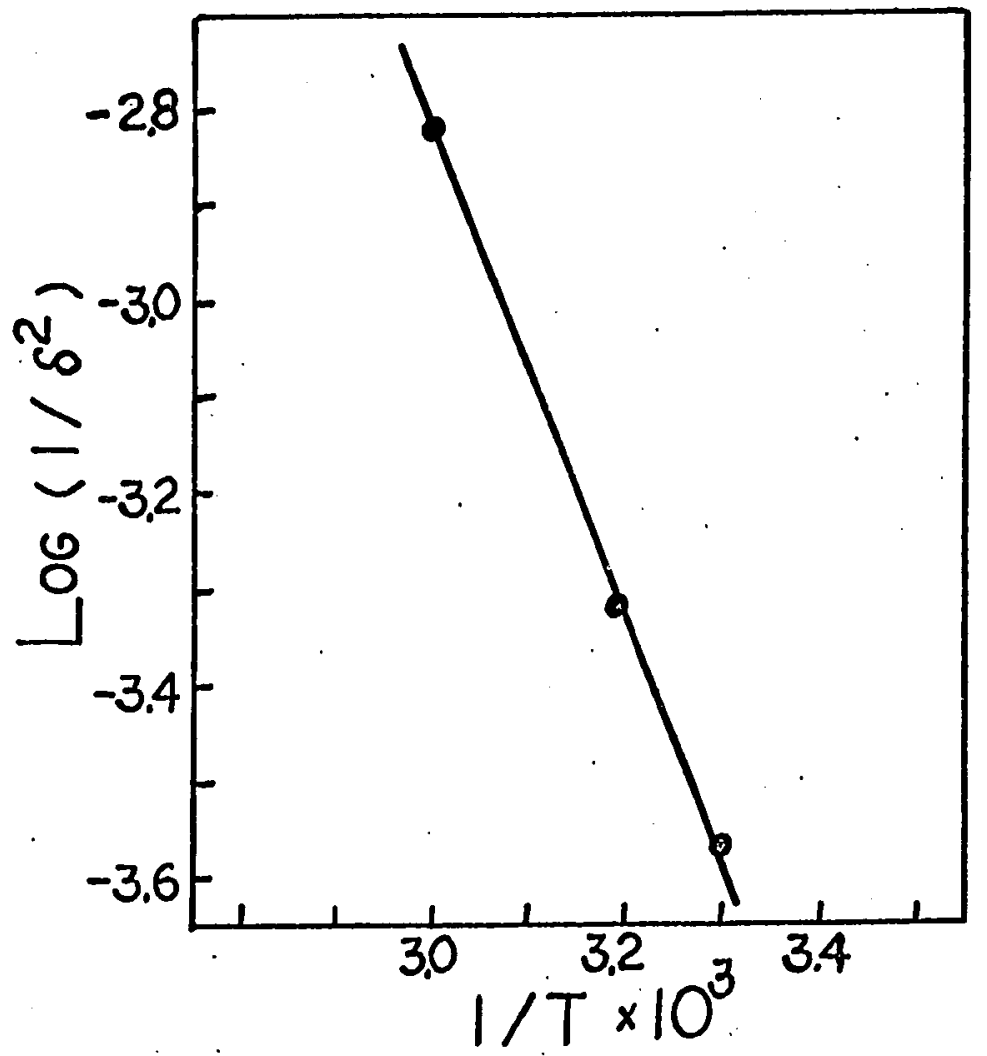

Figure 11. Graph of $\log \left(1 / \delta^{2}\right)$ vs. $1 / T$ for the AIBN-Initiated Polymerization of PFS in Bulk. 
Data on the Thermal Polymerization of PFS in Solvents at

$60^{\circ}$.

Transfer Constants in Thermal Polymerization. Thermal polyermization of PFS was carried out in a number of solvents in which poly-PFS is soluble. Table 8 gives the data obtained. In addition, transfer to some non-solvents such as toluene and benzene was studied using THF and/or fluorobenzene as a cosolvent, and the results are shown in Table 9. Equation 55 was used to calculate transfer constants 55 in the presence of a cosolvent such as THF.

$$
\frac{1}{\overline{\mathrm{P}}}=\frac{\delta^{2}}{2[\mathrm{M}]^{2}} \mathrm{R}_{\mathrm{P}}+\mathrm{C}_{\mathrm{M}}+\mathrm{C}_{\mathrm{I}} \frac{[\mathrm{I}]}{[\mathrm{M}]}+\mathrm{C}_{\mathrm{S}} \frac{[\mathrm{S}]}{\mathrm{SM}]}+\mathrm{C}_{\mathrm{THF}} \frac{[\mathrm{THF}]}{[\mathrm{M}]}
$$

The terms due to transfer to PFS monomer, $C_{M}$, and to AIBN, $C_{I}[I] /[M]$, have been taken as approximately zero and $S$ is a variable solvent. Comparable data for styrene for the solvents THF, methyl isobutyl ketone (MIBK), methyl isopropyl ketone (MIPK), fluorobenzene, benzonitrile, benzotrifluoride, and hexafluorobenzene were also obtained as shown in Table 10. It should be noted that in some cases the sanples were prepared in the air and the $R_{p} / R_{p}^{0}$ ratios are larger than 5 where $R_{P}^{0}=R_{P, t h}[M] /[M]_{0},[M]_{0}$ and $[M]$ are the molar concentrations of pure monomer and diluted monomer and $R_{P}$ is the observed rate of polymerization. It is necessary to $\mathrm{p}$ lot $\left\{\frac{1}{\overline{\mathrm{p}}}-\frac{\delta^{2^{2}}}{2[\mathrm{M}]^{2}} R_{\mathrm{P}}-\mathrm{C}_{\mathrm{M}}\right\}$ against $[\mathrm{S}] /[\mathrm{M}]$ in order to obtain the correct values of $C_{S}$ for these systems. ${ }^{56}$. In the cases where $R_{p} / R_{p}^{0}$ is smaller than 5 , the Mayo plot of $1 / \overline{\mathrm{P}}$ vs. [S]/[M] gives the correct values of $\mathrm{C}_{\mathrm{S}}$. Figures 12-15 show plots of Equation 55 in the form necessary to determine the transfer constants. Table 11 compares 
the transfer constants for PFS with data for styrene. As Table 11 shows, plots like Figure 13 and 14, which are corrected for enhanced rates of polymerization, ${ }^{56}$ gave the same transfer constant as did the normal Mayo plot for all transfer agents except MIBK.

Selectivity. The data of Table 11 show that the radical from PFS is approximately as selective toward benzylic hydrogens as is the polystyryl radical. The reactivity of primary- secondary-tertiary hydrogens (per hydrogen) in the serfes toluene-ethylbenzene-cumene is $1: 6.7: 17$ for PFS and $1: 7.8: 20$ for styrene. Transfer constants can be rationalized in terms of dipolar forms for the resonance structures of the transition states. ${ }^{47}$ As expected, the PFS radical is much less able to bear positive charge as required in dipolar form II than is the polystyryl radical.

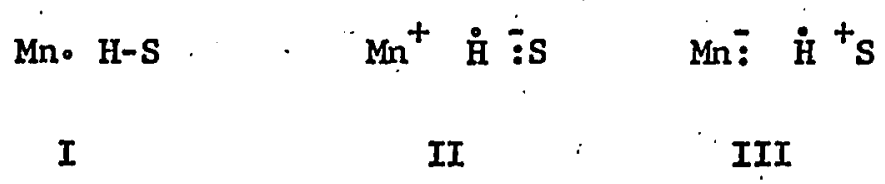

Thus the polystyryl radical has an enhanced transfer constant to the ketones relative to toluene, whereas the reverse is true of the radical from $\mathrm{PFS}$.

Order in Monomer for PFS and Styrene. Figures 16 and 17 are the graphs of $\log R_{P, t h}$ vs. $\log [M]$ for $P F S$ and styrene, respectively, using the data from Tables 8 and 10. The slopes of Figures 16 and 17 are listed in Table 12. It is seen that the orders in styrene monomer determined in substituted benzene solvents lie close to $5 / 2$ (average 2.3 ). 
On the other hand, the corresponding orders in PFS are all less than 2, ranging from 1.57 for fluorobenzene to 1.93 for benzotrifluoride (average 1.8 ).

Difficulties in Solvent Purification. The peroxide tests (described by Fieser ${ }^{102}$ ) showed that THF, MIBK and MIPK form peroxides very easily and rapidly on standing. The non-oxygen containing solvents like fluorobenzene, benzonitrile, benzotrifluoride, benzene, toluene, ethylbenzene, cumene, hexafluorobenzene form peroxides more slowly. Therefore, the previous data on thermal polymerization of PFS in THF and ketones might be in error since the solvents used were exposed to air while ampoules were filled. In order to check these data, the thermal polymerization of PFS in THF and ketones were repeated with great caution. The solvent and the monomer were distilled (in the presence of nitrogen) Into the calibrated ampoules and sealed on a vacuum line. The new data for these solvents are given in Table 8. The new ratios of $R_{P} / R_{P}^{0}$ are much closer to 1 and in most cases are less than 5. We believe that all of these values should be much closer to unity, and probably all of them should be less than 1. That is, it is unlikely that any colvents increase the fractional rate of thermal polymerization. 103,131-2 (Note that the $R_{P} / R_{P}^{0}$ ratio used here is equivalent to the ratio of fractional rate of polymerization in solvent to that in no solvent case). The reason the values are larger than 1 is probably due to the presence of impurities such as peroxides in the solvents studied. (The slopes of the plot of $\log R_{\mathrm{p}}$ vs. $\log [\mathrm{M}]$ for MIPK and MIBK are still too 10w, see Figure 16). On the other hand, 
both the orders in monomer (Figure 16) and the value of the transfer constants to THF, MIBK and MIPK are not altered significantly. Therefore, the data reported ${ }^{13}$ for $R_{P} / R_{P}^{0}$ for THE, MIBK and MIPK must be corrected but the values of $\mathrm{C}_{\mathrm{S}}$ and monomer orders are essentially unchanged (see Tables 11 and 12). It is believed that the corresponding data reported in Table 10 on the thermal polymerization of styrene in solvents, especially THF, might be in error also. In the polymerization of PFS in cumene where either $\mathrm{THF}^{13}$ or fluorobenzene was used as cosolvent (see Table 9), the transfer constants obtained for cumene agreed excellently. ${ }^{13}$ However, only in the cases where THF (but not fluorobenzene) was used as cosolvent, were the $R_{P} / R_{P}^{0}$ ratios observed much greater than 1. Apparently the purity of cumene itself does not play a major role in the enhancement of the over-all rate. This observation could be true also for other aromatic solvents like benzene and ethylbenzene in the cosolvent systems studied since these. solvents do not peroxidize rapidly. It should be noted that the transfer constant of THF from the AIBN-initiated runs is found to be $1.61 \times 10^{-4}$ in excellent agreement with $1.53 \times 10^{-4}$ obtained from the uncatalyzed runs. 13 This also indicates that peroxide impurities in the THF did not significantly affect the $\mathrm{C}_{S}$, since they would contribute negligibly to the over-all rate in the AIBN-initiated polymerization. Activation Energy of Thermal Initiation. The activation energy for the thermal initlation can be estimated as follows. 57 Assume that $k_{p}$ and $k_{t}$ have the same value for both the thermal and the initiated polymerization. If the rate of thermal initiation is given 
as: $R_{1, t h}=k_{i, t h}[M]^{a}$, whe re a is a constant, then Equation 10 becomes

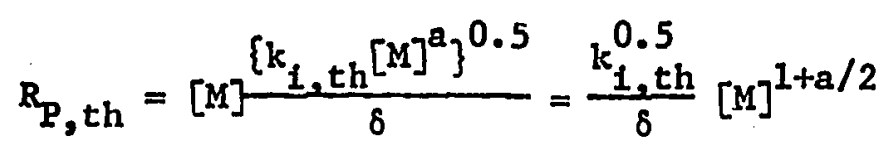

Thus in a, thermal polymerization, $R_{P, t h}$ is proportional to $k_{p}\left(k_{i, t h} / k_{t}\right)^{0.5}$, and the observed over-all activation energy, $E_{t h}$, can be shown $30,57 b$ to be

$$
E_{t h}=\left(E_{p}-E_{t} / 2\right)+E_{1, t h} / 2
$$

where $E_{1, t h}$ is the activation energy for the thermal initiation. The over-all activation energy, $E_{t h}$, obtained for thermal polymerization of PFS in bulk is $16.8 \mathrm{kcal} / \mathrm{mole}$ and the $\left(E_{p}-E_{t} / 2\right)$ value obtained from the AIBN-initiated polymerization of PFS (see previous sections) is $5.6 \mathrm{kcal} / \mathrm{mole}$. Therefore, from Equation 57 the $E_{i, t h}$ value for PFS is $2 \underline{x}(16.8-5.6)=22 \mathrm{kcal} / \mathrm{mole}$. Another method of calculating $E_{i, t h}$ is provided by a plot of $\log \bar{P}_{n}$ vs. $1 / T$ as in Figure 3 . Since all the transfer reactions are absent in the thermal polymerization of PFS $\left(C_{M}=0\right)$, Equation 46 is applicable. From the slope of Figure 3, $E_{p}-E_{t} / 2-E_{1, t h} / 2=-4.2$. Substituting in the value of $\left(E_{p}-E_{t} / 2\right)=5.6$ yields $E_{1, t h}=20 \mathrm{kcal} / \mathrm{mole}$. Thus two values of $E_{i, t h}$ are in good agreement. The 1iterature values of $E_{i, t h}, E_{t h}$ and $E$ for other vinyl monomers are glven in Table 13.

The Mechanism of Thermal Initiation. The mechanism for the spontaneous initiation of polymerization of styrene which has received the most support is that first postulated by Mayo. 109,110 It involves 
a reversible Diels-Alder condensation of two styrenes to form an adduct, $\mathrm{AH}$, which then transfers a hydrogen to another styrene molecule:

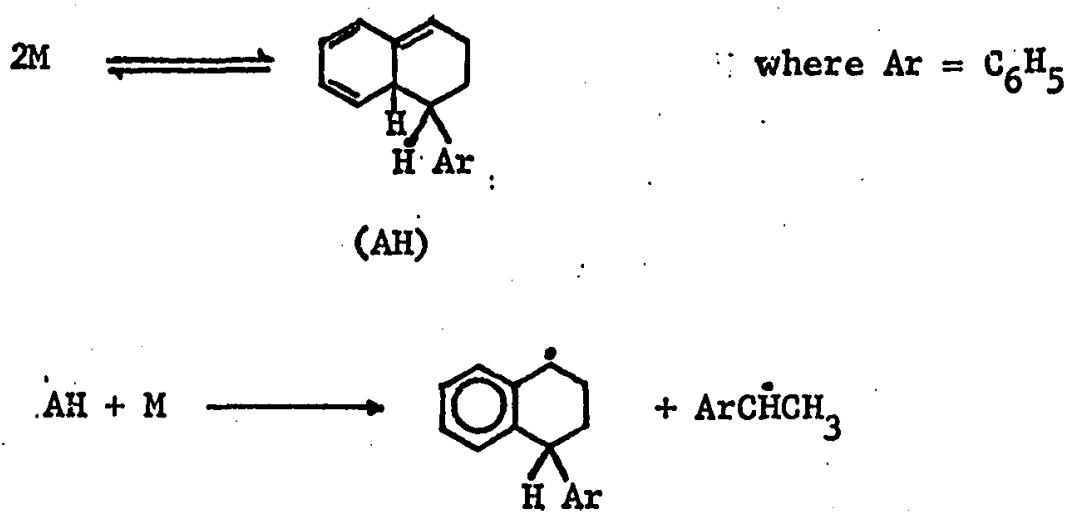

Scheme I

Mayo's mechanism (Scheme I) is substantiated by the following observations.

(1) 1-Phenyltetraline, as well as other derivatives, are isolated in a substantial yield from styrene heated at $130^{\circ}$ for $1 \mathrm{hr} .51$ (2) The over-all rate of thermal polymerization is 2.5 order in styrene as required for a termolecular initiation-mechanism. 28,118 (3) The kinetic 1sotope effect studies $27,118,121-2,127-8$ have confirmed the involvement of ortho hydrogen atoms in the initiation reaction. (4) Mayo's mechanism has been shown to be consistent with the observed activation energy for thermal initiation of styrene (29 kcal/mole). 109,110 (5) Statistical calculations ${ }^{133-4}$ indicate that small diradicals could not propagate to give high-molecular-weight polymer, because they would be very prone to undergo cyclization reactions. A mechanism involving initial formation of diradicals which then undergo transfer to monomer 
to form monoradicals was also calculated to be improbable. ${ }^{28}$ (6) The kinetic studies on the related monomers 2-vinylfuran and 2-vinylthiophene 58,59 have suggested that the thermal initiation for these monomers also is a termolecular process in support of Mayo's mechanism. Also a rearranged Diels-Alder type dimer of the structure similar to 1-pheny1tetraline was isolated for each of these two monomers.

These findings suggest that the Mayo mechanism may be valid for other vinyl monomers such as 2-vinylfuran ${ }^{59}$ and 2-vinylthiophene 58 as well as styrene. However, a recent study by Brown ${ }^{117}$ indicates that a more extended reaction scheme for the thermal polymerization of styrene (Scheme II) may be needed. Brown ${ }^{117}$. observed that the principal dimeric products isolated from the heated styrene are cis- and trans-1,2diphenylcyclobutane in a 1:2 ratio and that 1-phenyltetraline is not the major dimeric product as claimed by Milller. 51 Therefore, Brown ${ }^{117}$ proposed a more extended scheme for styrene (Scheme II) in which the Diels-Alder dimer (AH) is the common intermediate, giving rise to cyclobutanes (either directly by ring contraction or via the diradical intermediate) and other dimeric products such as 1-phenyltetraline:

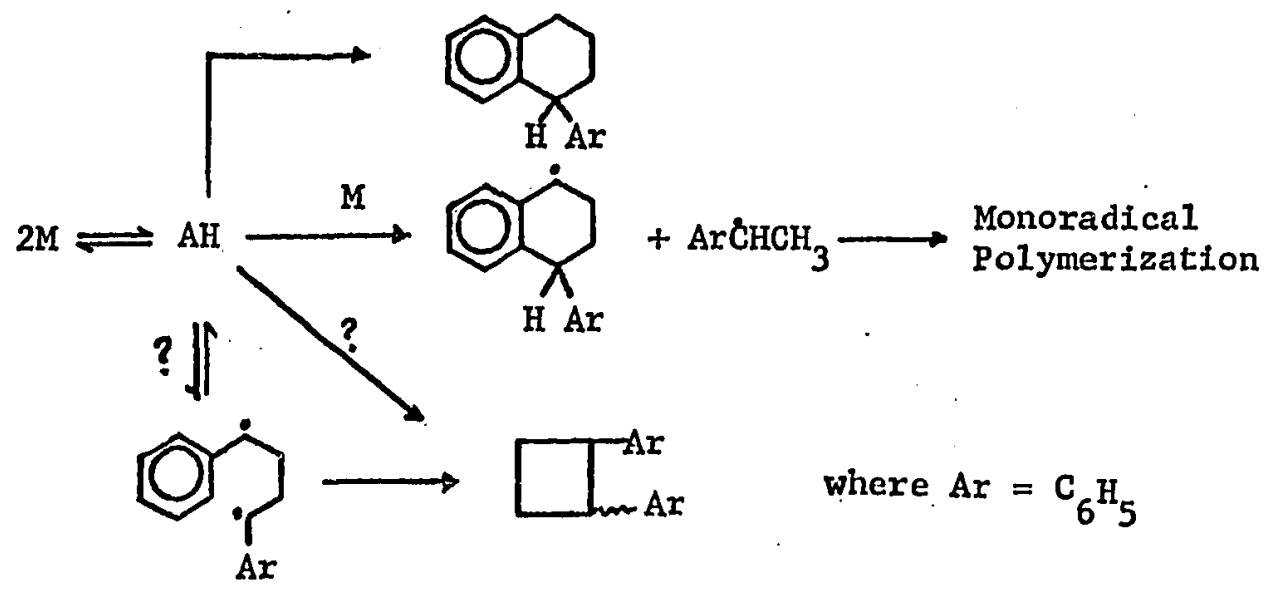

Scheme II 
We believe that the differences in the behavior of PFS and styrene suggest that these 2 similar monomers have important differences In their mechanisms of thermal initiation. We propose the following scheme (Scheme III) for the thermal polymerization of PFS:

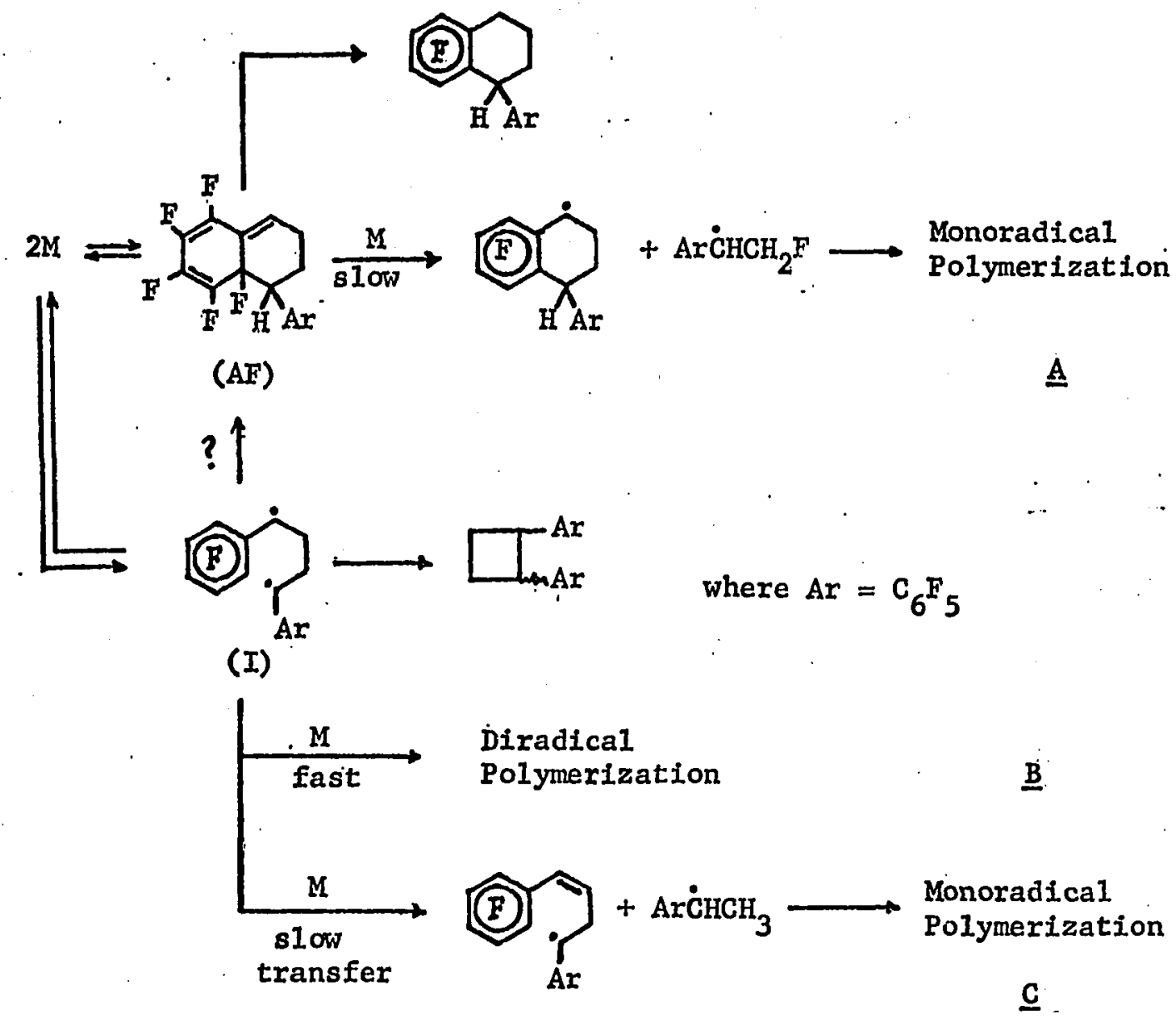

Scheme III

This scheme is supported by the following facts and arguments: (1) The thermal rate of PFS polymerization is similar to that of styrene; 
therefore, in the PFS polymerization there must be a step (or steps) In which monomer disappears at a rate comparable to that of styrene. We do not believe that a fluorine atom could be transferred from AF the same rate as a hydrogen, atom from AH since a $\mathrm{C}-\mathrm{F}$ bond is stronger than a corresponding $\mathrm{C}-\mathrm{H}$ bond. The arguments for a stronger $\mathrm{C}-\mathrm{F}$ bond are as follows: (a) The bond dissociation energy (BDE) for an "allylic" $\mathrm{C}-\mathrm{H}$ bond (i.e., $\mathrm{CH}_{2}=\mathrm{CH} \mathrm{CH}_{2}-\mathrm{H}$ bond) is $85 \mathrm{kcal}$ at $25^{\circ} \mathrm{C} .108$ The corresponding $B D E$ for an "allylic" C-F bond is not available in the literature. However, an estimation may be made in the following way: .... The $\mathrm{BDE}$ values for $\mathrm{n}-\mathrm{C}_{3} \mathrm{H} /-\mathrm{H}$ bond and $\mathrm{n}-\mathrm{C}_{3} \mathrm{H}_{7}-\mathrm{F}$ bond are $98 \mathrm{kcal}$ and $106 \mathrm{kcal}$ at $25^{\circ} \mathrm{C},{ }^{108}$ respectively. The difference between a $\underline{\mathrm{n}}$-propyl-H bond and an "allylic" C-H bond is $98-85=13 \mathrm{kcal}$. If the difference between a n-propyl-F and an "allylic" C-F bond is the same as that between a n-propyl-H bond and an "allylic" C-H bond, then the BDE of an "allylic" $\mathrm{C}-\mathrm{F}$ bond is $106-13=93 \mathrm{kcal}$ at $25^{\circ} \mathrm{C}$. Since the BDE value for a $\mathrm{CH}_{3}-\mathrm{F}$ bond is $108 \mathrm{kcal}^{108}$ compared to $104 \mathrm{kcal}$ for a corresponding $\mathrm{CH}_{3}-\mathrm{H}$ bond, ${ }^{108}$ the allylic radical resonance energy is then $108-93=15 \mathrm{kcal}$ for fluorine compound and 104-85 = $19 \mathrm{kcal}$ for the corresponding hydrogen compound. Therefore, the $\Delta H$ value needed for breaking an allylic $C-F$ bond is $93-15=78 \mathrm{kcal}$; for an allylic $\mathrm{C}-\mathrm{H}$ bond, $\Delta \mathrm{H}=85-19=66 \mathrm{kcal}$. Thus it takes a considerably higher energy to dissociate an allylic C-F bond than does a corresponding $\mathrm{G}-\mathrm{H}$ bond; (b) Benson ${ }^{129}$ estimated that the actiyation energies for hydrogen atom abstractions by organic radicals from|organic molecules in exothermic reactions are all about $8 \pm 2 \mathrm{kcal}$ and are not too sensitive to the over-all exothermicity of the reaction. In contrast, the atoms of fluorine appear never to be 
abstracted or to shift in cyclopropane pyrolysis, and a lower limit for such abstractions is estimated to be about $16 \mathrm{kcal} / \mathrm{mole}$; (c) It is observed that the transfer constant to PFS is negligible compared to that of styrene at $60^{\circ} .13 \mathrm{Also}$, the transfer constant to solvents by poly-PFS is in the following order: benzene $>$ fluorobenzene $>$ hexafluorobenzene; (d) There are cases where perfluorinated compounds are less resistant to oxidation than their hydrocarbon analog. ${ }^{124}$ For example, polyperfluorophenylene is markedly less resistant to oxidation at temperatures up to $500^{\circ} \mathrm{C}$ than its hydrocarbon analog. However, if the polyperfluorophenylene is pretreated at $400^{\circ} \mathrm{C}$ for 1 hour, ${ }^{135}$ the oxidative stability increases considerably and compares favorably with the stability of the poly-p-phenylenes in air. On the other hand, poly-PFS is remarkably more stable thermally than polystyrene. It is also more resistant to oxidation than polystyrene. ${ }^{5}$ Apparentiy, the generality of such oxidation stability is not known, it may still be safe to assume that a $\mathrm{C}-\mathrm{F}$ bond is stronger than a corresponding $\mathrm{C}-\mathrm{H}$ bond). Therefore, the path A should be much slower than the analogous path for styrene. The path $\mathrm{C}$ should be slow also since the transfer constant to PFS is zero. The remaining path which is primarily responsible for the monomer disappearance (chain growth) would be path B. (2) The average order for polymerization of PFS using several substituted benzenes as solvents was close to 2 instead of 2.5 as for styrene (Table 12). This implies that a bimolecular initiation mechanism is operative, and the step which forms either the diradical (I) or the Diels-Alder adduct (AF) would be rate-determining. Again, we do not 
believe a fluorine atom would be transferred in path $A$ so fast that the formation of the adduct AF becomes the rate-determining step. Instead, the formation of the diradical (I) would be more likely to be rate-determining, and it would be able to add monomer at a reasonably fast rate so that the over-all rate is second order in PFS. (3) We believe that the diradical (I) formed in the PFS system would be more reactive than that formed in the styrene system due to inhibition of resonance by the fluorine atoms in the ring, 5 and that the former would be more extended than the latter due to dipole-dipole repulsion of both ends. The effect is that the PFS diradical. would have a reduced rate of intramolecular cyclization. 133 (It can be shown (see Appendix III) that, in a diradical polymerization, a first-order termination process such as intramolecular cyclization would raise the over-all order for the polymerization to 3 . If, on the other hand, the rate of termination is bimolecular as in the case of monoradical-initiated polymerization, the over-all rate of thermal polymerization will be second-order in monomer. Also, this bimolecular diradical mechanism would yield the equations identical to those found in monoradical polymerization such as Equations 13 and 57). (4) PFS has an activation energy of thermal inftiation which is much lower than that of styrene (Table 13). This may be explained also if the PFS polymerization follows a different mechanism from that of styrene. We believe that an activation energy of about $30 \mathrm{kcal} / \mathrm{mole}$ may be required for a monomer undergoing termolecular initiation, and that the calculated $E_{i, t h}$ value for PFS, $\alpha$-vinylnaphthalene or acenaphthylene is either too low or too high 
to allow a Mayo type termolecular mechanism to be significant in the thermal initiation reactions of these monomers. Aso et a1. ${ }^{58,59}$ suggest that both 2-vinylfuran and 2-vinylthiophene follow Mayo mechanism, and these monomers have an activation energy of thermal initiation of about $30 \mathrm{kcal} / \mathrm{mole}$ very near that for styrene. On the other hand, Gelhaar and Ueberreiter, ${ }^{45}$ in support of Kirchner and Patat's hypothesis, 67 proposed that the thermal polymerization of acenaphthylene is initiated by a bimolecular mechanism which involves the hydrogen transfer between two monomer molecules yielding two monoradicals. For this monomer, the activation energy $E_{i, t h}$ is extremely high (38 $\mathrm{kcal} / \mathrm{mole}$ ) as a result of steric hinderance. 45 (5) No identification or isolation of any Diels-Alder type dimer (e.g., AH or AF) and its derivatives has yet been reported. However, all the dimers isolated so far for the thermal dimerization of fluorinated olefins in non-polymer systems are of cyclobutane structure. ${ }^{113-5} \cdot \alpha, \beta, \beta-\operatorname{Trifl}$ uorostyrene has a strong tendency to thermally dimerize, ${ }^{136}$ yielding a dimer of cyclobutane structure. ${ }^{136-7}$ This dimerization process competes with high polymer formation even in the presence of either benzoyl peroxide or th-butyl perbenzoate. 136 Dimers of similar cyclobutane structure have been observed with tetrafluoroethylene, ${ }^{138}$ chlorotrifluoroethylene, ${ }^{139}$ and 1,1-dich1oro-2,2-difluoroethylene also. ${ }^{139}$ Under pressure, perfluorostyrene aled tends to dimerize, ${ }^{124}$ yielding two dimers presumably of the cyclobutane structure. In addition, the dimerization of acrylonitrile was also shown to give 1,2-dicyanocyclobutane via a diradical intermediate. 112 The failure to isolate a Diels-Alder dimer for the 
fluorinated olefins suggests that path A in Scheme III may be of minor f.mportance in the thermal polymerization of these olefins. A direct examination of the product distribution of the dimers and the trimers of PFS would be necessary to clarify this. 


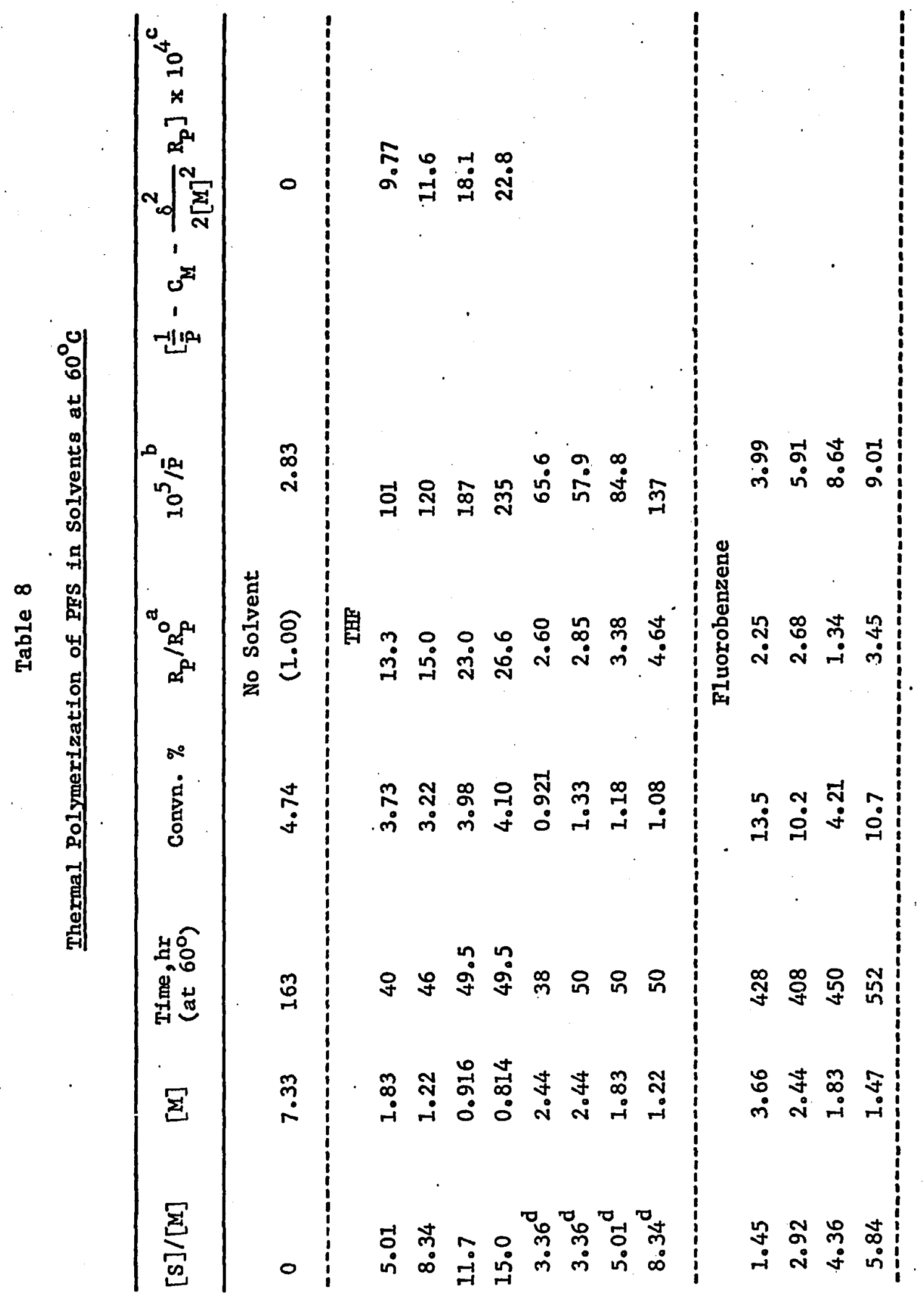




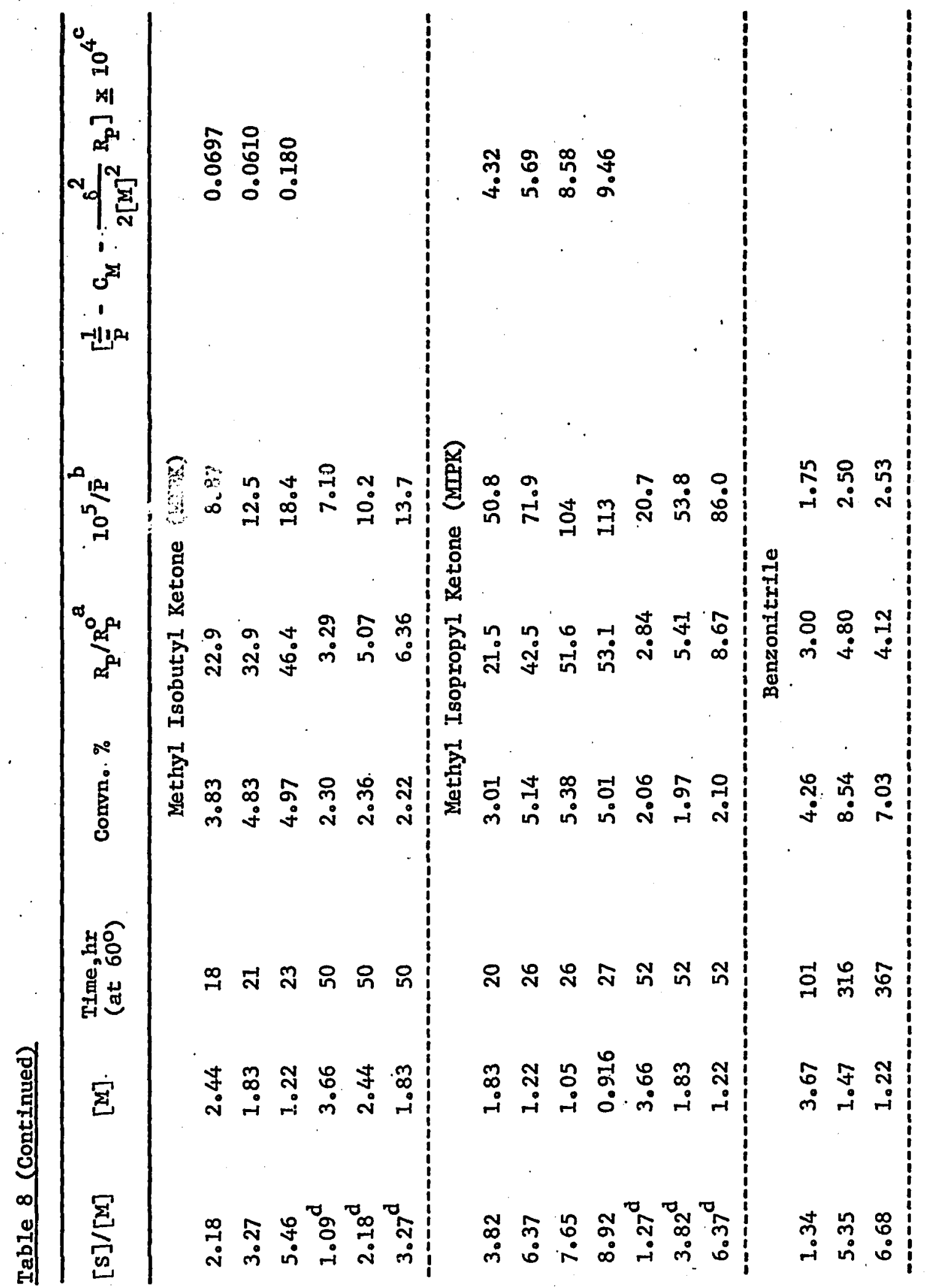


Table 8 (Continued)

\begin{tabular}{|c|c|c|c|c|c|c|c|}
\hline$[\mathrm{S}] /[\mathrm{M}]$ & {$[\mathrm{M}]$} & $\begin{array}{l}\text { Time, hr } \\
\left(\text { at } 60^{\circ}\right)\end{array}$ & Convn. \% & $R_{P} / R_{P}^{o^{a}}$ & $10^{5} / \overline{\mathrm{p}}^{\mathrm{b}}$ & {$\left[\frac{1}{\bar{P}}-c_{M}=\right.$} & $\left.\frac{\delta^{2}}{2[M]^{2}} R_{P}\right] \times 10^{4}$ \\
\hline
\end{tabular}

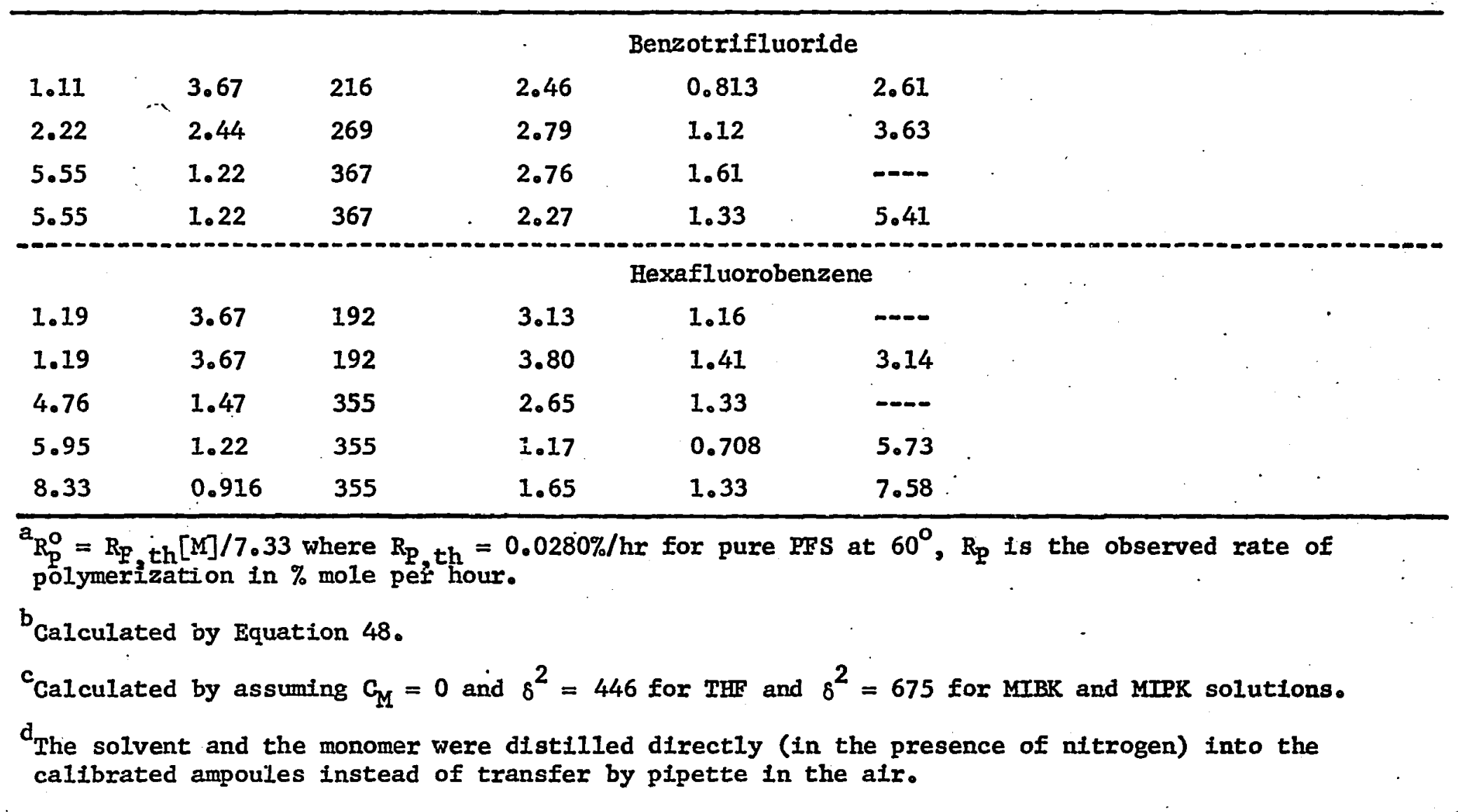


Table 9

Thermal Polymerization of PFS in Mixed Solvents Consisting of THF and Third Component

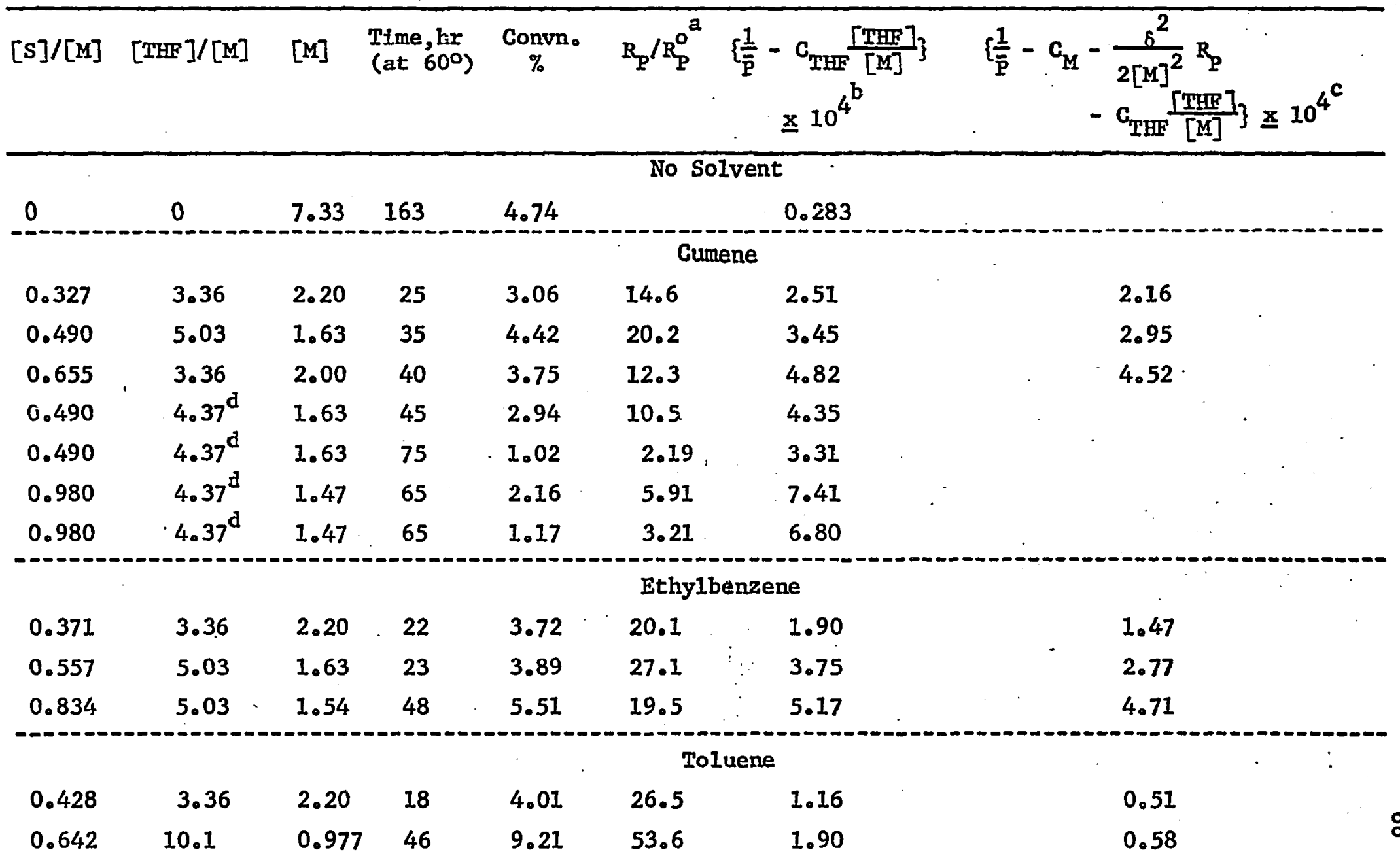




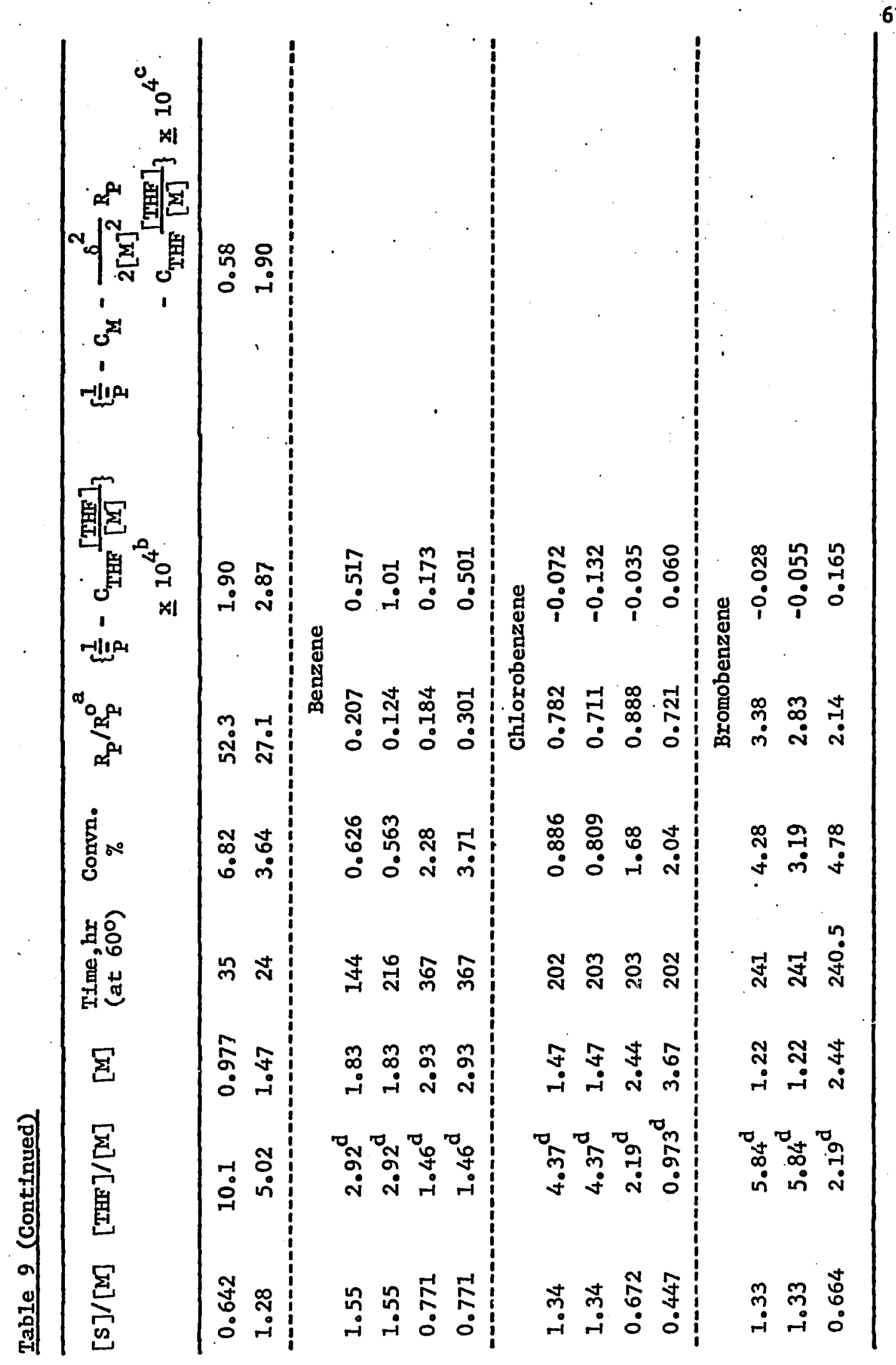




\section{Footnotes to Table 9}

${ }^{\text {a }}$ See footnote a in Table 8.

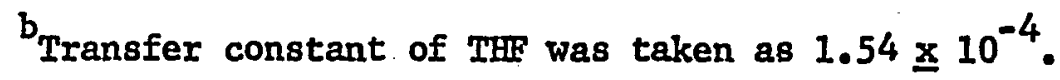

${ }^{c}$ Calculated by assuming $C_{M}=0$ and $\delta^{2}=446$.

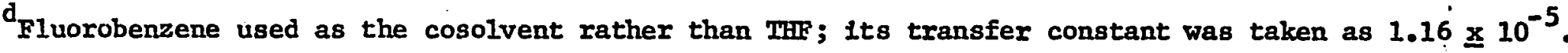




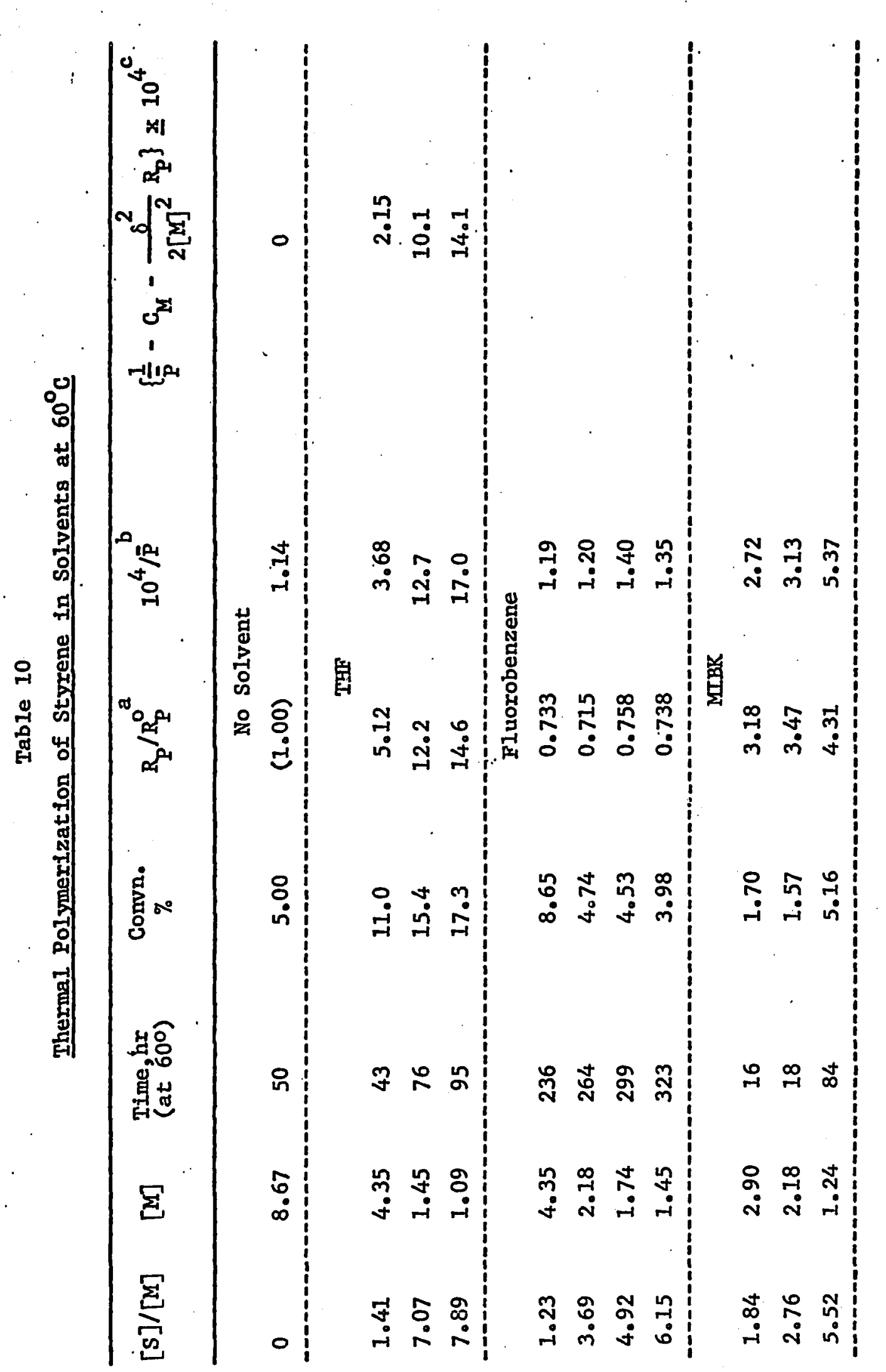




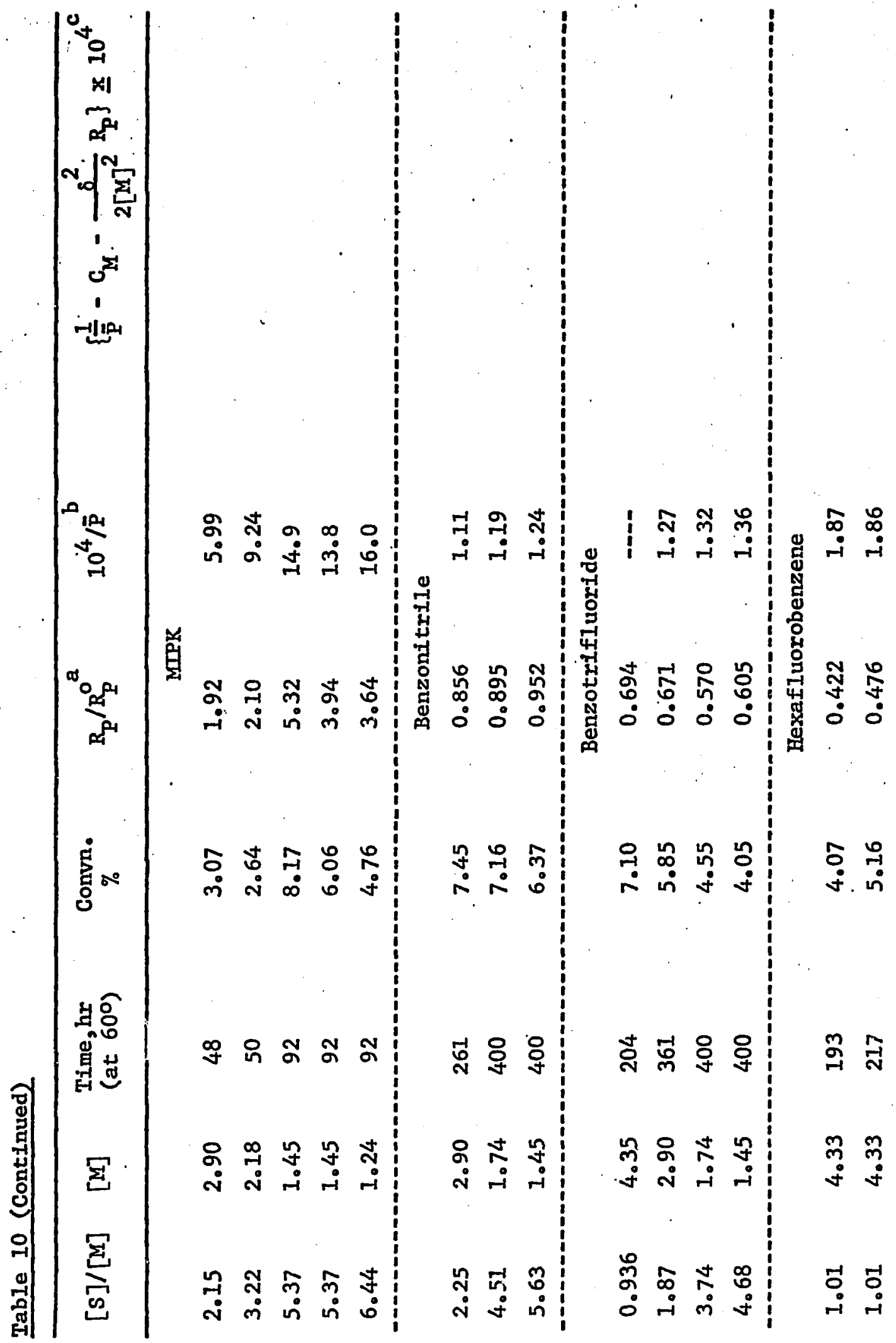


Table 10 (Continued)

\begin{tabular}{|c|c|c|c|c|c|c|}
\hline$[S] /[M]$ & [M] & $\begin{array}{l}\text { Time, hr } \\
\text { (at } 60^{\circ} \text { ) }\end{array}$ & $\underset{\%}{\text { Comvn. }}$ & $R_{P} / R_{P}^{a}$ & $10^{4} / \overrightarrow{\mathrm{p}}^{\mathrm{b}}$ & $\left\{\frac{1}{P}-G_{M}-\frac{\delta^{2}}{2[M]^{2}} R_{P}\right\} \times 10^{4^{c}}$ \\
\hline 2.02 & 2.89 & 217 & 2.32 & 0.320 & 2.84 & \\
\hline 2.02 & 2.89 & 217 & 2.15 & 0.296 & 3.24 & • \\
\hline
\end{tabular}

$a_{R_{P}^{0}}=R_{P}$ th $x[M] / 8.67$ where $R_{P, t h}=0.10 \% /$ hr for pure styrene at $60^{\circ}$. $R_{P}$ is the observed rate of polymerlation in \% per hour.

Intrinsic viscositles were measured in benzene at $30^{\circ}$ and the molecular weights were calculated using Mayo's equation (ref.31).

${ }^{c}$ Calculated by assuming $C_{M}=8 \underline{x} 10^{-5}$ (ref.32) and $\delta^{2}=900$ for pure styrene (ref.33). 
Table 11

A Comparison of the Transfer Constants for PFS and Styrene Toward Several Solvents at $60^{\circ}$

\begin{tabular}{|c|c|c|}
\hline . & $\mathrm{C}_{\mathrm{S}} \mathrm{x}$ & \\
\hline Solvent & THF & Styrene \\
\hline Tetrahydrofuran (THF) & $1.61^{1}$ & $1.42(1.86)^{b}$ \\
\hline Cumene & $6.76(6.51)^{d, h}$ & $1.04^{c}$ \\
\hline Ethylbenzene & $5.35(5.86)^{d}$ & $0.83^{c}$ \\
\hline Toluene & $1.20(2.25)^{d}$ & $0.16^{\mathrm{c}}$ \\
\hline Benzene & $0.296^{\mathrm{e}}$ & $0.04^{c}$ \\
\hline Methyl Isobutyl Ketone (MIBK) & $0.328^{1}$ & $0.757^{b}$ \\
\hline Methyl Isopropyl Ketone (MIPK) & $1.30^{1}$ & $2.39^{b}$ \\
\hline Fluorobenzene & 0.116 & $0.0384^{b}$ \\
\hline Chlorobenzene & $20^{e}$ & $0.133^{f}$ \\
\hline Bromobenzene & $\sim 0^{e}$ & $1.78^{8}$ \\
\hline Benzonitrile & 20 & $0.0141^{b}$ \\
\hline Benzotrifluoride & 0.0470 & $0.0451^{b}$ \\
\hline Methano1 & 0.355 & $-\ldots$ \\
\hline Hexafluorobenzene & 0.0554 & $0.813^{b}$ \\
\hline
\end{tabular}

Bigures not in parentheses are obtained from plots like Figure 13 or 14 where $R_{P} / R_{P}$ was greater than 5 . The numbers in parentheses were determined from the ordinary Mayo plot.

betermined in this study. All values are computed from least square fits of Equation 55.

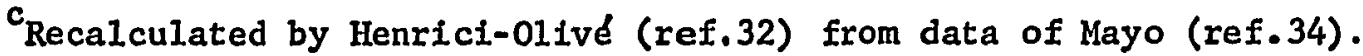
Determined in the presence of the cosolvent THF. Eetermined in the presence of the cosolvent fluorobenzene. IDetermined by Misra and Chadha (ref.35).

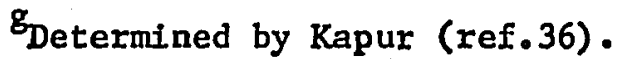
Using fluorobenzene instead of THF as cosolvent gives $\mathrm{C}=6.98$. $\mathrm{x} 10^{-4}$. ${ }^{1}$ Measured by distilling solvents and PFS directly into ampoules and sealing on a vacuum 1 ine. The values obtained by transferring solvents and PFS in the air are as follows: THF, 1.48(1.54); MCBK, 0.033(0.287); MIPK, 1.09(1.24). 
Table 12

The Order in Monomer for Thermal Polymerization of PFS and Styrene in Solvents, $60^{\circ}$

\begin{tabular}{llc}
\hline \multicolumn{1}{c}{ Solvent } & \multicolumn{2}{c}{$\mathrm{a}$ in $\mathrm{R}_{\mathrm{P}, \mathrm{th}}=\mathrm{K}[\mathrm{M}]^{\mathrm{a}}$} \\
\hline Fluorobenzene & $\mathrm{PFS}$ & Styrene \\
Benzonitrile & 1.54 & 2.07 \\
Benzotrffluoride & 1.65 & 1.95 \\
Hexafluorobenzene & 1.85 & 2.21 \\
THF & 1.86 & 2.92 \\
MIPK & $1.23^{\mathrm{a}}$ & 1.24 \\
MIBK & $1.00^{\mathrm{a}}$ & 1.22 \\
& $1.05^{\mathrm{a}}$ & 1.64 \\
\hline
\end{tabular}

Measured by distilling solvents and PFS directly into ampoules and sealing on a vacuum line. The values obtained by transferring solvents and PFS in the air are as follows: THF, 1.13; MIPK, 1.18; MIBK, 0.99. 
Table 13

The Activation Energies for Thermal and Initiated Polymerization of Some Vinyl Monomers ${ }^{a}$

\begin{tabular}{|c|c|c|c|c|}
\hline Monumer & $E_{\text {th }}$ & $E_{i, \text { th }}$ & $\mathbf{E}$ & Réference \\
\hline PFS & 16.8 & $20-22$ & 20.6 & This study \\
\hline Styrene & 21.0 & 28.9 & $21.4^{c}$ & Mayo, ref. 28 \\
\hline 2-Vinylthiophene & 15.6 & 28.2 & $16.5^{\mathrm{d}, \mathrm{e}}$ & Aso et a1., ref. 58 \\
\hline 2-Vinylfuran & 17 & 30.0 & $17^{d, e}$ & Aso et al., ref.59 \\
\hline Acenaphthylene & 30.9 & $38^{f}$ & $\cdots$ & $\underset{\text { ref.45 }}{\text { Gelhaar \& Ueberreiter, }}$ \\
\hline$\alpha$-Vinylnaphthalene & 17.4 & $22^{b}$ & $21.5^{c}$ & Loshaek et a1., ref. 60 \\
\hline o-Chlorostyrene & 17.5 & $30^{b}$ & $17.5^{\mathrm{d}}$ & Rubens, ref. 63 \\
\hline 2-Vinylpyridine & 20.2 & $29.4^{b}$ & $20.5^{c, g}$ & Koton, rẹef. 65 \\
\hline
\end{tabular}

${ }^{a}$ All In kcal/mole.

$b_{\text {Estimated from the equation, } E-E_{t h}}=\left(E_{i}-E_{i}, t h\right) / 2$ (derived by corioining the Equations 54 and 57 and assuming $E_{f}=E_{d}=30 \mathrm{kcal} / \mathrm{mole}$ for AIBNand benzoyl peroxide initiated polymerization). $E_{\text {th }}$ and $E$ are the over-all activation energies for the thermal. (uncatalyzed) and the

initiated polymerization, respectively. $E_{i, t h}$ and $E_{i}$ are the activation energies of the initiation for the thermal and the initiated polymerization, respectively.

Initiated by AIBN.

dinitiated by benzoyl peroxide.

e Determined by Koton, ref.64.

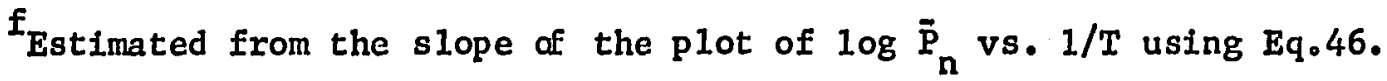

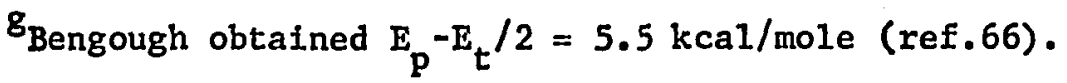




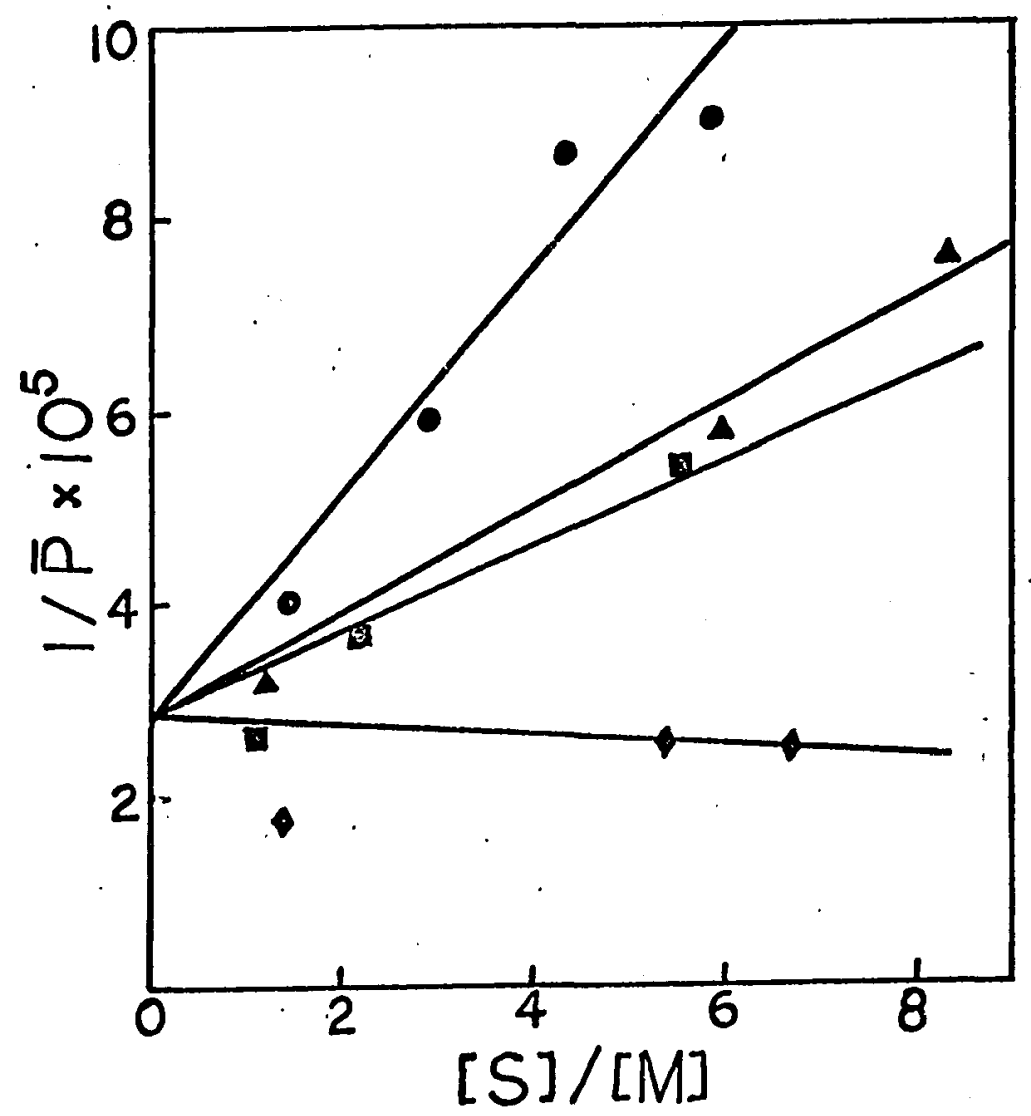

Figure 12. Transfer to Fluorobenzene (0), Hexafluorobenzene $(\Delta)$, Benzotrifluoride ( $\boldsymbol{D}$ ), and Benzonitrile $(\phi)$ by PFS at $60^{\circ}$. 


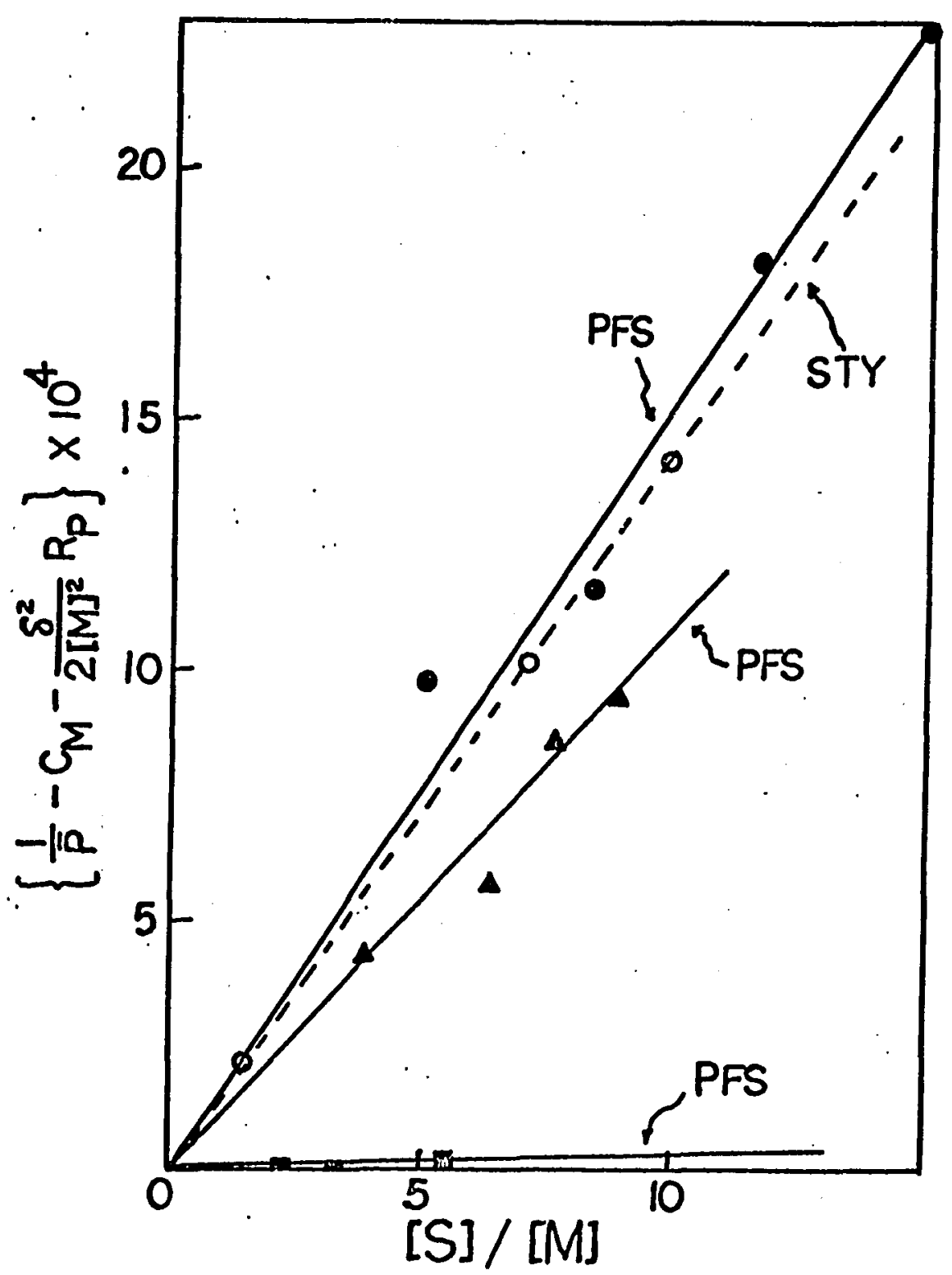

Figure 13. Transfer to THF ( $\bullet$ ), MIPK $(\Delta)$, and MIBK ( $\boldsymbol{m}$ ) by PFS (filled symbols) and to THF by styrene (open circles). 


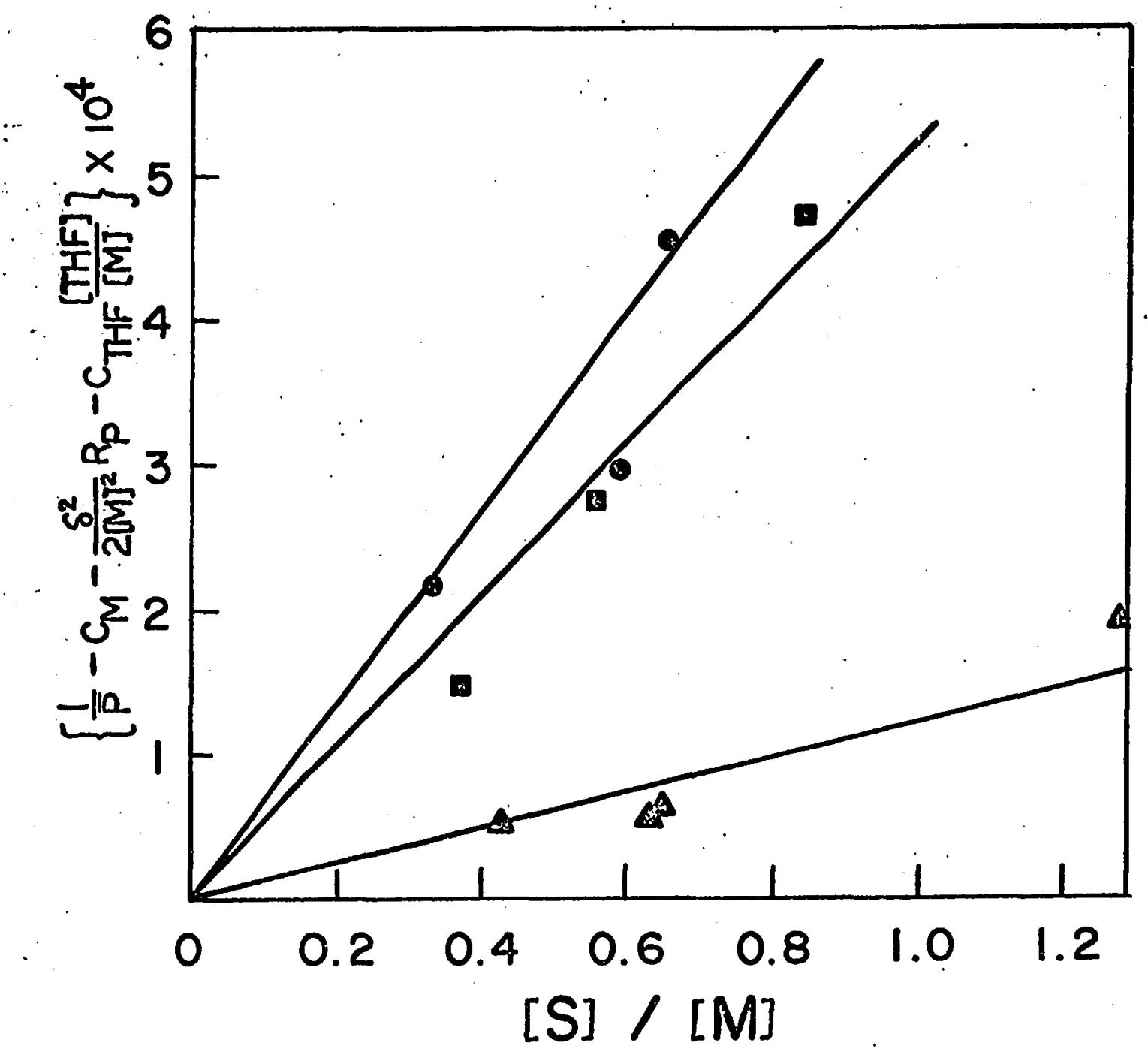

Figure 14. Transfer to Cumene (๑), Ethylbenzene ( $(0)$, and Toluene (A) by PFS at $60^{\circ}$ in the Presence of the Cosolvent THF. 


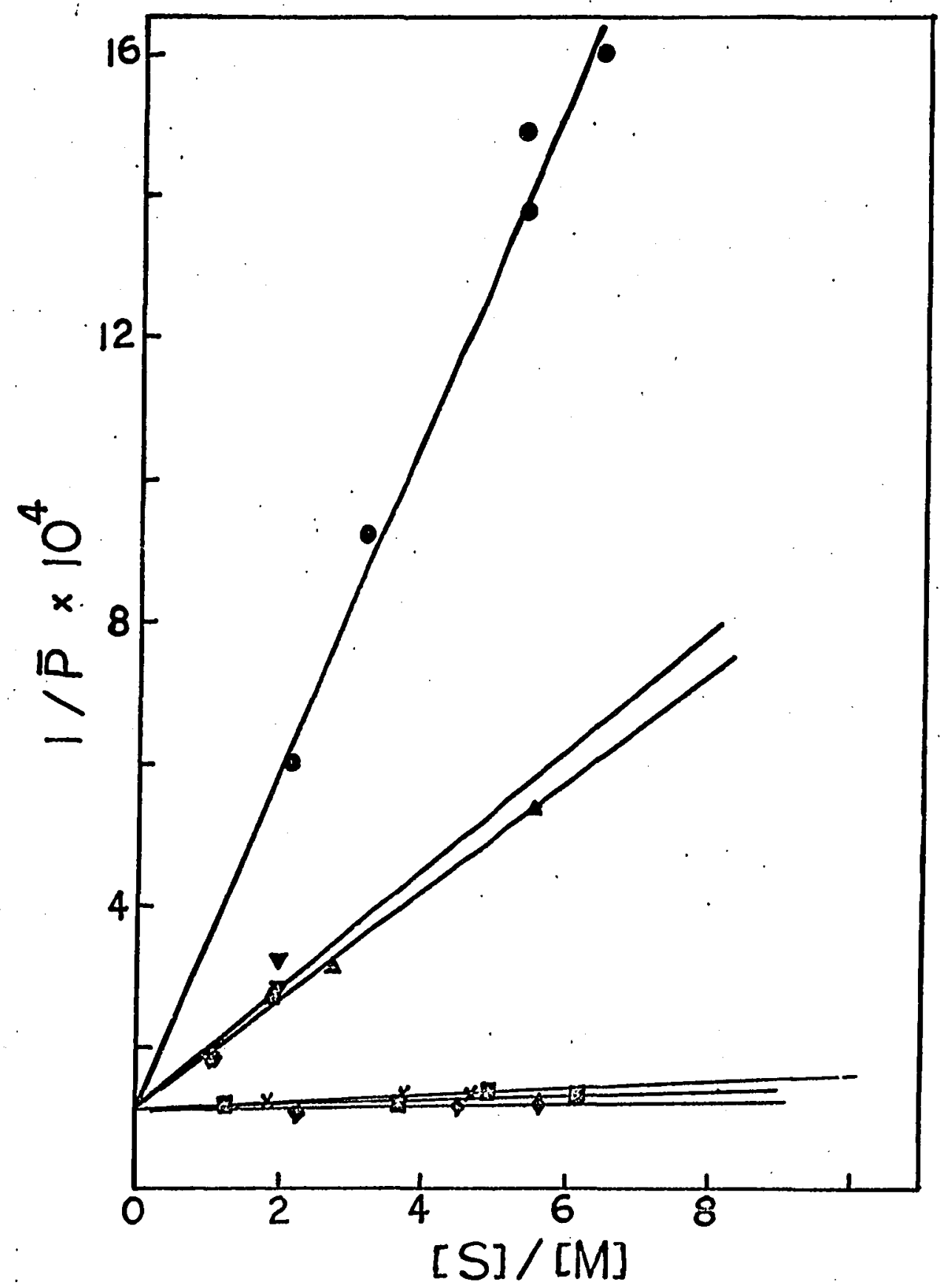

Figure 15. Transfer to $\operatorname{MIPK}(\theta), \operatorname{MIBK}(\Delta)$, Fluorobenzene (a), Benzonitrile $(\nabla)$, Hexafluorobenzene $(\nabla)$, and Benzotrifluoride $(X)$ by Styrene at $60^{\circ}$. 


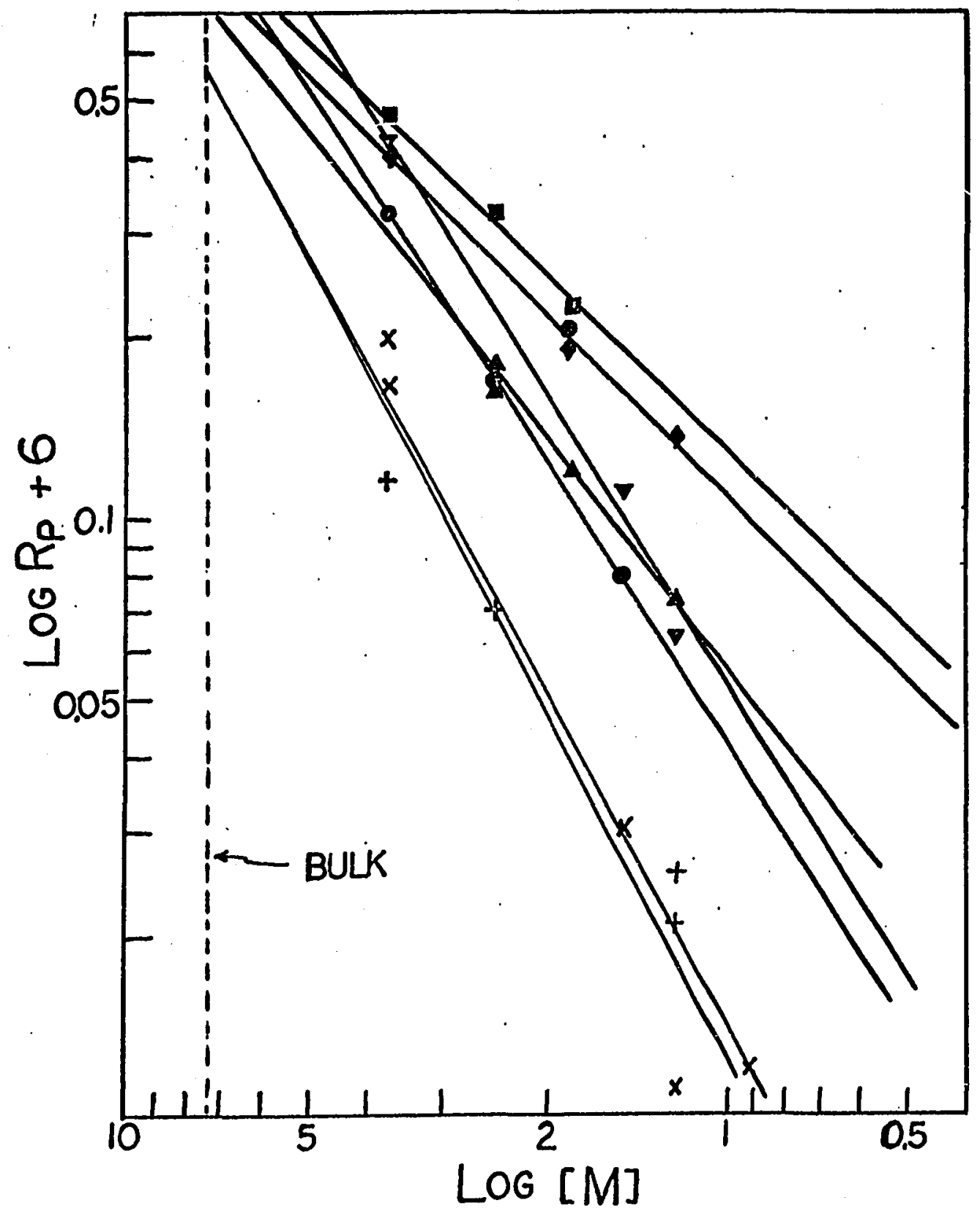

Figure 16. Graph of $\log R_{P}$ vs. $\log [M]$ for Thermal Polymerization of PFS in Solvents at $60^{\circ}$. Solvents are coded as follows:

- Fluorobenzene; $\Lambda, T H F ; \boldsymbol{~ M I B K ; ~} \bullet$, MIPK;

$\boldsymbol{\nabla}$, Benzonitrile; $\mathrm{X}$, Hexafluorobenzene; and + , Benzotrifluoride. 


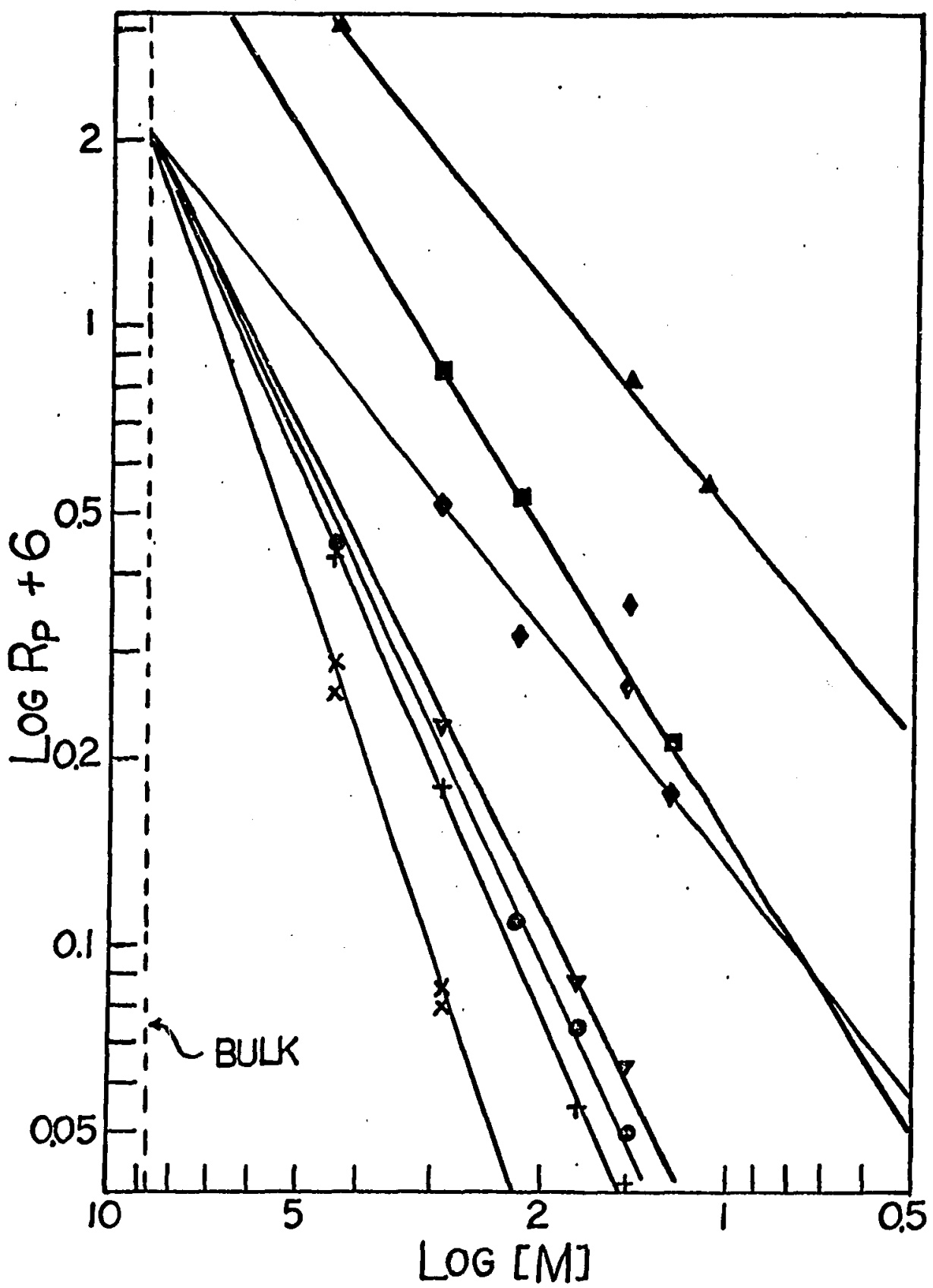

Figure 17. Graph of $\log R_{p}$ vs. $\log [M]$ for Thermal Polymerization of Styrene in Solvents at $60^{\circ}$. Solvents are coded as follows: 0 , Fluorobenzene; $\Delta$, THF; $\boldsymbol{\theta}, \mathrm{MIBK} ; 0, \mathrm{MIPK}$; $\boldsymbol{\nabla}$, Benzonitrile; $\mathrm{X}$, Hexafluorobenzene; and + , Benzotrifluoride. 
The Measurement of the Rate of Initiation for PFS. Two methods were employed in the measurement of the rates of finitiation for PFS:' the molecular weight method, and the inhibitor method. The molecular weight method, ${ }^{46}$ as already described in the section concerning the AIBN-initiated polymerization of PFS, gave reasonable values of the initiator efficiency, f, for PFS-solvent mixtures (see Table 6). The Inhibitor method ${ }^{46}$ involves the measurement of the rate of consumption of an Inhibitor which is added to the monomer to prevent polymerization. The rate of removal of inhibitor is proportional to the rate of initiation. However, to determine the proportionality constant, it is necessary to make an assumption regarding the number of free radicals which react with one molecule of inhibitor. If, and only if, each inhibitor molecule stops one free radical chain, the rate of removal of inhibitor is equal to the rate of initiation. When DPPH is used as a radical scavenger ${ }^{46}$ the usual assumption is that one free radical reacts with each DPPH radical, so that the rate of inftiation, $R_{1}$, is equal to the rate of disappearance of DPPH, $\mathrm{R}_{\mathrm{DPPH}}{ }^{\cdot}$ Since DPPH is a colored substance it Is possible to follow its rates of removal by the rate of disappearance of the color from the solution. 68 PFS was therefore polymerized photochemically at $80^{\circ} \mathrm{C}$ in the presence of $\mathrm{DPPH}$, and the disappearance of color followed spectrophotometrically at $520 \mathrm{~m} \mu$. Blank runs on DPPH-solvent mixtures were also performed, and sma11 corrections were made to the PFS systems. A typical plot of the disappearance of DPPH in PFS-solvent systems is shown in Figure 18 . Note that the 
plots of $\log \left(A_{t}-A_{\infty}\right)$ vs. time give straight lines for all cases (where $A_{t}$ and $A_{\infty}$ are the absorbance at time $t$ and at infinite point, respectiveiy) whereas the corresponding plots of $\left(A_{t}-A_{\infty}\right)$ vs. time always show the deviations from linearity. This observation would suggest that $R_{D P P H}$ is essentially first order with respect to $D P P H$. In contrast, Tobolsky ${ }^{69}$ found $R_{D P P H}$ to be nearly zero order with respect to DPPH in styrene. The data in Table 14 yield the values of monomer order $1.1,1.5$ and 2.2 (average 1.6) determined in benzonitrile, benzotrifluoride and fluorobenzene, respectively. This compares with the conclusion made by Tobolsky ${ }^{69}$ from two experiments with styrene in benzene solution that $R_{D P P H}$ is second order with respect: to styrene. A first-order dependence of $R_{D P P H}$ on the concentrations of DPPH could be explained in terms of the simple direct attack of DPPH radical on PFS monomer molecule. A dependence of the rate of DPPH removal on the 1.1 to 2.2 order of monomer could be explained in terms of the reaction of DPPH radical. yith PFS monomer, or with the complex of two PFS molecules or a combination of the two reactions. In the AIBN-initiated polymerization of PFS, DPPH failed to give any induction period at all as shown in Figure 19. Apparently, DPPH is not an "ideal" inhibitor 66,70 for the polymerization of PFS. However, a preliminary experiment using benzoquinone as inhibitor in the place of DPPH did show an induction period (see Figure 19a). From the length of this induction period, the value of $R_{1}$ was calculated to be $5.0 \times 10^{-8} \mathrm{M} \mathrm{sec}^{-1}$ at $[A I B N]=3.05 \times 10^{-3}$. From the molecular weight method, $R_{1}$ was 
estimated to be $3.5 \times 10^{-8} \mathrm{M} \mathrm{sec}-1$ at the same AIBN concentration. Bengough $^{46}$ studied the rate of initiation for MMA using three different methods. He observed that the value obtained using the Inhibitor method is approximately double those obtained by the molecular weight method and radioactive tracer method. Therefore, the results obtained here should be regarded as satisfactory.

The Determination of Radical Lifetime (The Rotating Sector

Method). Radical 1ifetimes were determined by the rotating sector method. As the kinetic chain lifetime is inversely proportional to the rate (Equation 22) it is often possible to adjust conditions so that one obtains a suitable value for the lifetime at a reasonable rate of polymerization. Table 15 shows the data obtained under the optimum conditions. The ratio of the rates measured at different sector speeds, $\mathrm{R}_{\mathrm{p}}$, to those obtained at steady light $\mathrm{R}_{\mathrm{P}_{\mathrm{g}}}$ were calculated, and they are listed in column 5 of Table 15. The flash times, $\lambda$, were measured for each sector speed. A sector with $r=2$ (1.e., the ratio of dark to light area is 2 to 1 ) was used for all runs. The experimental curves were obtained by plotting $R_{P} / R_{P_{S}}$ vs. $\log \lambda$ (see the line with circles in Figure 20). Since the dark rates are not negligible, Equations 26-28 were used to construct the theoretical curves. The computed values of $R_{P} / R_{P_{s}}$ as a function of $m$ and $z$ (see Introduction section) are collected in Table 17, and the theoretical curves were obtained by plotting the computed $R_{P} / R_{P s}$ vs. log. $m$. The values of radical lifetime, $T$, were calculated from the difference between the theoretical and experimental curves, and 
Table 14

DPPH Disappearance in PFS-Solvent Mixtures at $80^{\circ}$

(Measured at $520 \mathrm{m \mu})^{2}$

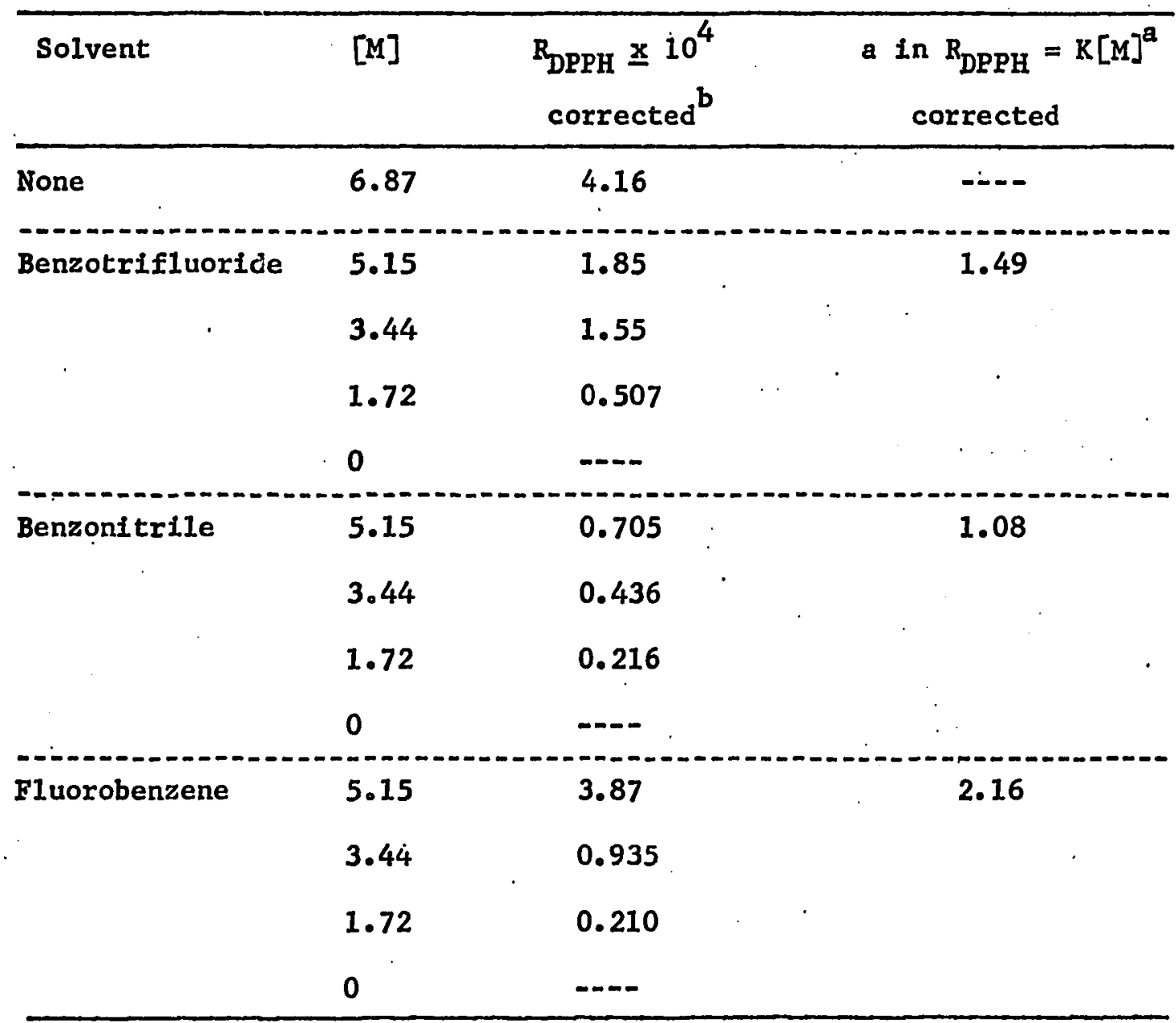

${ }^{a}$ In the presence of $[\mathrm{DPPH}]=9.79 \times 10^{-5} \mathrm{M}$

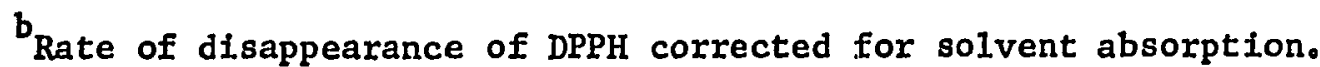
Rates are calculated from the slopes of the plots of $\log \left(A_{t}-A_{\infty}\right)$ vs. time where $A_{t}$ and $A_{\infty}$ are the absorbance at time $t$ and,at infinite point, respectively. 


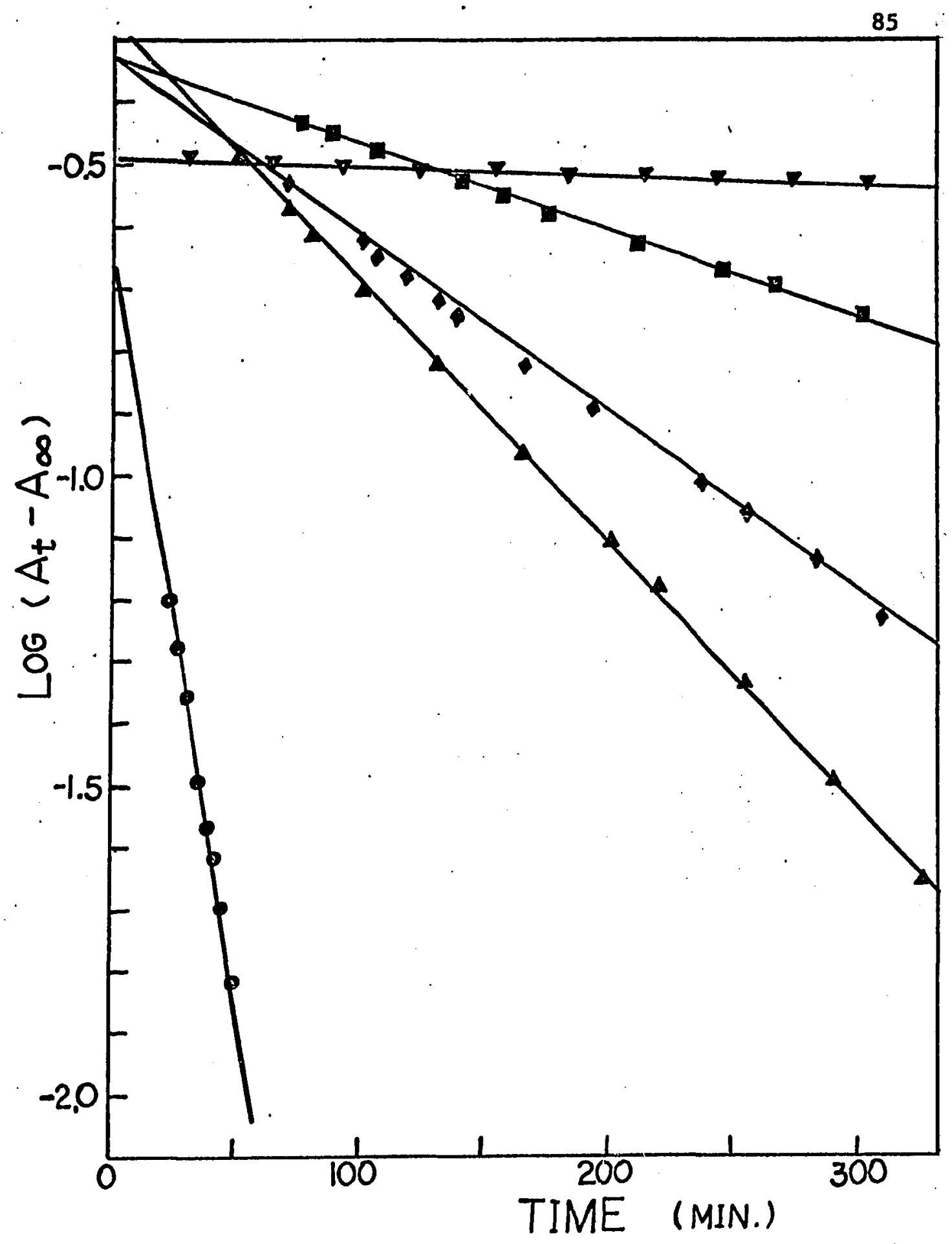

Figure 18. DPPH Disappearance in PFS-PhCN Mixtures at $80^{\circ}$.

- : $100 \%$ PFS; $\triangle: 75 \%$ PFS; : $50 \%$ PFS; : $25 \%$ PFS;

$\nabla:$ PhCN Blank. 


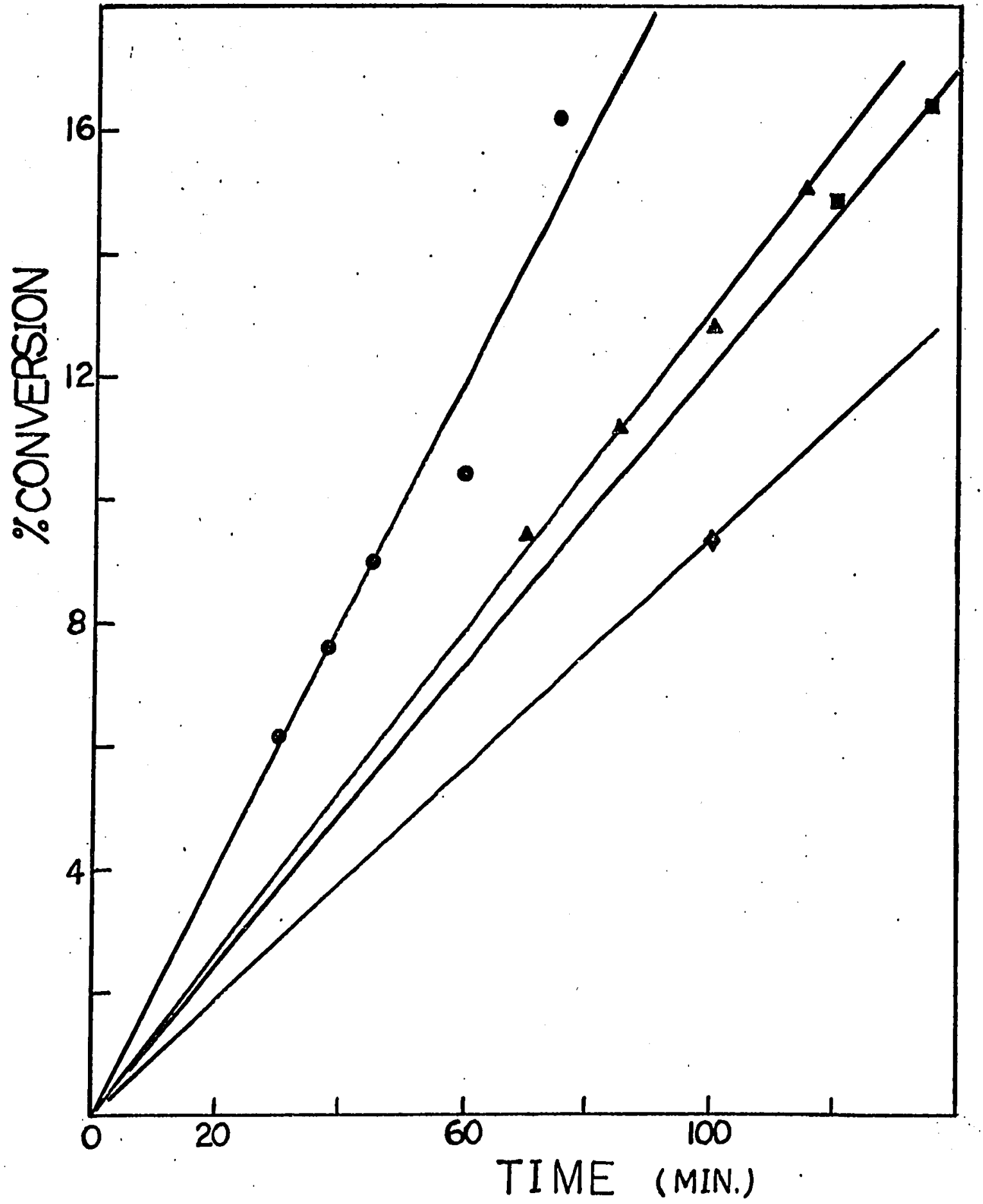

Figure 19. Graph of \% Conversion vs. Time for the Polymerization of PFS in the Presence of [AIBN] $=1.77 \times 10^{-2} \mathrm{M}$. Concentration of DPPH $0: 2.24 \times 10^{-5} \mathrm{M}$, $\Delta: 8.98 \times 10^{-5} \mathrm{M}, \quad \mathrm{m}: 18.0 \times 10^{-5} \mathrm{M}, \quad: 0$. 


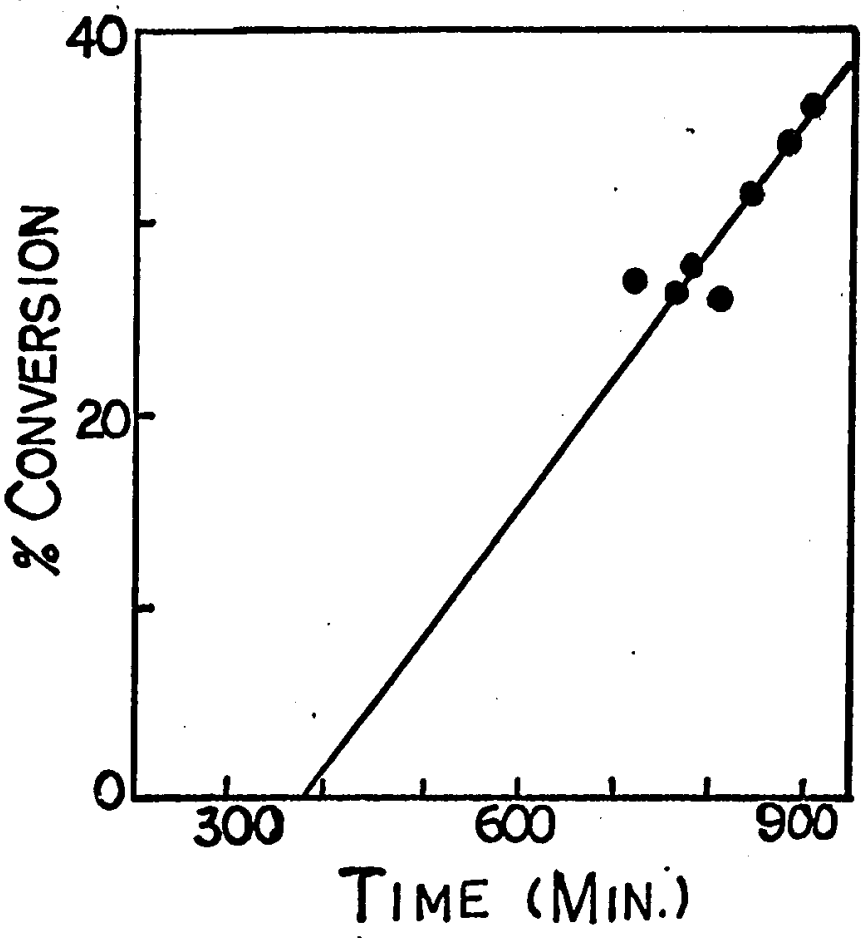

Figure 19a. Graph of \% Conversion vs. Time for the Polymerization of PFS in the Presence of $[\mathrm{AIBN}]=3.05 \times 10^{-3} \mathrm{M}$ and [Benzoquinone] $=1.14 \times 10^{-3} \mathrm{M}$. 
the average values are given in the column 6 of Table ${ }_{i}$. The values of $k_{p} /\left(2 k_{t}\right)$, calculated from Equation 22 using the known values of $T$, may be combined with the previousiy determined $\delta^{2}$ values obtained from AIBN experiments. The $k_{p}$ and $2 k_{t}$ values calculated by this way are listed in Table 16. To serve as a comparison, the corresponding data for the photopolymerization of styrene at $30^{\circ}$ were also collected. A comparison of the absolute rate constants for some substituted styrenes is given in Table 18. For styrene, $k_{p}=107 \mathrm{M}^{-1} \sec ^{-1}$ and $2 k_{t}=1.09 \underline{x} 10^{8} \mathrm{M}^{-1} \mathrm{sec}^{-1}$ are obtained. These values are in excellent agreement with the values reported by Imoto et al. $:^{48} \mathrm{k}_{\mathrm{p}}=106 \mathrm{M}^{-1} \mathrm{sec}^{-1}$ and $2 k_{t}=1.08 \times 10^{8} \mathrm{M}^{-1} \mathrm{sec}^{-1}$. For PFS, $k_{p}=195 \mathrm{M}^{-1} \mathrm{sec}^{-1}$ and $2 k_{t}=1.39 x 10^{8} \mathrm{M}^{-1} \mathrm{sec}^{-1}$. Thus $k_{p}$ for PFS is about twice that of styrene whereas $2 k_{t}$ is about the same for both monomers. In other words, PFS propagates with greater ease than styrene. Since the propagation reaction involves two reactants, $M \cdot$ and $M$ (see Introduction section), it is not possible from values of $k_{p}$ alone to decide whether the reactivity of polymer radical $M \cdot$ or that of the monomer $M$ has the greater influence upon $k_{p}$. To distinguish between radical and monomer reactivities it is necessary to consider the rates of transfer reactions and copolymerizations. $55 \mathrm{~b}, 73$ since $c_{s}=k_{t r, s} / k_{p}$ by definition, the values of $k_{t r, s}$ may be calculated from $C_{S}$ and $k_{p}$. If the difference of reaction temperature $\left(60^{\circ}\right.$ for transfer reaction and $30^{\circ}$ for photopolymerization) is ignored, 74 and assessment of radical reactivity can be deciuced from the rate of transfer to the same substrate by using the data in Table 11 . These values of $k_{t r, s}$ 
for some hydrocarbons are 1isted in Table 19, and show that the reactivity in this reaction appears to run parallel to the propagation rate constant, but further information on the separate reactivities of monomer and free radical can be more easily deduced from the copolymerization stidies (see p.100). 
Table 15

Determination of Average Lifetime of PFS Radical at $30^{\circ}$

\begin{tabular}{|c|c|c|c|c|c|c|c|}
\hline Solvent & & {$[\mathrm{M}]$} & $\log \lambda^{b}$ & $\begin{array}{l}R_{P} \times 10^{6 b} \\
\left(M \sec ^{-1}\right)\end{array}$ & $\mathbf{R}_{\mathbf{P}} / \mathbf{R}_{\mathbf{P}_{\mathbf{S}}} \mathbf{b}$ & $\begin{array}{c}\text { verage } \\
\text { (sec) }\end{array}$ & ${ }_{p} / 2 k_{t} \times 10^{6^{c}}$ \\
\hline \multirow{9}{*}{\multicolumn{2}{|c|}{ None }} & 7.28 & $-\cdots$ & 5.50 & 1.000 & 1.83 & 1.39 \\
\hline & & & -0.169 & 3.18 & 0.578 & & \\
\hline & & & 0.137 & 3.11 & 0.565 & & \\
\hline & & & 0.535 & 2.85 & 0.519 & & \\
\hline & & & 0.838 & 2.56 & 0.465 & & \\
\hline & & & 1.140 & 2.35 & 0.428 & & \\
\hline & & & 1.538 & 2.19 & 0.398 & & \\
\hline & & & 1.838 & 2.03 & 0.369 & . & \\
\hline & & & 2.140 & 1.98 & 0.360 & & \\
\hline \multirow[t]{8}{*}{ Benzonitrile } & & 3.64 & --- & 4.67 & 1.000 & 1.48 & 1.90 \\
\hline & & & 0.137 & 2.60 & 0.556 & & \\
\hline & & & 0.535 & 2.34 & 0.501 & $\cdot$ & \\
\hline & & & 0.838 & 2.13 & 0.457 & & . \\
\hline & & & 1.140 & 1.94 & 0.416 & & \\
\hline & & & 1.538 & 1.79 & 0.383 & & \\
\hline & . & & 1.838 & 1.70 & 0.365 & & \\
\hline & & & 2.140 & 1.64 & 0.352 & & \\
\hline \multirow[t]{7}{*}{ Benzotrifluorid } & & 3.64 & $-\ldots$ & 2.69 & 1.000 & 1.77 & 1.31 \\
\hline & & & 0.137 & 1.48 & 0.549 & & \\
\hline & & & 0.535 & 1.33 & 0.493 & & \\
\hline & & & 0.838 & 1.25 & 0.466 & & \\
\hline & . & & 1.140 & 1.16 & 0.430 & & \\
\hline & & & 1.538 & 1.03 & 0.383 & & \\
\hline & & & 1.838 & 0.917 & 0.341 & & \\
\hline
\end{tabular}


Table 15 (Continued)

\begin{tabular}{|c|c|c|c|c|c|c|c|}
\hline Solvent & [M] & $\log \lambda^{b}$ & $\begin{array}{l}R_{P} \times 10^{6} \\
\left(M \sec ^{-1}\right)\end{array}$ & $\mathrm{R}_{\mathrm{P}} / \mathrm{R}_{\mathrm{P}_{\mathrm{S}}} \mathrm{b}$ & $\begin{array}{l}\text { Average } \\
\text { (sec) }\end{array}$ & $T$ & $k_{p} / 2 k_{t} \times 10^{6}$ \\
\hline \multirow[t]{4}{*}{ Fluorobenzene } & 3.64 & $-\infty$. & 2.71 & $1.000^{\circ}$ & 1.79 & & 1.33 \\
\hline & & 0.137 & 1.50 & 0.552 & & & \\
\hline & & 0.535 & 1.37 & 0.507 & & . & \\
\hline & & 0.838 & 1.26 & 0.464 & & & \\
\hline \multirow[t]{4}{*}{. } & & 1.140 & 1.17 & 0.430 & & & \\
\hline & . & 1.538 & 1.08 & .0 .398 & & & \\
\hline & & 1.838 & 1.02 & 0.377 & & . & \\
\hline & & 2.140 & 0.965 & 0.356 & & & . \\
\hline
\end{tabular}

${ }^{a}$ In the presence of $3.00 \times 10^{-3} \mathrm{M}$ ACHN as photosensitizer. All solvents are $50 \%$ by volume.

${ }^{b_{R}}$ is the measured rate of photopolymerization under intermittent light $(\underline{x}=2)$. $R_{P_{S}}$ is the rate observed under steady light. $\lambda$ is flash time in seconds.

${ }^{c}$ Calculated from the Equation $k / 2 k_{t}=R_{P} x T /[M]$, where $T$ is the average lifetime of propagating radicals. 
Table 16

The Photopolymerization of PFS at $30^{\circ}$. [ACHN] $=3.00 \times 10^{-3} \mathrm{M}$

\begin{tabular}{|c|c|c|c|c|c|c|c|c|}
\hline Solvent & $R_{p} \times 10^{6^{a}}$ & $\begin{array}{c}T^{\prime} \\
\text { sec }\end{array}$ & $\frac{k_{p}}{2 k_{t}} \times 10^{6}$ & $\delta^{2}$ & $k_{p}^{b}$ & $2 k_{t} \times 10^{-}$ & $R_{1} \times 10^{8^{d}}$ & $10^{4} / \overline{\mathrm{P}}$ \\
\hline None & 5.50 & 1.83 & 1.39 & 3710 & 195 & 1.39 & 0.212 & 2.11 . \\
\hline PhCN & 4.67 & 1.48 & 1.90 & 1530 & 346 & 1.83 & 0.249 & 2.47 \\
\hline $\mathrm{PhCF}_{3}$ & 2.69 & 1.77 & 1.31 & 4160 & 184 & 1.41 & 0.227 & 3.49 \\
\hline $\mathrm{PhF}$ & 2.71 & 1.79 & 1.33 & 4000 & 187 & 1.40 & 0.222 & 3.62 \\
\hline
\end{tabular}

a See footnote b under Table 15. All solvents are $50 \%$ by volume.

$b_{k_{p}}=R_{P} /[M] R_{i} T$ in $M^{-1} \sec ^{-1}$.

$c_{2 k_{t}}=\left(R_{1} x T^{2}\right)^{-1}$ in $M^{-1} \sec ^{-1}$.

$d_{R_{1}}=\delta^{2} \times R_{P}^{2} /[M]^{2}$.

ealculated from Equation 48 . 
Table. 17

Theoretical Values of $R_{P} / R_{P_{B}}$ as a Function of $m$ and $z$ for $r=2$

\begin{tabular}{|c|c|c|c|c|c|}
\hline $\mathbf{m}$ & $z=0$ & $z=0.01$ & $z=0.02$ & $z=0.03$ & $z=0.04$ \\
\hline 0.1 & 0.577 & 0.577 & 0.577 & 0.578 & 0.578 \\
\hline $0: 2$ & 0.576 & 0.576 & 0.576 & 0.577 & 0.577 \\
\hline 0.3 & 0.574 & 0.575 & 0.575 & 0.575 & 0.575 \\
\hline 0.4 & 0.572 & 0.573 & 0.573 & 0.573 & 0.573 \\
\hline 0.5 & 0.569 & 0.570 & 0.570 & 0.570 & 0.571 \\
\hline 0.6 & 0.566 & 0.567 & 0.567 & 0.567 & 0.568 \\
\hline 0.7 & 0.562 & 0.564 & 0.564 & 0.564 & 0.565 \\
\hline 0.8 & 0.558 & 0.560 & 0.560 & 0.561 & 0.561 \\
\hline 0.9 & 0.555 & 0.556 & 0.557 & 0.557 & 0.557 \\
\hline 1.0 & 0.552 & 0.553 & 0.553 & 0.553 & 0.553 \\
\hline 1.5 & 0.533 & 0.533 & 0.533 & 0.534 & 0.534 \\
\hline 2.0 & 0.515 & 0.515 & 0.515 & 0.516 & 0.516 \\
\hline 2.5 & 0.500 & 0.500 & 0.500 & 0.501 & 0.501 \\
\hline 3.0 & 0.487 & 0.487 & 0.487 & 0.488 & 0.489 \\
\hline 3.5 & 0.477 & 0.477 & 0.477 & 0.478 & 0.478 \\
\hline 4.0 & 0.467 & 0.468 & 0.468 & 0.469 & 0.470 \\
\hline 4.5 & 0.460 & 0.460 & 0.460 & 0.461 & 0.462 \\
\hline 5.0 & 0.453 & 0.453 & 0.453 & 0.454 & 0.455 \\
\hline 5.5 & $0.44 \%$ & 0.447 & 0.447 & 0.448 & 0.449 \\
\hline 6.0 & 0.442 & 0.442 & 0.442 & 0.443 & 0.444 \\
\hline 6.5 & 0.437 & 0.437 & 0.437 & 0.438 & 0.440 \\
\hline 7.0 & 0.432 & 0.433 & 0.433 & 0.434 & 0.435 \\
\hline 7.5 & 0.429 & 0.429 & 0.429 & 0.430 & 0.432 \\
\hline 8.0 & 0.425 & 0.425 & 0.426 & 0.427 & 0.428 \\
\hline 8.5 & 0.422 & 0.422 & 0.423 & 0.424 & 0.425 \\
\hline 9.0 & 0.419 & 0.419 & 0.420 & 0.421 & 0.422 \\
\hline 9.5 & 0.416 & 0.416 & 0.417 & 0.418 & 0.420 \\
\hline 10 & 0.413 & 0.414 & 0.414 & 0.416 & 0.417 \\
\hline 20 & 0.384 & 0.385 & 0.386 & 0.388 & 0.391 \\
\hline
\end{tabular}


Table 17 (Continued)

\begin{tabular}{llllll}
\hline $\mathrm{m}$ & $\mathrm{z}=0$ & $\mathrm{z}=0.01$ & $\mathrm{z}=0.02$ & $z=0.03$ & $z=0.04$ \\
\hline 30 & 0.372 & 0.372 & 0.374 & 0.377 & 0.381 \\
40 & 0.364 & 0.365 & 0.368 & 0.371 & 0.376 \\
50 & 0.360 & 0.361 & 0.364 & 0.368 & 0.373 \\
60 & 0.356 & 0.357 & 0.361 & 0.365 & 0.371 \\
70 & 0.354 & 0.355 & 0.359 & 0.364 & 0.369 \\
80 & 0.352 & 0.353 & 0.357 & 0.362 & 0.368 \\
90 & 0.350 & 0.352 & 0.356 & 0.361 & 0.367 \\
100 & 0.349 & 0.3507 & 0.3552 & 0.3606 & 0.3664 \\
200 & 0.342 & 0.3454 & 0.3509 & 0.3570 & 0.3632 \\
300 & 0.340 & 0.3436 & 0.3495 & 0.3558 & 0.3621 \\
400 & 0.388 & 0.3427 & 0.3488 & 0.3551 & 0.3616 \\
500 & 0.3375 & 0.3422 & 0.3484 & 0.3548 & 0.3613 \\
\hline
\end{tabular}


Table 18

A Comparison of Absolute Rate Constants for Substituted Styrenes

\begin{tabular}{|c|c|c|c|}
\hline Monomer & $k_{p}$ & $2 k_{t} \geq 10^{-8}$ & Reference \\
\hline PFS & 195 & 1.39 & This study \\
\hline \multirow[t]{4}{*}{ Styrene } & 107 & 1.09 & This study \\
\hline & 106 & 1.08 & $\begin{array}{l}\text { Imoto et al., } \\
\text { ref. } 48\end{array}$ \\
\hline & 26 & 0.052 & Melville, ref. 71 \\
\hline & 55 & 0.505 & Matheson, ref.25 \\
\hline 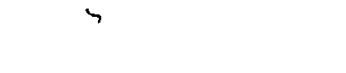 & 73 & 0.67 & Norrish, ref.72 \\
\hline p-Fluorostyrene & 112 & 1.27 & ${ }_{\text {ref. } 48}^{\text {Imoto et ale, }}$ \\
\hline p-Chlorostyrene & 150 & 0.77 & $\begin{array}{l}\text { Imoto et al., } \\
\text { ref. } 48\end{array}$ \\
\hline p-Bromostyrene & 186 & 0.46 & $\begin{array}{l}\text { Imoto et a1., } \\
\text { ref. } 48\end{array}$ \\
\hline p-Cyanostyrene & 219 & 0.35 & $\begin{array}{l}\text { Imoto et al., } \\
\text { ref. } 48\end{array}$ \\
\hline p-Methylstyrene & 84 & 0,66 & $\operatorname{Imoto}_{\text {ref. } 48}^{\text {et al. }}$ \\
\hline p-Methoxystyrene & 71 & 0.33 & $\begin{array}{l}\text { Imoto et al., } \\
\text { ref. } 48\end{array}$ \\
\hline
\end{tabular}

${ }^{a}$ All values are in $\mathrm{M}^{-1} \mathrm{sec}^{-1}$ at $30^{\circ} \mathrm{C}$. 
Table 19

A. Comparison of Radical Reactivities for PFS and Styrene ${ }^{a, e}$

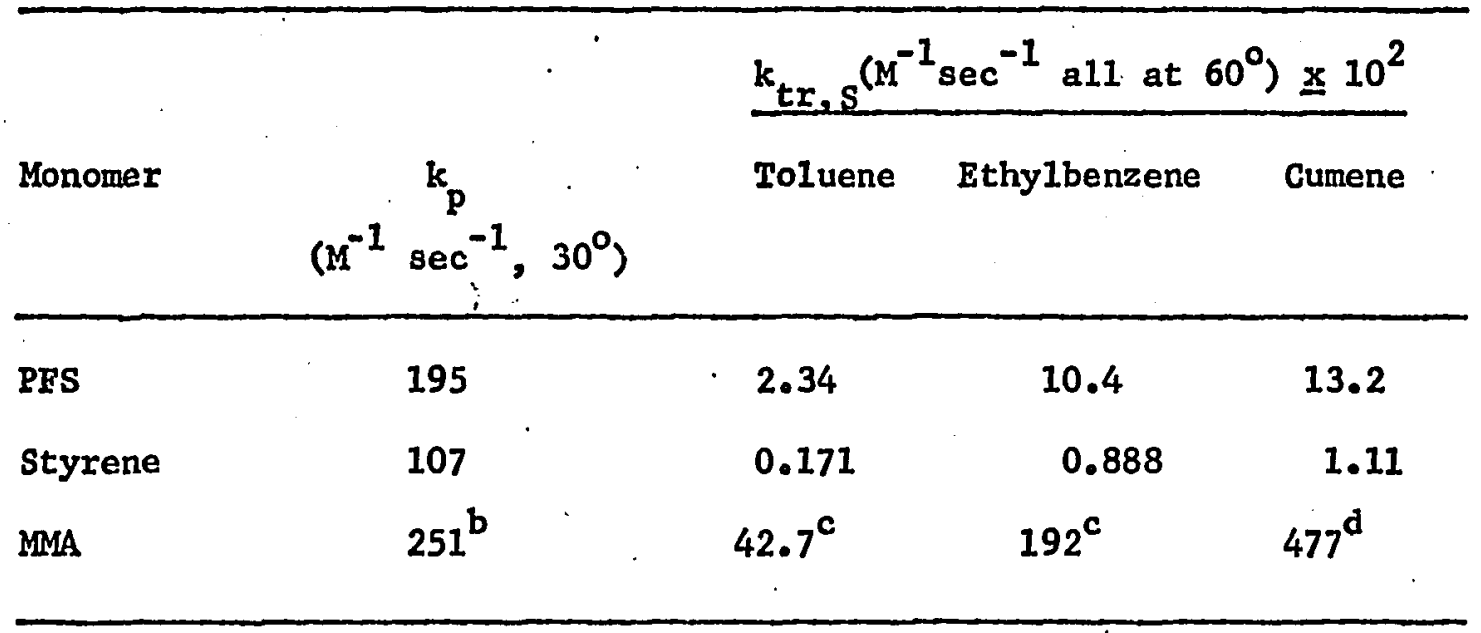

${ }^{a}$ Calculated using the data in Table 11 and the equation $k_{t y}, s=C_{S} x_{p}$.
Note that $k_{p}$ and $k_{t r, s}$ are given at different temperatures bata of Schulz et al., ref.77.

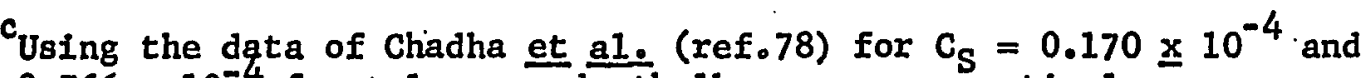
$0.766 \times 10^{-4}$ for toluene and ethylbenzene, respectively.

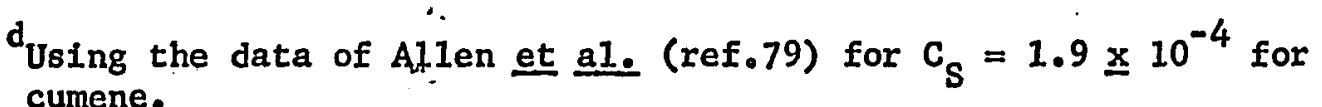

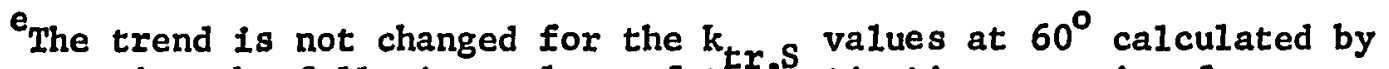
assuming the following values of the activation energies for propagation: PFS, 7-8 kcal/mole (ref.48); styrene, $7 \mathrm{kcal} / \mathrm{mole}$ (ref.48); MMA, $5 \mathrm{kcal} / \mathrm{mole}$ (ref.7). 


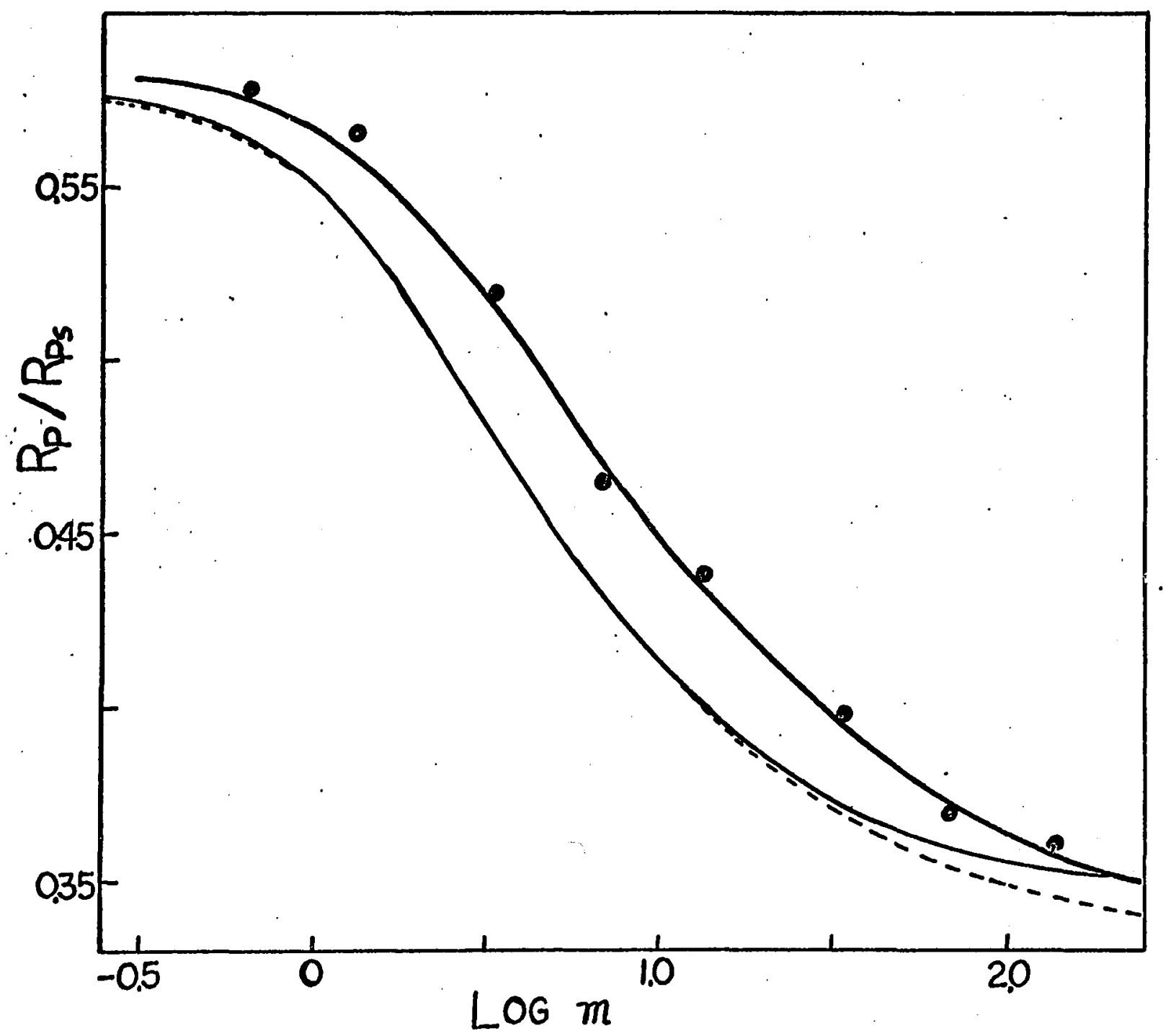

Figure 20. Determination of the Average Li.fetime of Poly-PFs Radicals -: Calculated for $z=$ dark rate/steady light rate $=0.02$ and $T=1.00 \mathrm{sec}$; - with 0 : Calculated for $z=0.02$ and $\tau=1.83$ sec.; -..: Calculated for $z=0.00$ and $T=1.00 \mathrm{sec}$. 
COPOL YMERIZATION

EXPERIMENTAL SECTION

\section{Copolymerization of PFS and Styrene. Copolymer was}

1solated by the freeze-dry procedure developed by Liewis and Mayo for styrene ${ }^{19}$ since the copolymer is soluble in benzene. Copolymer composition was evaluated using \% carbon from elemental analysis in the following way: The fraction styrene in the copolymer, $f_{1}$, is related to the fraction carbon in the polymer; $x$; the molecular weight of PFS, 194.1, and that of styrene, 104.1, and the fraction of carbon In PFS and styrene, 0.4950 and 0.9226 , respectively, by the formula:

$$
f_{1}=(194.1 x-96.079) /(90.0 x-0.036) \cong 2.157-1.067 / x
$$

Copolymerization of PFS and Methyl Methacrylate. The same procedures were followed in isolating the copolymer. Copolymer composition, however, was determined using ultraviolet spectroscopy. (\% carbon analysis would introduce great error due to the closeness of the theoretical values of $\%$ in PFS and MMA: $49.5 \%$ vs. $60 \%$ ). In THF as solvent, the specific absorbance for PFS (in units of absorbance per mole per liter) is $\epsilon=1.92$ at $\lambda_{\max }=259 \mathrm{~m}_{\mu}$ and is independent of molecular weight. Beer's law is obeyed. At this wavelength, MMA has $\epsilon=0,095$. The equation used is $\epsilon=1.92 x+(1-x)(0.095)$ where $x$ is the weight fraction of PFS in the copolymer. 


\section{RESULTS AND DISCUSSION}

\section{Copolymerization of PFS and Styrene Initiated by AIBN.}

Styrene $\left(M_{1}\right)$ and PFS $\left(M_{2}\right)$ were allowed to copolymerize at $60^{\circ}$ using AIBN as initiator. Copolymer composition was evaluated using \% carbon from elemental analysis. The method of Fineman-Ross ${ }^{15}$ was used to evaluate $r_{1}$ and $r_{2}$ (see Equation 37). Table 20 gives the data; the values of $r_{1}=0.42 \pm 0.01$ and $r_{2}=0.22 \pm 0.06$ are obtained from the Fineman-Ross graph (least square fit of data). These data are compared with values for pentachlorostyrene $40-1,53$ and $p^{-f 1 u o r o s t y r e n e^{53}}$ in Table 22. Values of $1 / r_{1}$, which give the rate constant for addition of a styryl radical to these monomers relative to the rate constant for addition to styrene, show that the monomers increase in activity in the order pentachlorostyrene < styrene < p-fluorostyrene < PFS. Using the Equation 41 and 42 and the values of $Q_{1}=1.00$ and $e_{1}=-0.80$ for styrene gives $Q_{2}=0.69$ and $e_{2}=0.74$ for PFS. A typical graph for the relationship between copolymer and feed (monomer mixture) compositions is shown In Figure 20a.

The copolymerization was also studied at $60^{\circ}$ using AIBN inftlation to determine the value of the cross-termination ratio $b$ (see Introduction). Equation 45 was used for calculation. Table 20 gives the data. A value of $\phi=7.2$ is found, Indicating a substantial tendency toward cross-termination. 7,47 
Copolymerization of PFS and Methyl Methacrylate Initiated

by AIBN. The same procedures were followed in evaluating copolymerization parameters for MMA $\left(M_{1}\right)$ and PFS $\left(M_{2}\right)$. The composition of the copolymer was determined using ultraviolet spectroscopy. Table 21 gives the data. The Fineman-Ross treatment yields $r_{1}=0.99 \pm 0.03$ and $r_{2}=0.91 \pm 0.06$. These data are compared with values of pentachlorostyrene ${ }^{40-1,53}$ and styrene in Table 22 . Values of $1 / x_{1}$, which give the rate constant for addition of a poly-MMA radical to these monomers relative to the rate constant for addition to MMA, show that the monomer increase in activity in the order pentachlorostyrene $\angle$ MMA $\approx$ PFS < styrene. By using $Q_{1}=0.74$ and $e_{1}=0.40,40$ the values of $Q_{2}=0.87$ and $e_{2}=0.75$ are obtained for PFS. These values are in fairly satisfactory agreement with 0.69 and 0.74 , respectively, obtained from the styrene-PFS copolymerization. Table 21 also gives rate data, and the value of $\phi=5.3$ is obtained.

Table 23 summarizes the copolymerization behavior of PFS. The average value of e of 0.75 for PFS appears quite reasonable compared with -0.8 for styrene, -0.12 for $p$-fluorostyrene; and 0.52 for pentachlorostyrene. 53 The average value of $Q$ of 0.78 for $P F S$ can be compared with 1.00 for styrene, 0.83 for $\mathrm{p}$-fluorostyrene, and 0.22 for pentahclorostyrene. 53 Alfrey and Ebelke ${ }^{41}$ have suggested that the reduced $Q$ value of pentachlorostyrene results from a steric Inhibition of resonance due to the o-chloro substituents. A similar explanation could be evoked for PFS (Atomic radif in Angströms are $\mathrm{H}, 0.28 ; \mathrm{F}, 0.64 ; \mathrm{Cl}, 0.99) .76$ 
It is usually expected that a large tendency toward alternation of monomers in a copolymer will be reflected in a large value of 6 . The data of Table 23 do not agree with this expectation; the styrene copolymer; which is appreciably alternating, has a rather small o value. Table 24 summarizes similar data for the iiterature. Walling ${ }^{43}$ found that the 6 for the styrene-diethyl fumarate system was surprisingly low despite the pronounced alternating tendency of the copolymer. Apparently, the radical recombination reaction is far less sensitive to polar factor than is the more activated addition to a double bond.

Combination of $r_{2}$ from the copolymerization studies with $k_{p}$ from the photopolymerization experiments enables us to discuss the relative reactivities $\left(k_{21}\right)$ of poly-PFS and polystyryl radicals as shown in Table 23. The difference of reaction temperature $\left(60^{\circ}\right.$ for copolymerization and $30^{\circ}$. for homopolymerization) is not considered. The order of radical reactivities is the same as that observed in transfer reactions (see Table 19), 1..e., styrene < PFS < MMA. Quite obviously it follows from the $Q$ values and the individual rate constants shown in Tables 23 and 19 that the monomer PFS is less reactive than styrene (since the $Q$ value for $P F S$ is smaller than that of styrene, see Table 23), but that the radical is more reactive (for example, the values of $k_{t r, s}$ for PFS in toluene-ethylbenzene-cumene series are always larger than those of styrene, see Table 19), in accord with the general picture in vinyl polymerization (see Introduction). 


\section{Thermal Copolymerization of PFS and Styrene. Copoly-} merization of PFS and styrene was carried out in the absence of initlator. The same procedures were followed in evaluating copolymerization parameters. Table 25 gives the data. As expected, the Fineman-Ross treatment yields $i_{1}=0.39 \pm 0.02$ and $r_{2}=0.17 \pm 0.12$ - In agreement with those obtained from the AIBN-initiated copolymerization of PFS and styrene. Since $\phi$ is known to be 7.2 for PFSstyrene copolymerization, the measurement of over-all rates of thermal copolymerization of the same system should permit the detection of any cross-initiation process ${ }^{7,44}$ by using Equation 45 . The results are shown in Table 25. Walling ${ }^{44}$ predicted that much larger values of the specific rate of cross-initiation might be expected for more strongly alternating pairs of monomers. The data of Table 25 do not agree with this expectation; the system PFSstyrene, which is appreciably alternating $\left(r_{1} r_{2}=0.093\right)$, the rates observed not only fail to indicate cross-initiation, but are actually lower than those which would be expected from the known rate of thermal polymerization of styrene alone (the thermal rate of polymerization of PFS is slower than that of styrene). There are a few reports available in the literature on cross initiation systems. Walling 44 studied the thermal copolymerization of styrene and MMA, and found preferential cross initiation, (presumably due to polar effects in the transition state) although the system is only. moderately alternating $\left(r_{1} r_{2}=0.26^{53}\right)$. Gilbert et al. ${ }^{80}$ observed a rapid cross initiation for the vinylidene cyanide-styrene and the 
vinylidene-2,5-dichlorostyrene systems. Both of these systems are very strongly alternating $\left(r_{1} r_{2}=5.0 \times 10^{-6}\right.$ for vinylidene cyanide- . styrene; $2.8 \times 10^{-4}$ for vinylidene cyanide-2,5-dichlorostyrene). On the other hand, however, no cross initiation was detected in the case of styrene-diethyl fumarate, ${ }^{43}$ although the system is strongly alternating also $\left(r_{1} x_{2}=0.021\right)$. Apparently, the generality of such cross initiations is unknown, and the precise interpretation is difficult since the meaning of the value of $\phi$ in the usual copolymer rate equation is obscure. ${ }^{12 b}$

Thermal Copolymerization of PFS and Methyl Methacrylate. Copolymerization of PFS and MMA was carried out in the absence of any initiator. Table 27 gives the data. As expected, the FinemanRoss treatment yields $r_{1}=0.93 \pm 0.11$ and $r_{2}=0.91 \pm 0.25\left(M_{2}\right.$ is PFS), in agrecment with those obtained from the AIBN-initiated copolymerization of PFS and MMA. The same procedures were followed in evaluating the specific rate of cross initiation. Table 27 also gives the data. Again, the rates observed indicate no cross Intiation.

Copolymerization of PFS and Styrene in Solvents. PFS and styrene were allowed to copolymerize in a number of solvents. Table 26 gives the results. The Fineman-Ross treatment yields $r_{1}=0.39 \pm 0.01$, $r_{2}=0.30 \pm 0.06,\left(M_{2}\right.$ is $\left.\mathrm{PFS}\right)$ for the AIBN-initiated copolymerization of PFS and styrene in benzonitrile; $r_{1}=0.40 \pm 0.02, r_{2}=0.56 \pm 0.07$, for the corresponding thermal copolymerization of PFS and styrene in benzonitrile. This restit compares with $r_{1}=0.42 \pm 0.01, r_{2}=0.22 \pm 0.06$, for the AIBN-initiated and $r_{1}=0.39 \pm 0.02, r_{2}=0.17 \pm 0.12$ for the 
thermal copolymerization of PFS and styrene in the absence of solvent. Since the rate constant for chain initiation or chain termination does not appear in the copolymerization equation, the equation predicts no dependence of copolymer composition and hence monomer reactivity ratios on the over-all rate of polymerization process, nor upon the particular initiator starting the radical chain. This independence has been confirmed for styrene-MMA radical copolymerization Intiated therma11y, 81 photochemically, 82 by benzoyl peroxide, ${ }^{16,81-3}$ by p-chlorobenzoyl peroxide, ${ }^{83}$ by t-butyl peroxide, ${ }^{83}$ by AIBN, ${ }^{84}$ by trifsopropylboron, 85 (a free-radical-type catalyst), by $\beta$-ray irradiation, ${ }^{86}$ and by $\gamma$-ray irradiation. ${ }^{87}$. With styrene-MMA no change in monomer reactivity ratios has been detected upon the addition of water, ethylbenzene, dodecyl mercaptan, or hydroquinone, or the presence or absence of $a i r,{ }^{81}$ nor by changing the reaction medium from mixtures of pure monomers to monomer solutions in a number of solvents such as ethyl acetate, benzene, or acetonitrile, or even methanol. $81,82,88,89$ However, Bradbury and Melville ${ }^{90}$ studied the copolymerization of styrene and butyl acrylate in benzene solution (using ${ }^{14} \mathrm{C}$-labelled AIBN as inftiator), and observed an appreciable increase of $r_{1}$ and $r_{2}$ in the most dilute solution. Drougas and Guile ${ }^{93}$ also reported a substantial deviation from constant values of $r_{1}$ and $r_{2}$ in the copolymerization of itaconic anhydride and styrene using benzene and THF as solvents. In recent years, it has been found by several groups of workers ${ }^{91-2}$ that the monomer reactivity ratios of polar vinyl monomers such as acrylonitrile may 
be altered by complexing with Lewis acids such as aluminum chloride 92 and zinc chloride. 91 On the other hand, Overberger et al. ${ }^{94}$ observed no difference in monomer reactivity ratios for the copolymer system styrene-p-chlorostyrene in solvent mixtures of carbon tetrachloride and nitrobenzene using aluminum bromide, ferric chloride, titanium tetrachloride, stannic chloride and titanium tetrachloridetrichloroacetic acid as catalysts in homogeneous solution. Thus, although the monomer reactivity ratios show general insensitivity to the environment in which polymerization occurs, there are cases where their solvent dependence are not negligible. It is not surprising, therefore, for the present system PFS-styrene to show some positive deviation from constancy of $r_{1}$ and $r_{2}$. For example, in benzonitrile solution there is an appreciable increase of $r_{2}$ which involves an average increase of PFS content of corresponding polymers of about $8 \%$ (compare Tables 25 and 26). It is not known whether this represents a real increase of $r_{2}$ or is due to a large amount of transfer to benzonitrile and PFS with consequent incorporation of phenyl groups into the polymer. The latter possibility could be ruled out since the transfer constants to benzonitrile and PFS are approximately zero. Apparently, a systematic study on the monomer reactivity ratios over a wide range of benzonitrile (and on the other solvents as well) concentration would be necessary to completely clarify this observation. 
Table 20

Copolymerization of PFS $\left(M_{2}\right)$ and Styrene $\left(M_{1}\right)$ at $60^{\circ}$

$\left[\mathrm{M}_{1}\right] \quad\left[\mathrm{M}_{2}\right] \quad$ Rate $x 10^{5^{\mathrm{b}}} \quad$ Polymer Composition $\quad \mathrm{F} \mathrm{c}_{2}^{\mathrm{c}} \quad \mathrm{F} \quad \phi^{\mathrm{d}}$

$\begin{array}{llll}8.70 & 0 & 7.03 & 0\end{array}$

$\begin{array}{lllllll}7.25 & 1.22 & 9.18 & 23.0 & 3.35 & 5.94 & 10\end{array}$

$\begin{array}{lllllll}6.53 & 1.83 & 9.54 & 28.9 & 2.46 & 3.56 & 9.0\end{array}$

$\begin{array}{llllllll}5.81 & 2.44 & 10.0 & & 32.6 & 2.07 & 2.38 & 7.9\end{array}$

$\begin{array}{lllllll}4.36 & 3.66 & 11.2 & 44.7 & 1.24 & 1.19 & 5.6\end{array}$

$\begin{array}{lllllll}2.18 & 5.50 & 10.4 & 57.5 & 0.739 & 0.396 & 5.3\end{array}$

$\begin{array}{lllllll}1.45 & 6.11 & 10.4 & 65.8 & 0.520 & 0.238 & 4.6\end{array}$

$\begin{array}{llll}0 & 7.33 & 7.66 & 100\end{array}$

${ }^{a}$ In the presence of $8.85 \times 10^{-3} \mathrm{M}$ AIBN.

${ }^{b}$ In $M \sec ^{-1}$.

From \% carbon in copolymer. Analysis by nmr in carbon tetrachloride was less precise but gave data consistent with these.

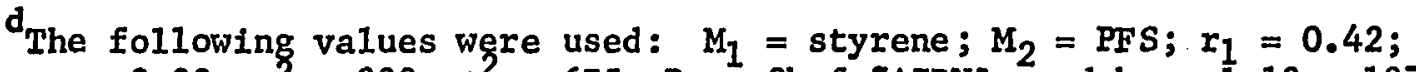
$r_{2}=0.22 ; \delta \frac{1}{1}=900 ; \delta_{2}^{2}=675 ; R_{1}=2 k_{d} f$ [AIBN], and $k_{d}=1.13 x 10^{-5}$ $\mathrm{sec}^{-1}$. The value of $f^{2}$ in pure $\mathrm{PFS}$ was determined as 0.52 (see Table 6) and in a 50/50 mirsture of styrene and PFS to be 0.55 ; $f$ in pure styrene is 0.60 (ref.37). In all the calculations in Table 20, $f$ was taken as 0.57 . Variation of $f$ between 0.52 and 0.60 does not appreciably affect the value of $\phi$. 
Table 21

Copolymerization of PFS $\left(M_{2}\right)$ and Methyl Methacrylate $\left(M_{1}\right)$ at $60^{\circ}$

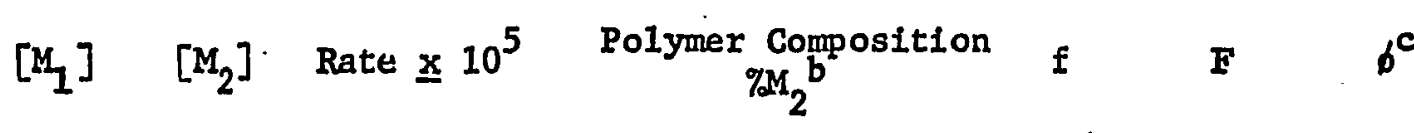

\begin{tabular}{lllccccc}
\hline 9.35 & 0 & 29.5 & 0 & & & \\
7.79 & 1.22 & 17.4 & 14.9 & & & 6.0 \\
7.01 & 1.83 & 16.4 & 20.6 & 3.85 & 3.83 & 4.5 \\
6.23 & 2.44 & 13.1 & 27.4 & 2.65 & 2.55 & 5.7 \\
4.68 & 3.66 & 11.9 & 44.8 & 1.23 & 1.28 & 4.6 \\
2.34 & 5.50 & 9.92 & 67.8 & 0.475 & 0.425 & 4.5 \\
1.56 & 6.11 & 8.77 & 79.1 & 0.264 & 0.255 & 6.5 \\
0 & 7.33 & 7.66 & 100 & & & \\
\hline
\end{tabular}

${ }^{a}$ In the presence of $8.85 \times 10^{-3} \mathrm{M}$ AIBN.

b From UV spectroscopy.

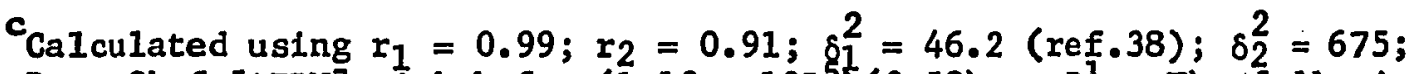
$R_{f}=2 k_{d f}$ [AIBN] with $k_{d f}=\left(1.13 \times 10^{-5}\right)(0.50) \mathrm{sec}^{-1}$. The following values of $f$ have been measured: 0.52 in pure PFS; 0.50 in a 50:50 mixture of PFS and MMA; 0.46 in pure MMA (ref.39). The variation of $f$ between 0.52 and 0.46 affects the value of $\phi$ by less than $8 \%$. 
Table 22

Copolymerization Parameters for Several Monomers With Styrene and MMA

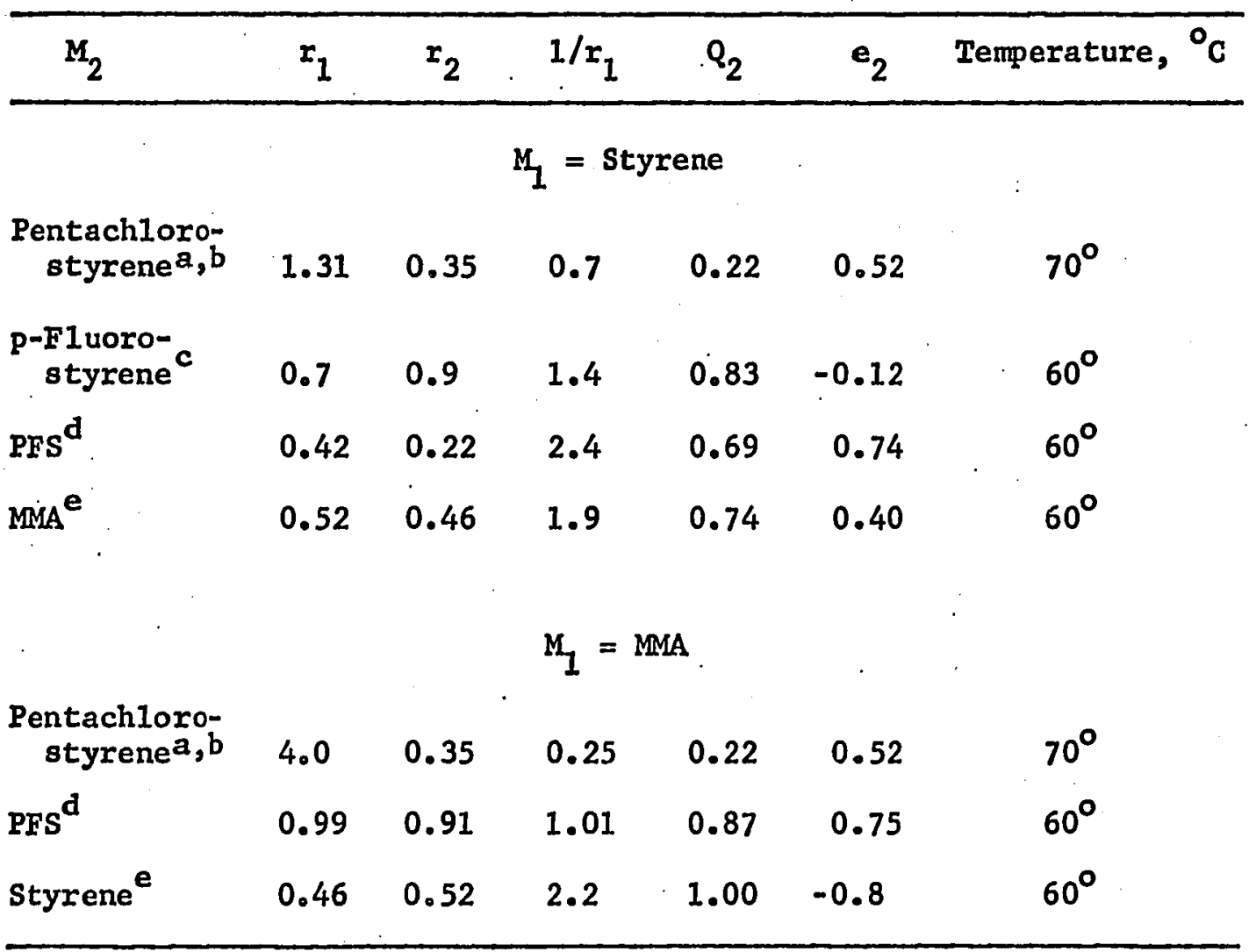

asee Young, ref.40.

${ }^{b}$ See Alfrey and Ebelke, ref.41.

'see ref.53' and 75 .

This study.

esee Lewis et al., ref.16. 
Table 23

A Summary of the Copolymerization Parameters for PFS (M 2

\begin{tabular}{lccccccccc}
\hline$M_{1}$ & $r_{1}$ & $r_{2}$ & $Q_{1}$ & $Q_{2}$ & $e_{1}$ & $e_{2}$ & $k_{12}^{a, c}$ & $k_{21}^{b}, c$ & $\phi$ \\
\hline Styrene & 0.42 & 0.22 & 1.00 & 0.69 & -0.80 & 0.74 & $255(726)$ & $886(2527)$ & 7.2 \\
MMA & 0.99 & 0.91 & 0.74 & 0.87 & 0.40 & 0.75 & $254(536)$ & $214(611)$ & 5.3 \\
\hline
\end{tabular}

$a_{k_{12}}=k_{11} / x_{1}$, where $k_{11}=107 \mathrm{M}^{-1} \sec ^{-1}$ for styrene; $251 \mathrm{M}^{-1} \sec ^{-1}$ for MMA

$b_{k_{21}}=k_{22} / r_{2}$, where $k_{22}=195 \mathrm{M}^{-1}$ sec $^{-1}$ for PFS.

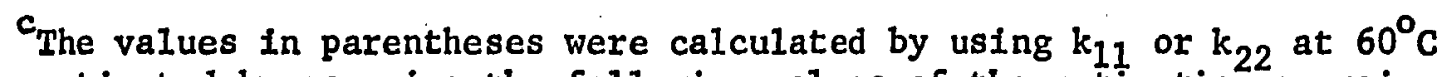
estimated by assuming the following values of the activation energies for propagation: styrene and PFS, $7 \mathrm{kcal} / \mathrm{mole}$ (ref.48); MMA, $5 \mathrm{kcal} / \mathrm{mole}$ (ref.7d). 
Table 24

Values of the Cross-Termination Constant 6

\begin{tabular}{|c|c|c|c|}
\hline System & 6 & & $r_{1} r_{2}$ \\
\hline PFS-styrene ${ }^{\mathbf{a} .}$ & 7.2 & & 0.093 \\
\hline PFS-MMA ${ }^{a}$ & 5.3 & & 0.90 \\
\hline p-Methoxystyrene-styrene ${ }^{b}$ & 1.0 & & 0.95 \\
\hline p-Methoxystyrene-MMA & 24 & & 0.09 \\
\hline Styrene-MMA & 14 & $\cdot$ & 0.26 \\
\hline Styrene-diethyl fumarate ${ }^{c}$ & 8 & & 0,028 \\
\hline Styrene-butyl acrylate & 150 & · & 0.07 \\
\hline
\end{tabular}

aresent value.

${ }^{b}$ see ref.42.

see ref.43. 
Table 25

Thermal Copolymerization of PFS $\left(M_{2}\right)$ and Styrene $\left(M_{1}\right)$ at $60^{0^{a}}$

\begin{tabular}{|c|c|c|c|c|c|c|c|c|c|}
\hline$\left[M_{1}\right]$ & {$\left[\mathrm{M}_{2}\right]$} & Rate $x 10^{5}$ & $\begin{array}{c}\text { Polymer } \\
\text { Composition } \\
\mathrm{FM}_{2}\end{array}$ & $f$ & $\mathbf{F}$ & $\begin{array}{l}R_{1,12, t h} \\
\times 10^{1 I^{b}}\end{array}$ & $\begin{array}{r}R_{1,1, \text { th }} \\
\times 10^{11 C}\end{array}$ & $\begin{array}{l}R_{1,2, t h} \\
\times 10^{11 d}\end{array}$ & $\frac{R_{1,12, \text { th }}}{R_{i, 1, t h}}$ \\
\hline 8.70 & 0 & 0.206 & 0 & $-\infty$ & $\cdots$ & $\cdots$ & 5.03 & --- & --- \\
\hline 7.25 & 1.22 & 0.239 & 24.0 & 3.17 & 5.94 & 6.30 & 7.26 & 14.7 & 0.868 \\
\hline 6.53 & 1.83 & 0.257 & 28.4 & 2.52 & 3.57 & 7.14 & 8.97 & 6.54 & 0.796 \\
\hline 5.81 & 2.44 & 0.269 & 35.5 & 1.82 & 2.38 & 7.78 & 11.3 & 3.68 & 0.688 \\
\hline 4.36 & 3.66 & 0.257 & 42.2 & 1.37 & 1.19 & 7.29 & 20.1 & 1.63 & 0.363 \\
\hline 4.36 & 3.66 & 0.251 & 45.2 & 1.21 & 1.19 & & & & \\
\hline 1.45 & 6.11 & 0.124 & 70.1 & 0.427 & 0.238 & 2.36 & 182 & 0.587 & 0.013 \\
\hline 0 & 7.33 & 0.0570 & 100 & $-\infty$ & $-\infty$ & $-\ldots$ & $-\infty-\infty$ & 0.408 & $\cdots$ \\
\hline
\end{tabular}

${ }^{a}$ See footnotes under Table 20. No initiator was added.

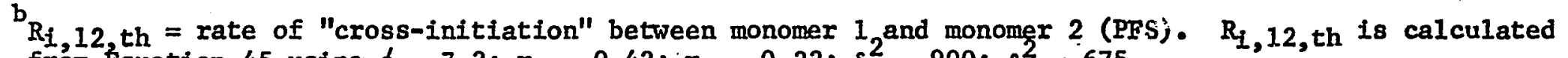
from Equation 45 using $\phi=7.2 ; r_{1}=0.42 ; r_{2}=0.22 ; \delta_{1}^{2}=900 ; \delta_{2}^{2}=675$.

$c_{R_{1}, 1, t h}$ is the rate of thermal initiation of monomer 1 calculating from the equation $R_{1,1, t h}=\delta_{1}^{2} R_{\mathrm{P}, 1, t h}^{2} /[\mathrm{M}]^{2}$ where $\delta_{1}^{2}=900$ and $R_{\mathrm{P}, 1, t h}=2.06 \underline{x} 10^{-6} \mathrm{M} \mathrm{sec}^{-1}$.

$d_{R_{1}, 2, t h}$ is the rate of thermal initiation of monomer 2 (PFS) calculating from the equation $\mathrm{R}_{i, 2, \mathrm{th}}^{1,2, t h}=\delta_{2} \mathrm{R}_{\mathrm{P}, 2, \mathrm{th}}^{2} /[\mathrm{M}]^{2}$ where $\delta_{2}^{2}=675$ and $\mathrm{R}_{\mathrm{P}, 2, \mathrm{th}}=5.70 \mathrm{x} 10^{-7} \mathrm{M} \mathrm{sec}-1$. 
Table 26

Thermal Copolymerization of PFS $\left(M_{2}\right)$ and Styrene $\left(M_{1}\right)$ in solvents, $60^{0^{\circ}}$

\begin{tabular}{|c|c|c|c|c|c|c|}
\hline Solvent & {$\left[\mathrm{M}_{1}\right]$} & {$\left[\mathrm{M}_{2}\right]$} & Rate $x 10^{6}$ & $\begin{array}{c}\text { Polymer } \\
\text { Composition } \\
\% M_{2}\end{array}$ & $f$ & $\mathbf{F}$ \\
\hline Benzonitrile & 4.35 & 0 & 0.520 & 0 & $-\infty-\infty$ & $-\infty-\infty$ \\
\hline Benzonitrile & 3.27 & 0.916 & 1.10 & 32.2 & 2.11 & 3.57 \\
\hline Benzonitrile & 2.90 & 1.22 & 1.25 & 38.8 & 1.58 & 2.38 \\
\hline Benzonitrile & 2.18 & 1.83 & 2.14 & 50.3 & 0.988 & 1.19 \\
\hline Benzonitrile & 2.18 & 1.83 & 2.09 & 51.6 & 0.938 & 1.19 \\
\hline Benzonitrile & 1.09 & 2.75 & 1.22 & 64.6 & 0.548 & 0.396 \\
\hline Benzonitrile & 0 & 3.67 & 0.427 & 100 & $--\infty$ & $--m-$ \\
\hline Benzonitrile & 3.63 & 0.611 & 44.2 & 24.3 & 3.12 & 5.94 \\
\hline Benzonitrile $e^{b}$ & 3.27 & 0.916 & 51.9 & 31.2 & 2.21 & $3.57^{\prime}$ \\
\hline Benzonitrile & 3.27 & 0.916 & 51.2 & 30.9 & 2.24 & 3.57 \\
\hline Benzonitrile & 2.90 & 1.22 & 66.7 & 37.1 & 1.70 & 2.38 \\
\hline Benzonitrile & 2.18 & 1.83 & 75.6 & $44 \cdot 7$ & 1.24 & 1.19 \\
\hline Benzonitrile & 1.09 & 2.75 & 71.2 & 64.1 & 0.560 & 0.396 \\
\hline Benzene & 2.18 & 1.83 & 0.423 & 47.0 & 1.13 & 1.19 \\
\hline Fluorobenzene & 2.18 & 1.83 & 0.649 & 43.9 & 1.28 & 1.19 \\
\hline Chlorobenzene & 2.18 & 1.83 & 0.634 & .47 .7 & 1.10 & 1.19 \\
\hline Bromobenzene & 2.13 & 1.83 & 0.613 & 46.2 & 1.16 & 1.19 \\
\hline Toluene & 2.18 & 1.83 & 0.633 & 43.4 & 1.30 & 1.19 \\
\hline Benzotrifluoride & 2.18 & 1.83 & 0.578 & 48.6 & 1.06 & 1.19 \\
\hline Anisole & 2.18 & 1.83 & 0.803 & 42.4 & $1.36^{\circ}$ & 1.19 \\
\hline Anisole & 2.18 & 1.83 & 0.805 & 42.0 & 1.38 & 1.19 \\
\hline Hexafluorobenzene & 2.18 & 1.83 & 0.315 & 50.1 & 0.996 & 1.19 \\
\hline MIBK. & 2.18 & 1.83 & 3.57 & 48.1 & 1.08 & 1.19 \\
\hline
\end{tabular}

${ }^{a}$ See footnotes under Table 20. No initiator was added.

${ }^{b}$ In the presence of $[A I B N]=8.85 \times 10^{-3} \mathrm{M}$, and $[\mathrm{PhCN}]=4.90 \mathrm{M}$ corresponding to $50 \%$ by volume. 
Table 27

Thermal Copol ymerization of PFS $\left(M_{2}\right)$ and MMA $\left(M_{1}\right)$ at $60^{\circ}$

\begin{tabular}{|c|c|c|c|c|c|c|c|c|c|}
\hline$\left[\mathrm{M}_{1}\right]$ & {$\left[\mathrm{M}_{2}\right]$} & Rate $x 10^{6}$ & $\begin{array}{c}\text { Polymer } \\
\text { Composition } \\
\mathrm{OM}_{2}\end{array}$ & $\mathbf{f}$ & $\mathbf{F}$ & $\begin{array}{l}R_{1,12, t h} \\
\underline{x} 10^{11 b}\end{array}$ & $\begin{array}{l}R_{1,1, t h} \\
\times 10^{12^{C}}\end{array}$ & $\begin{array}{l}R_{1,2, t h} \\
x 10^{11}\end{array}$ & $\frac{R_{1,12, t h}}{R_{1,2, t h}}$ \\
\hline 9.35 & 0 & 0.240 & 0 & --- & --- & $--\infty$ & 0.0304 & --- & $-\infty$ \\
\hline 7.01 & 1.83 & 1.90 & 21.0 & 3.76 & 3.83 & 1.54 & 0.0542 & 6.54 & 0.235 \\
\hline 6.23 & 2.44 & 1.01 & 27.8 & 2.60 & 2.55 & 0.564 & 0.0686 & 3.68 & 0.153 \\
\hline 4.68 & 3.66 & 0.885 & 49.0 & 1.04 & 1.28 & 0.624 & $0: 122$ & 1.63 & 0.383 \\
\hline 2.34 & 5.50 & 0.632 & 64.4 & 0.553 & 0.425 & 0.446 & 0.486 & 0.772 & 0.618 \\
\hline 1.56 & 6.11 & 0.569 & 78.6 & 0.272 & 0.255 & 0.388 & 1.09 & 0.587 & 0.661 \\
\hline 0 & 7.33 & 0.570 & 100 & --- & --- & $-\cdots$ & --- & 0.408 & --- \\
\hline
\end{tabular}

${ }^{a}$ See footnotes under Table 21. No initiator was added.

${ }^{b}$ Calculated from Equation 45 using $\phi=5.3 ; r_{1}=0.99 ; r_{2}=0.91 ; \delta_{1}^{2}=46.2 ; \delta_{2}^{2}=675$.

${ }^{c}$ Calculated from the equation $R_{1,1, t h}=\delta_{1}^{2} \mathrm{R}_{\mathrm{P}, 1, \mathrm{th}}^{2} /[\mathrm{M}]^{2}$ where $\delta_{1}^{2}=46.2$ and $\mathrm{R}_{\mathrm{P}, 1, \text { th }}=2.4 \mathrm{x} 10^{-7} \mathrm{M} \mathrm{sec}-1$
(Walling, ref.44). ${ }^{d}$ Calculated from the equation $R_{1,2, t h}=\delta_{2}^{2} R_{P, 2, t h}^{2} /[M]^{2}$ where $\delta_{2}^{2}=675$ and $R_{p, 2, t h}=5.70 \mathrm{x}: 10^{-7} \mathrm{M} \mathrm{sec}{ }^{-1}$. 


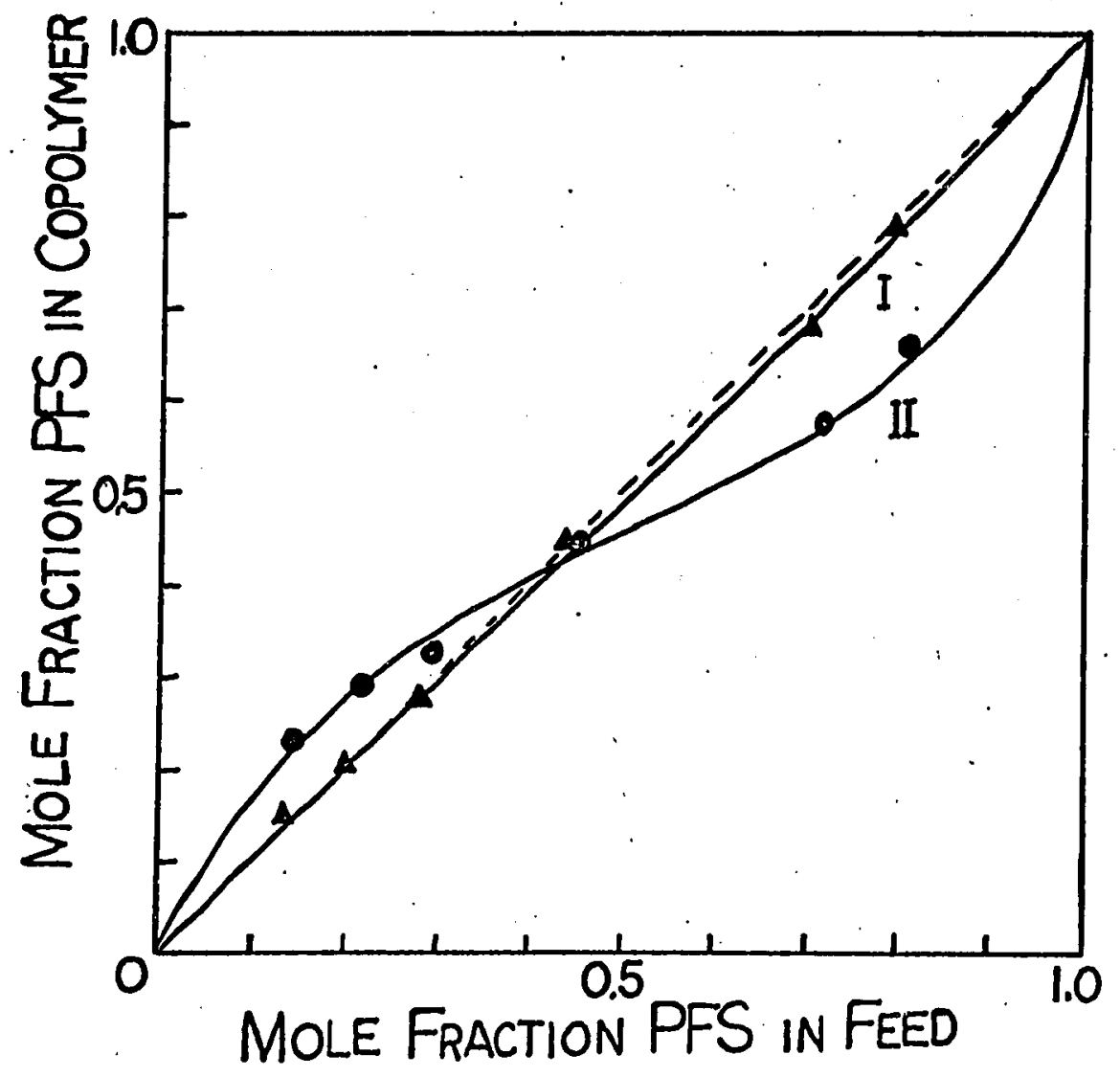

Figure 20a. Relationship between Copolymer and Feed Compositions.

Curve I: PFS-MMA system $\left(r_{1}=0.99, r_{2}=0.91\right), M_{1}=$ MMA.

Curve II: PFS-Styrene system $\left(r_{1}=0.42, r_{2}=0.22\right)$, $\mathrm{M}_{2}=\mathrm{PFS}$ 


\section{HETEROPOLYMERIZATION}

\section{EXPERTMENTAL SECTION}

Materials. The PFS and AIBN used were purified by the same procedures as those described in the Homopolymerization section. The methanol used in this study was of c.p. grade and was distilled under nitrogen immediately before use.

Kinetics. The polymerization rates were followed by an ampoule technique. Solvent, monomer, and catalyst were added in that order under a stream of nitrogen. The polymer, was isolated by the modified freeze-dry technique described in the previous section. The number average molecular weight of the poly-PFS samples was obtained from measurements of intrinsic viscosity in MIBK at $30^{\circ}$, using the Equation 48.

\section{RESULTS AND DISCUSSION}

Variation of $\mathrm{R}_{\mathrm{P}}$ and $\overline{\mathrm{P}}$ With [M]. The polymerization of PFS in methanol (a diluent that causes precipitation of the polymer) at $60^{\circ}$ is homogeneous when the Initial monomer concentration is equal to or higher than $2 \mathrm{M}$. However, even under these conditions, the polymerizing system separates in two phases (one dilute and one concentrated in polymer) when a certain conversion is reached. This conversion depends on the solvent-monomer ratio and on the molecular 
weight of the produced polymer. For monomer concentrations lower than $2 \mathrm{M}$, the system becomes heterogeneous from the onset of the reaction. Table 28 shows the data and Figure 21 is a plot of $\log R_{P}$ vs. $\log$ [M] (where $R_{P}$ is the observed rate of polymerization in $M \sec ^{-1}$, and [M] is the initial monomer concentration in $M$ ) in the presence of a constant concentration of AIBN of $1.85 \times 10^{-4} \mathrm{M}$. The figure shows that, as the initial monomer concentration is reduced by the addition of methanol, the rate at first declines, until $[M] \cong 2 M$ is reached. Then the rate increases as the monomer concentration diminishes to about 1M. The rate decreases again when $[M]$ is below $1 M$, where the reaction order with respect to monomer is approximately 2 (see the dotted Iine portion in Figure 21). During the initial decrease in rate the polymer remains in solution, but the point where the rise in rate occurs the polymer begins to separate as a gelatinous precipitate, and the enhancement of rate is no doubt due to the accompanying reduction in the $k_{t}$ value. This observation is supported by the concomitant increase in the degree of polymerization as shown in Figure 23. Thus, typical occlusion phenomena 95 are operative, a reduction in the rate of termination being the dominant feature. In support of this observation, individual runs in this region, $\underline{i} \cdot \underline{e} \cdot$, $[M]<2 M$, show a marked autocatalytic effect. As can be seen from Table 28, higher conversion runs always give faster rates under otherwise Identical conditions, and consequently the polymerization rate also must be compared at the same conversion. In the region $[\mathrm{M}]<2 \mathrm{M}$ the rates were determined between $3-5 \%$ conversion. However, a few points 
determined at conversion somewhat beyond this range do not appear to change the trend of the curve significantly. It should be noted that the polymerization of styrene in methanol has been shown by Abere et al. ${ }^{96}$ to behave like a typical occlusion system also. Chapiro's experiments 97,98 in initiation by gamma radiation and a more recent study by Odian et al. ${ }^{99}$ on the accelerating effect of methanol on the gamma radiation-induced graft copolymerization of styrene to polyethylene have confirmed this.

Variation of $R_{\mathrm{p}}$ With [I]: In order to obtain the variation of the polymerization rate with the initiator concentration under heterogeneous conditions, a series of polymerization experiments with constant Initial monomer concentrations $(1.83 \mathrm{M}$ and $0.611 \mathrm{M})$ and with varying Initiator concentrations was carried out. The data are also given in Table 28. Figure 22 shows a double logarithmic plot of the observed rate versus initlatior concentration. The reaction order with respect to initiator was found to be 0.8 at $[\mathrm{M}]=1.83 \mathrm{M}$ and 0.9 at $[M]=0.611 \mathrm{M}$. The points at $[M]=0.611 \mathrm{M}$ are somewhat scattered probably as a result of a stronger autocatalytic effect. The molecular weight of the polymers prepared at constant concentration of initiator (1.85 $\left.\times 10^{-4} \mathrm{M}\right)$ and corresponding to a conversion of about $6 \%$, increases sharply with the monomer concentration changing from about $2 \mathrm{M}$ to $1.5 \mathrm{M}$ (see Figure 23). The maximum of the molecular weight occurs at a monomer concentration close to that of the maximun rate value. According to Talamint et a1., 100-1 the change of the molecular weight and of the polymerization rate with the initial monomer concentration should follow 
the same trend in the absence of a very active chain transfer agent. An estimation of the chain transfer constant to methanol from the IInear portion of a Mayo plot yields a value of $3.55 \times 10^{-5}$, which Indicates that methanol is not a very active chain transfer agent compared to THF (a.very active agent) and supports Talamini's postulate. 


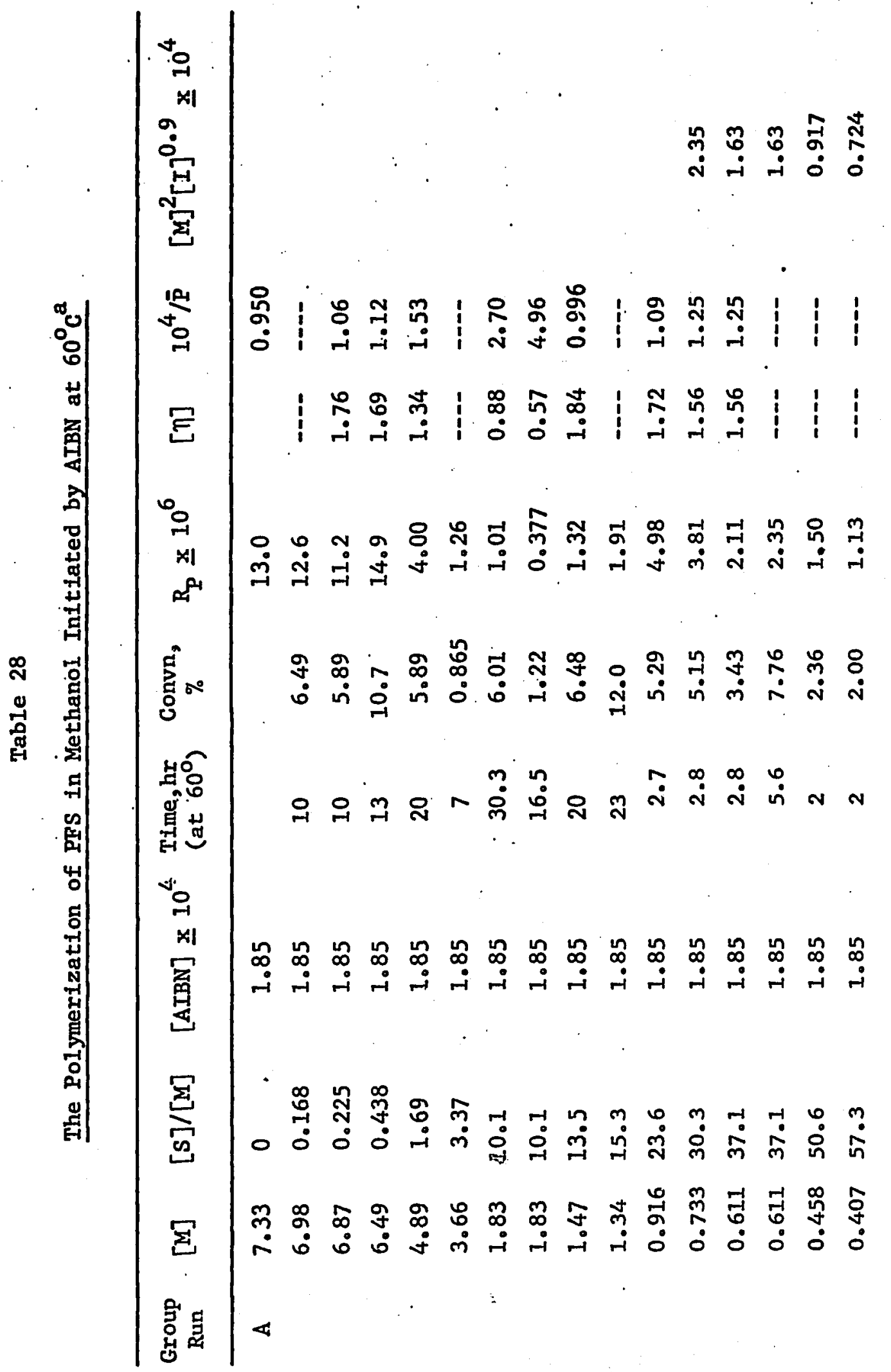




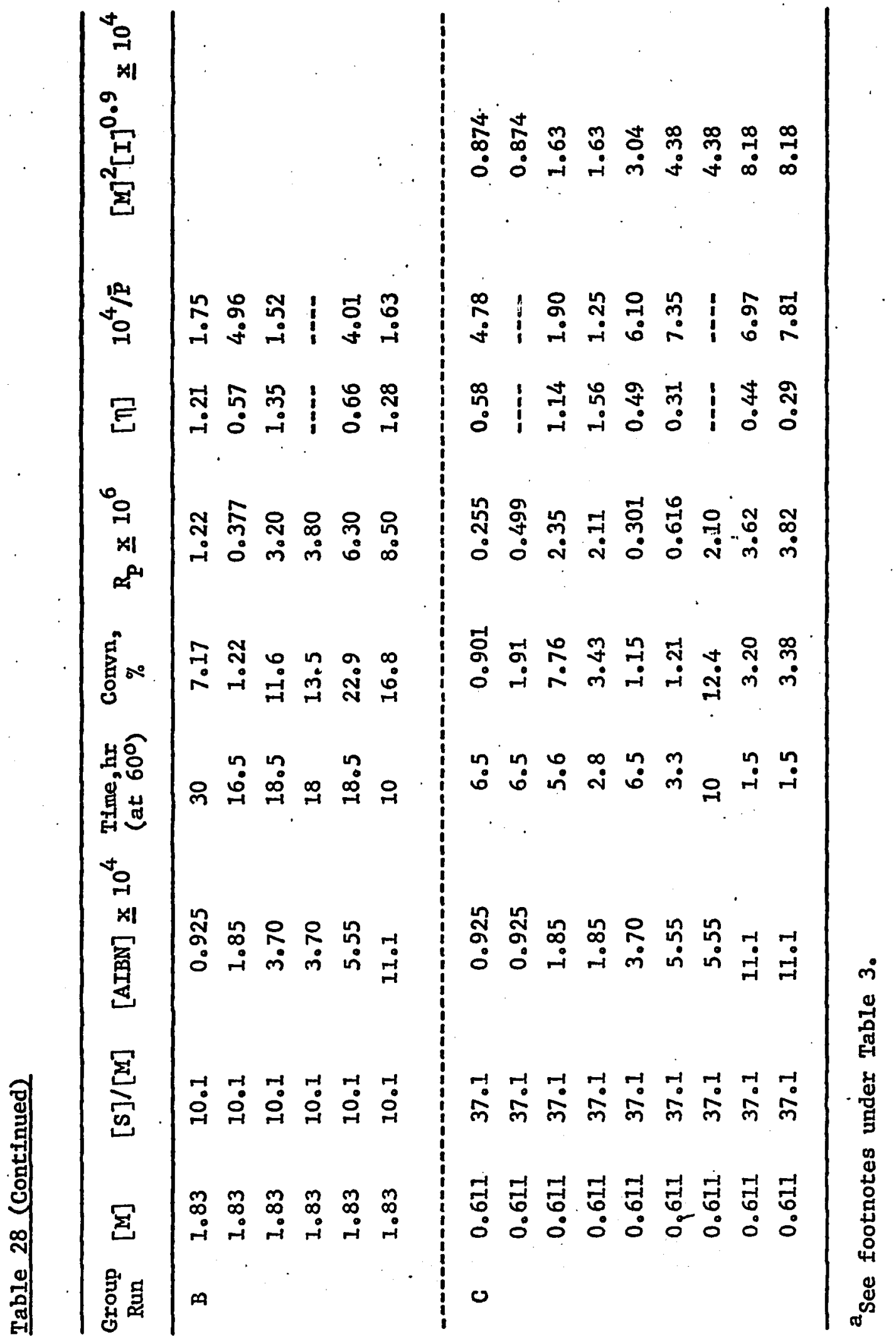


121

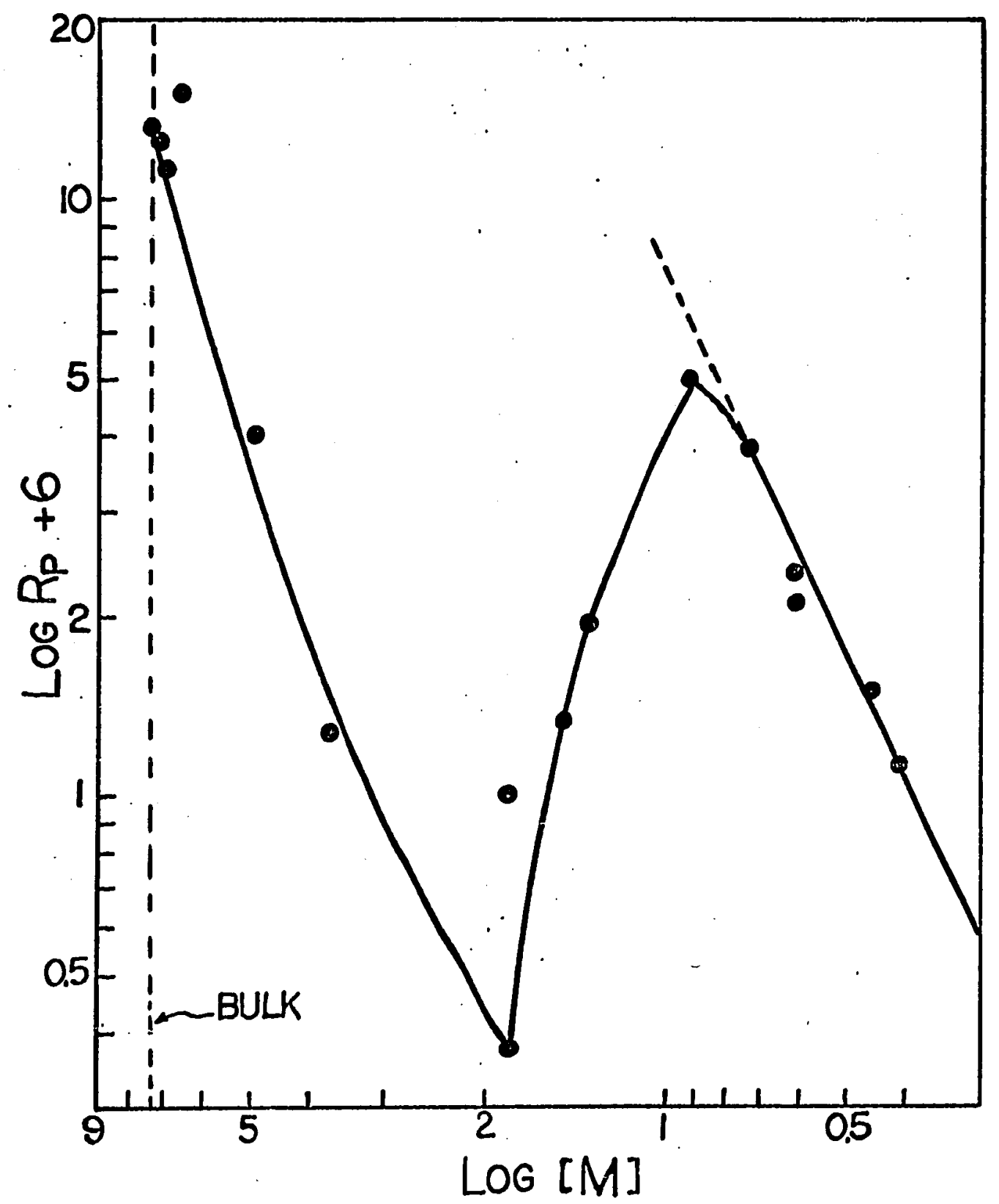

Figure 21. Graph of $\log R_{P}$ vs. $10 g[M]$ for the Polymerization of PFS in Methanol at $60^{\circ} \mathrm{C}$. [AIBN] $=1.85 \underline{x} 10^{-4} \mathrm{M}$.

Reproduced with permission of the copyright owner. Further reproduction prohibited without permission. 


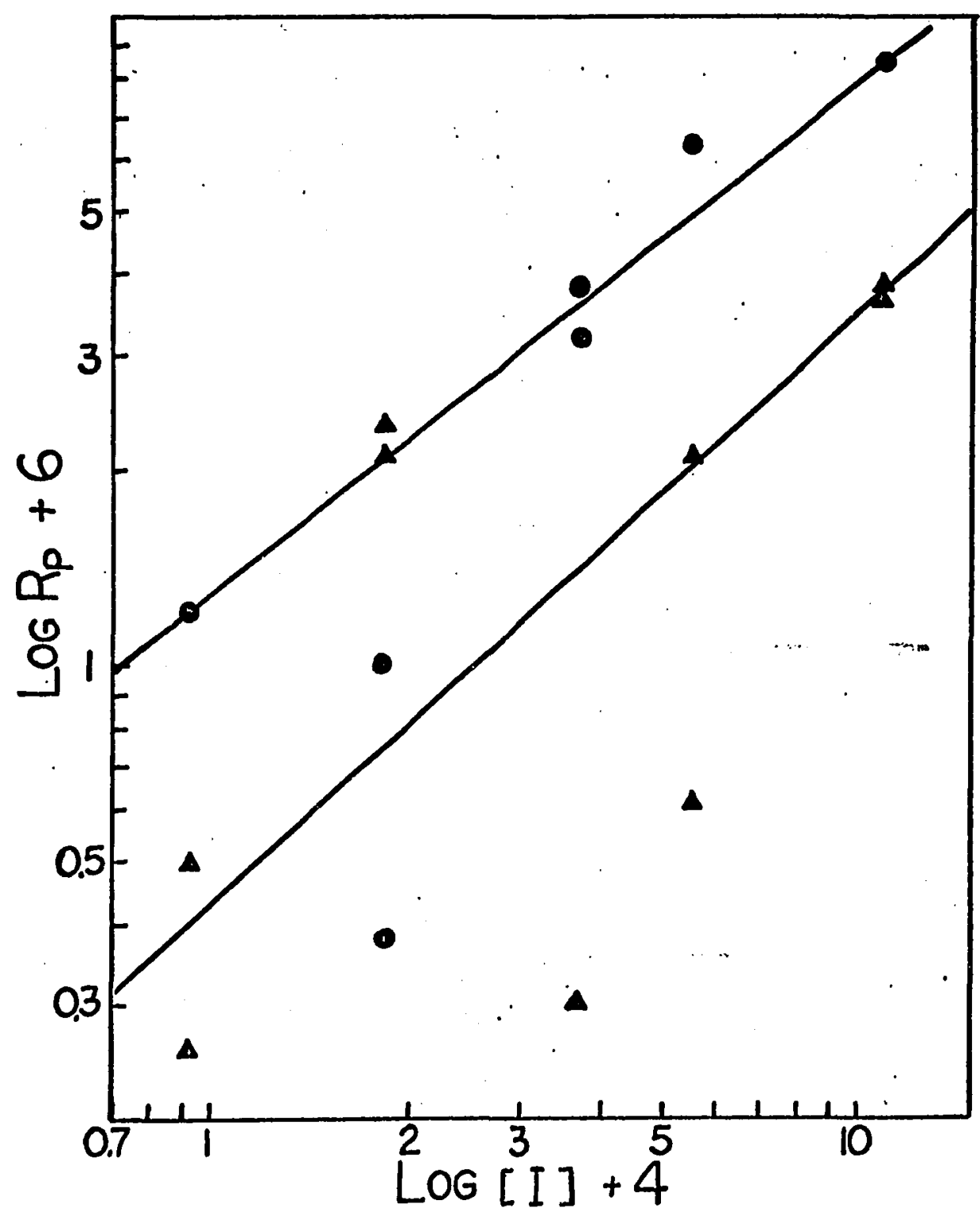

Figure 22. Graph of $\log R_{\mathrm{p}}$ vs. $\log$ [AIBN] for the Polymerization of PFS in Methanol at $[M]=1.83 \mathrm{M}(0)$, and at $[M]=0.611 \mathrm{M} \quad(\Delta)$. 


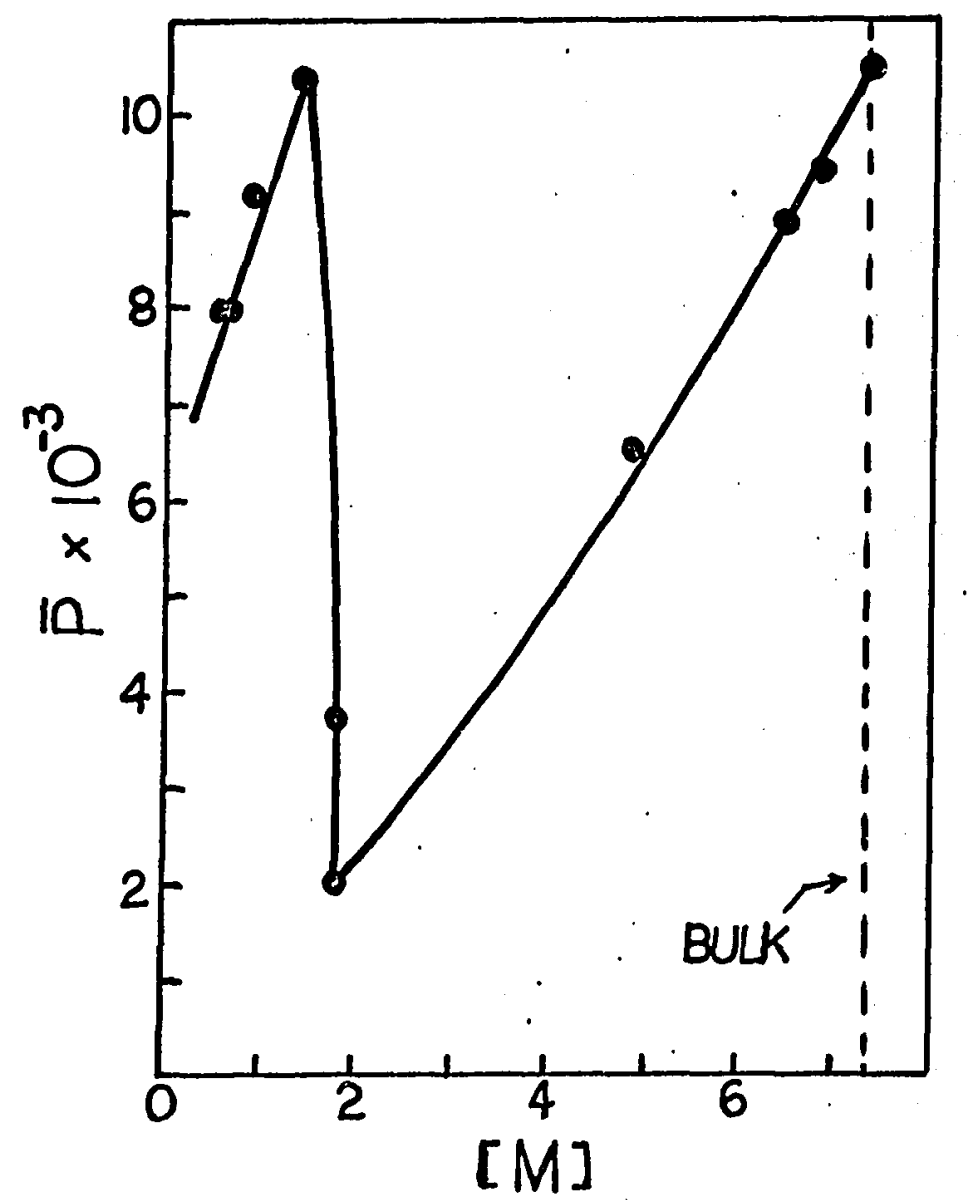

Figure 23. Graph of $\overline{\mathrm{P}}_{\mathrm{n}}$ vs. [M] for the Polymerization of PFS in Methanol at $\left[\right.$ AIBN] $=1.85 \times 10^{-4} \mathrm{M}$. 


\section{SUMMARY}

\section{Homopolymerization}

(1) Thermal polymerization of PFS in bulk was done at different temperatures. The over-all activation energy for thermal polymerization was found to be $16.8 \mathrm{kcal} / \mathrm{mole}$. The numberaverage degree of polymerization of poly-PFS is higher than that of polystyrene by about 3 times at $60^{\circ}$ to about 13 times at $129^{\circ}$. The rates of the polymerization of PFS are similar to those of styrene at the same temperature.

(2) The polymerization of PFS initiated by AIBN was done at different temperatures. The value of $C_{M}$ for PFS was found to be zero. The calculated over-all activation energy for the AIBN-initiated polymerization is $20.6 \mathrm{kcal} / \mathrm{mole}$. The values of $\delta^{2}$ were obtained for pure PFS and PFS-solvent systems.

(3) The polymerization of PFS initiated by $A I B N-{ }^{3} \mathrm{H}$ was done at $60^{\circ}$. It is concluded that the termination mechanism is entirely by combiration.

(4) Thermal polymerization of PFS in solvents was done at $60^{\circ}$. The over-all rates in substituted benzenes are approximately second order in monomer. The transfer constants to solvents were calculated. An extended thermal initiation mechanisal of the type proposed by Brown is adopted.

(5) The measurement of the rate of initiation for PFS was done by 
using two different methods: the molecular weight method and the Inhibitor method. The molecular weight method gave reasonable values of $f$ for PFS-solvent mixtures. The inhibitor method was less successful. In the cases where DPPH used as Inhibitor, abnormal results were obtained. Benzuquinone, however, did give satisfactory data.

(6) The determination of radical lifetime was done by using the rotating sector method, and the absolute rate constants $k_{p}$ and $k_{t}$ are calculated for both pure PFS and the PFS-solvent systems.

\section{Copolymerization}

(1) Copolymerization of PFS and styrene initiated by AIBN was done at $60^{\circ}$. The monomer reactivity ratios, and $Q$, e values were obtained. The foctor calculated from the kinetic data is 7.2.

(2) Copolymerization of PFS and MMA initiated by AIBN was done at $60^{\circ}$. The monomer reactivity ratios and $Q, e$ values were obtained. The factor calculated is 5.3. Based on the chain transfer, the

$\therefore$ absolute rate constant and the copolymerization data, it is concluded that the PFS monomer is less reactive than styrene, but that the radical is more reactive.

(3) Thermal copolymerization of PFS and styrene was done at $60^{\circ}$ in the absence of initiator. The observed rates fail to indicate cross-initiation. The values of the monomer reactivity ratios were found to be the same as those in the AIBN-initiated copolymerization. 
(4) Thermal copolymerization of PFS and MMA was done at $60^{\circ}$ in the absence of initiator. No cross-initiation was observed either. The values of the monomer reactivity ratios were found to be the same as those in the AIBN-initiated copolymerization.

(5) Copolymerization of PFS and styrene in solvents was done at $60^{\circ}$ with and/or without AIBN as initiator. The monomer reactivity ratios are apparently changed in benzonitrile.

\section{Heteropolymerization}

The heteropolymerization of PFS in methanol was studied at $60^{\circ}$ with AIBN as initiator. It was shown that typical occlusion phenomena are operative in this system. 


\section{REFERENCES}

1. W.J. Plummer and I.A. Wall, J. Res. Natl. Bur. Stand., 63A, 167 (1959).

2. E. Nield, R. Stephens, and J.C. Tatlow, J. Chem. Soc., 166 (1959).

3. J.D. Park, R.J. Seff1, and J.R. Lacher, J. Amer. Chem. Soc., 78, 59 (1956) .

4. L.A. Wall, W.J. Plummer, J.E. Fearn, and J.M. Antonucc1, J. Res. Nat1. Bur. Stand., 67A, 481 (1963).

5. I.A. Wall, J.M. Antonucci, S. Straus, and M. Tryon, "Degradation of Poly-2,3,4,5,6-Pentafluorostyrene", Proc. Sym. Polymer Degradation, Soc, of Chem. Ind., Monograph No.13, 295 (1961).

6. D.W. Brown, R.E. Florin, and L.A. Wall, J. Res. Nat1. Bur. Stand., 64A, 269 (1960).

7. C. Walling, "Free Radicals in Solution", John Wiley and Sons, Inc., New York, N.Y., 1957, Chap.3-5. (a) p.66; (b) p.145 (c) pp.146-147; (d) p.95.

8. P.D. Bartlett and R. Altschul, J. Amer. Chem. Soc., 67, 816 (1945).

9. F.R. Mayo, J. Amer. Chem. Soc., 65, 2324 (1943).

10. G.M. Burnett and H.W. Melville, "Technique of. Organic Chemistry", Volume VIII, A. Weissberger, Editor, Interscience Publishers, New York, N.Y., 1953, pp.133-169.

11. W.G. Burns and F.S. Dainton, Trans. Faraday Soc., 46, 411 (1950). 12. M.H. George, in G.E. Ham ed., "Vinyl Polymerization", Part I. Marce1 Dekker, Inc., New York, N.Y., 1967, Chap.3, "Styrene", (a) p.148; (b) p.151; (c) p.143; (d) p.149; (e) p.150. 
13. W.A. Pryor and T.I. Huang, Macromolecules, 2, 70 (1969).

14. T. Alfrey and G. Goldfinger, J. Chem. Phys., 12, 205, 322 (1944).

15. M. Fineman and S.D. Ross, J. Polymex Sci., 5, 259 (1950).

16. F.M. Lewis, C. Walling, W. Cummings, E.R. Briggs, and F.R. Mayo, I. Amer. Chem. Soc., 70, 1519 (1948).

17. T. Alfrey and C.C. Price, J. Polymer Sci., 2, 101 (1947).

18. G.E. Ham, "Copolymerization", Interscience Publishers, New York, N.Y., 1964.

19. F.M. Lewis and F.R. Mayo, Ind. Eng. Chem., 17, 134. (1945).

20. J. Thiele and K. Heuser, Ann., 290, 1 (1896).

21. W.A. Pryor and T.R. Fiske, Macromolecules, 2, 62 (1969).

22. M. Kinoshita and M. Imoto, Kobunshi Kagaku, 20, 231 (1963).

23. M. Kinoshita and M. Imoto, Kobunshi Kagaku, 20, 237 (1963).

24. M. Kinoshita, Kogyo Kagaku Zassi, 66,982 (1963).

25. M.S. Matheson, E.E. Auer, E.B. Bevilacqua, and E.J. Hart, J. Amer. Chem. Soc., 73, 1700 (1951).

26. W.M. Thomas, E.H. Gleeson, and J.J. Pellon, J. Polymer Sci., 17, 275 (1955).

27. W.A. Pryor, R. Henderson, N. Carrol1, and E. Ciuffarin, Abstracts of Papers, 150th National Meeting of the American Chemical Society, Atlantic City, N.J., Sept. 1965, p.75.'

28. F.R. Mayo, J. Amer. Chem. Soc., 75, 6133 (1953).

29. R.H. Boundy and R.F. Boyer, "Styrene", Reinhold Publishing Corp., New York; N.Y., 1952. (a) p.224; (b) P.220; (c) p.222;

(d) P.216. 
30. F.W. Billmeyer, "Textbook of Polymer Science", Interscience Publishers, New York, N.Y., 1962, Chap.9.

31. W.A. Pryor and T.L. Pickering, J. Amer. Chem. Soc., 84, 2705 (1962).

32. G. Henrici-01ivé and S. Olivé, Fortschr.-Hochpolym. Forsch., 2, 496 (1961).

33. W.A. Pryor and E.P. Pultinas, J. Amer. Chem. Soc., 85, 133 (1963).

34. R.A. Gregg and F.R. Mayo, Discusstons Faraday Soc., 2, 328 (1947).

35. G.S. Misra and R.N. Chadha, Makromol: Chem., 23, 134 (1957).

36. S.L. Kapur, J. Polymer Sci., 11, 399 (1953).

37. J.C. Bevington and H.G. Troth, Trans. Faraday Soc., 58, 186 (1962).

38. E.P. Bonsa11, L. Valentine, and H.M. Melville, Trans. Faraday Soc., $4 \dot{8}, 763$ (1952).

39. G.M. Burnett, W.S. Dalley, and J.M. Pearson, Trans. Faraday Soc., 61, 1216 (1965).

40. I.J. Young, J. Polymer Sci., 54, 411 (1961).

41. T. Alfrey, Jr., and W.H. Ebelke, J. Amer. Chem. Soc., 71, 3235 (1949).

42. G.M. Burnett, "Mechanism of Polymer Reastions", Interscience Publishers, New York, N.Y., 1954, pp.295-297.

43. C. Walling and E.A. McElhi11, J. Amer. Ghem. Soc., 73, 2819 (1951).

44. C. Walling, J. Amer。 Chem. Soc., 71, 1930 (1949).

45. H.G. Gelhaar and K. Ueberreiter, Kollold-Z. Z. Polymere, 209, 136 (1966).

46. W.I. Bengough, W. Henderson, and R.A.M. Thomson, Trans. Faraday Soc., 60, 1137 (1964). 
47. W.A. Pryor, "Free Radicals", McGraw-Hil1 Book Co., Inc., New York, N.Y., 1966. (a) p.236; (b) p.14.

48. M. Imoto, M. KInoshita, and M. Nishigak1, Makromol. Chem., 8̈6, 217 (1965).

49. W.A. Pryor and G.I. Kaplan, J. Amer. Chem. Soc., 86, 4234 (1964).

50. W.A. Pryor, A. Lee, and C.E. Witt, J. Amer. Chem. Soc., 86, 4229 (1964).

51. K.F. Müller, Makromol. Chem., 79, 128 (1964).

52. A.V. Tobolsky and J. Offenbach, J. Polymer Sc1., 16, 311 (1955).

53. J. Brandrup and E.H. Immergut, Ed., "Polymer Handbook", Interscience Publishers, New York, N.Y., 1966.

54. M.S. Matheson, E.E. Auer, E.B. Bevilacqua, and E.J. Hart, J. Amer. Chem. Soc., 71, 2610 (1949).

55. J.C. Bevington, "Radical Polymerization", Acadeṃ̣c Press, New York, N.Y., 1961. (a) p.2; (b) p.56.

56. T. Huff and E. Perry, J. Polymer Sci., Part A, 1, 1553 (19.63).

57. P.J. Flory, "Principles of Polymer Chemistry", Cornell University Press, Ithaca, N.Y., 1953. (a) p.131; (b) p.132; (c) pp.123124; (d) p.125; (e) pp.145-146.

58. C. Aso, T. Kunitake, M. Shinsenj1, and H. Miyazaki, J. Polymer Sc1., A-1, Z, 1497 (1969).

59. C. Aso, T. Kunitake, and Y. Tanaka, Bu11. Chem. Soc., Japan, 38, 675 (1965).

60. S. Loshaek, E. Broderick, and P. Bernstein, J. Polymer Sci., 39, 223 (1959). 
61. F.R. Mayo, J. Amer. Chem. Söc., 90, 1289 (1968).

62. W.A. Pryor, Chem. Eng. News, 46, 80 (Jan.15, 1968).

63. I.C. Rubens, J. App1. Polym. Sci., 9, 1473 (1965).

64. M,M. Koton, J. Polymer Sc1., 30, 331 (1958).

65. M.M. Koton and O.K. Surnina, Doklady Akad. Nauk. S.S.S.R., ii3, 1063 (1957). cf. c.A., 51, 14725e (1957).

66. W.I. Bengough and W. Henderson, Trans. Faraday Soc., 61, 141 (1965).

67. K. Kirchner and F. Patat, Makromol. Chem., 37, 251 (1960).

68. C.E.H. Bawn and S.F. Mel1ish, Trans, Faraday Soc., 47, 1216 (1951).

69. K.E. Russe11 and A.V. Tobolsky, J. Amer. Chem. Soc., 75, 5052 (1953).

70. W.I. Bengough, Chem. Ind., 599 (1955).

71. H.W. Melville and L. Valentine, Irans. Faraday Soc., 46, 210 (1950).

72. A.E. Nicholson and R.G.W. Norrish, Disc. Faraday Soc., 22, 104 (1956).

73. A.M. North and A.M. Scallan, Polymex, 5, 447 (1964).

74. K. Yokota, M. Kani and Y. Ishil, J. Polymex Sci., A-1, 6, 1325 (1968).

75. A.R. Gantmacher, Ju. I. Spirin and S.S. Medwedew, Vysokomol. Soedin., 1,1526 (1959); through Ghem. Zentr., 132, 10581 (1961).

76. "Tables of Interatomic Distance and Configuration in Molecules and Ions", Special Publication No.11, The Chemical Society, London. 
77. G.V. Schulz, G. Henrici-olivé and S. Olivé, z. phys. Chem., 27, $1(1960)$.

78. R.N. Chadha, J.S. Shukla and G.S. Misra, Trans. Faraday Soc., 53, 240 (1957).

79. P.W. Allen, F.M. Merrett and J. Scanlan, Trans. Faraday Soc., 51, 95 (1955).

80. H. Gilbert, F.F. Miller, S.J. Averil1, E.J. Carlson, V.L. Foltp H.J. Heller, F.D. Stewart, R.F. Schmidt and H.L. Trumbul1, J. Amer. Chem. Soc., 78, 1669 (1956).

81. F.R. Mayo and F.M. Lewis, J. Amer. Chem. Soc., 66, 1594 (1944).

82. C. Walling, E.R. Briggs, W. Cummings, and F.R. Mayo, J. Amer. Chem. Soc., 72, 48 (1950).

83. R.L. Dannley and E.L. Kay, J. Amer. Chem. Soc., 77, 1046 (1955).

84. W.A. Pryor and T.I. Huang, unpublished work.

85. A. Nishioka, Y. Kato and N. Ashikari, J. Polymer Sci., 62, S10 (1962).

86. W.H. Seitzer, R.H. Goeckermann and A.V. Tobolsky, J. Amer. Chem. Soc., 75,755 (1953).

87. W.J. Burlant and D.H. Green, J. Polymer Sci., 31, 227 (1958).

88. K. Nozaki, J. Polymer Sci., 1, 455 (1946).

89. C.C. Price and J.G. Walsh, J. Polymer Sci., 6, 239 (1951).

90. J.H. Bradbury and H.W. Melville, Proc. Roy. Soc. (London), A222, 456 (1954).

91. S. Yabumoto, K. Ishii and K. Arita, J. Polymer Sci., Part A-1, Z, 1577 (1969). 
92. H.C. Haas and E.R. Karlin, J. Polymer Sci., $\underset{i}{9}, 588$ (1952).

93. J. Drougas and R.I. Guile, J. Polymer Sci., 55, 297 (1961).

94. C.G. Overberger, R.J. Ehrig and D. Tanner, J. Amer. Chem. Soc., 76,772 (1954).

95. A.D. Jenkins, in G.E. Ham, Ed., "Viny1 Polymerization", Part I. Marce1 Dekker, Inc., New York, N.Y., 1967, Chap.6, P.389.

96. J. Abere, G. Goldfinger, H. Naldus, and H. Mark, J. Phys. Chem., 49, 211 (1945).

97. A. Chapiro, J. chim. Phys., 47, 764 (1950).

98. A. Chapiro, J. chim. Phys., 47, 747 (1950).

99. G.G. Odian, A. Rossi and E.N. Trachtenberg, J. Polymer Sci., 42 , 575 (1960).

100. G. Vidotto, A. Crosato-Arnaldi and G. Talamini, Makromol. Chem., 122, 91 (i969).

101. A. Crosato-Arnaldi, G. Talamini and G. Vidotto, Mák romol. Chem., iii, 123 (1968).

102. L.F. Fieser, "Experiments in Organic Chemistry", 3rd Ed., Revised, D.C. Heath and Company, Boston, Mass., 1957, p.287.

103. T. Yamamoto, unpublished work.

104. T.L. Cottre11, "The Strengths of Chemical Bonds", 2nd Ed., Butterworth's Scientific Publications, London, 1958.

105. C.H. Bamford, W.G. Barb, A.D. Jenkins and P.F. Onyon, "The Kinetics of Vinyl Polymerization by Radical Mechanism", Butterworth's Scientific Publications, London, 1958, p.72.

106. J.N. Atherion and A.M. North, Trans. Faraday Soc., 58, 2049 (1962). 107. E.P. Bonsall, L. Valentine and H.W. Melville, J. Polymer Sci., Z, 
39 (1951).

108. J.A. Kerr, Chem. Reviews, 66, 465 (1966).

109. F.R. Mayo, Preprints of Papers, Division of Polymer Chemistry, Anerican Chemical Society, Chicago Meeting, Sept. 1961, Vol.2, No.2, p. 55 .

110. F.R. Mayo, International Symosium on Macromolecular Chemistry, Moscow, 1960. Papers and Summaries, Section II, p.11.

111. E.E. Lewis and M.A. Naylor, J. Amer. Chem. Soc., 69, 1968 (1947).

112. E.C. Coyner and W.S. Hiliman, J. Amer. Chem. Soc., 71, 324 (1949).

113. J.D. Roberts and C.M. Sharts, Org. Reactions, 12, 1 (1962).

114. P.D. Bartlett and K.E. Schueller, J. Amer. Chem. Soc., 90, 6071 (1968).

115. L.K. Montgomery, K.E. Schueller and P.D. Bartlett, J. Amer. Chem. Soc., 86, 622 (1964).

116. C.A. Stewart, Jr., J. Amer. Chem. Soc., 84, 117 (1962).

117. W.G. Brown, Makromo1. Chem., 128, 130 (1969).

118." K. Kirchner, Makromol. Chem., 128, 150 (1969).

119. G.V. Schulz and E. Husemann, Z. phys. Chem., 34B, 184, 187 (1936).

120. P.J. Flory, J. Amex. Chem. Soc., 59, 241 (1937).

121. W.A. Pryor, R.W. Henderson, R.A. Patsiga and N. Carrol1, J. Amer. Chem. Soc., 88, 1199 (1966).

122. K. Kirchner, Makromo1. Chem., 96,179 (1966).

123. Simon Miron, The Dow Chemical Company, Freeport, Texas. Frivate communication.

124. L.A. Wall, Amer. Chem. Soc., Division of Polymer Chem., Preprints ... of Papers, 7, 1113 (1966). 
125. W.J. Pummer and J.M. Antonucci, Amer. Chem. Soc., Division of Polymer Chem., Preprints of Papers, 7, 1071 (1966).

126. L.D. Lasswe11, unpublished work.

127. K.R. Kopecky and S. Evan, , Can. J. Chem., 47, 4049 (1969).

128. K. R. Kopecky and S. Evan1, Gan. I. Ghem., 47, 4041 (1969).

129. S.W. Benson, "Thermochemical Kinetics", John Wiley and Sons, Inc., New York, N.Y., 1968, p.101.

130. R. Hofmann and R.B. Woodward, J. Amer. Chem. Soc., 87, 2046 (1965).

13i. W.I. Bengough and N.K. Henderson, Chem. Ind., 657 (1969).

132. W.I. Bengough, N.K. Henderson and D. Patsavoudis, European Polymer J., 5, 463 (1969).

133. B.H. Zimm and J.K. Bragg, J. Polymer Sci., 9, 476 (1952).

134. R.N. Haward, Trans. Faraday Soc., 46, 204 (1950).

135. J.I. Cotter, J.M. Lancaster, and W.W. Wright, Amer. Chem. Soc., Division of Polymer Chem., Preprints of Papers, 5, 474 (1964).

136. M. Prober, J. Amer. Chem. Soc., 75, 968 (1953).

137. D.L. Livingston, P.M. Kamath, and R.S. Corley, J. Polymex Scl., 20,485 (1956).

138. J. Harmon, U.S. Patent 2,404,374 (July 23, 1946).

139. A.I. Henne and R.P. Ruh, J. Amer. Chem. Soc., 69, 281 (1947). 


\section{APPENDICES}

I. A Comparison of the American and the British Conventions In Polymerization Kinetics

(Those expressions which are different in the two conventions are denoted by the symbol (*))

\section{American Convention 7,47}

Initiation:

$I \rightarrow 2 R$.

$R \cdot+M \rightarrow M \cdot$
Rate

$-d[I] / d t=k_{d} f[I]$

$$
\dot{d}[R \cdot] / d t=2 k_{d} f[I]
$$

$k_{i}[R \cdot][M]$
British Convention 55, 105-107

Rate

$-d[I] / d t=k_{d} f[I]$

$d[R \cdot] / d t=2 k_{d} f[I]$

$k_{1}[R \cdot][M]$

Propagation:

$M \bullet+M \rightarrow M \cdot$

$$
R_{P}=k_{p}[M \cdot][M]
$$

$$
R_{P}=k_{p}[M \cdot][M]
$$

Termination:

$$
\begin{aligned}
& M_{m}+M_{n} \rightarrow M_{m}-M_{n} \quad \text { (combination) } \\
& -d[M \cdot] / d t=2 k_{t c}[M \cdot]^{2}(*)-d[M \cdot] / d t=k_{t c}[M \cdot]^{2} \\
& \left.\mathrm{~d}[\mathrm{P}] / \mathrm{dt}=\mathrm{k}_{\mathrm{tc}}[\mathrm{M} \cdot]^{2} \quad \dddot{\nLeftarrow}\right) \mathrm{d}[\mathrm{P}] / \mathrm{dt}=\frac{1}{2} \mathrm{k}_{\mathrm{tc}}[\mathrm{M} \cdot]^{2} \\
& \underset{m}{M_{0}}+M_{n} \rightarrow M_{m}+M_{n} \quad \text { (disproportionation) } \\
& -d[M \cdot] / d t=2 k_{t d}[M \cdot]^{2}(*)-d[M \cdot] / d t=k_{t d}[M \cdot]^{2} \\
& d[P] / d t=2 k_{t d}[M \cdot]^{2}(*) d[P] / d t=k_{t d}[M \cdot]^{2}
\end{aligned}
$$

Over-a11 Rate:

$$
\begin{array}{ll}
R_{P}=\frac{R_{1}^{0.5}}{\delta}[M]=\left[\frac{2 d_{d}^{f}}{\delta^{2}}\right]^{0.5}[M][I]^{0.5} & R_{P}=\frac{R_{1}^{0.5}}{\delta}[M]=\left[\frac{2 k_{d}^{f}}{\delta^{2}}\right]^{0.5}[M][I]^{0.5} \\
\text { where } \delta=\left(2 k_{t}\right)^{0.5} / k_{p}(*)(\operatorname{ref.7b}) & \text { where } \delta=k_{t}^{0.5} / k_{p}(*)(\text { refs.106,107) }
\end{array}
$$


The Reciprocal of the Degree of Polymerization:

$$
\begin{aligned}
& \frac{i}{\bar{P}}=\frac{\delta^{2}}{2[M]^{2} P}+C_{M}+C_{S[M]} \frac{[S]}{s[} \\
& \frac{1}{\mathrm{~F}}=\frac{8^{2}}{2[\mathrm{M}]^{2}} \mathrm{R}_{\mathrm{P}}+\mathrm{C}_{\mathrm{M}}+\mathrm{C} \cdot \frac{[\mathrm{S}]}{\mathrm{S}[\mathrm{M}]} \\
& \text { (combination) } \\
& \text { (combination) } \\
& \frac{1}{\mathrm{P}}=\frac{\delta^{2}}{[\mathrm{M}]^{2}} \mathrm{R}_{\mathrm{P}}+\mathrm{C}_{\mathrm{M}}+\mathrm{C}_{\mathrm{S}[\mathrm{M}]} \frac{[\mathrm{S}]}{} \\
& \frac{1}{\overline{\mathrm{F}}}=\frac{\delta^{2}}{[\mathrm{M}]^{2}} \mathrm{R}_{\mathrm{P}}+\mathrm{C}_{\mathrm{M}}+\mathrm{C}_{\mathrm{S}} \frac{[\mathrm{S}]}{\mathrm{M}]} \\
& \text { (disproportionation) }
\end{aligned}
$$

The Over-all Rate of Copolymerization:.

$$
\begin{aligned}
& \frac{-d\left\{\left[M_{1}\right]+\left[M_{2}\right]\right\}}{d t}=R_{p}= \\
& \frac{\left\{r_{1}\left[M_{1}\right]^{2}+2\left[M_{1}\right]\left[M_{2}\right]+r_{2}\left[M_{2}\right]^{2}\right\} R_{1}^{0.5}}{\left\{r_{1}^{2} \delta_{1}^{2}\left[M_{1}\right]^{2}+2 \phi r_{1} r_{2} \delta_{1} \delta_{2}\left[M_{1}\right]\left[M_{2}\right]+r_{2}^{2} \delta_{2}^{2}\left[M_{2}\right]^{2}\right\}^{0.5}}
\end{aligned}
$$

Same equation

as American

Convention

(refs.106, 107) where $\delta_{1}^{2}=2 \mathrm{k}_{\mathrm{t} 11} / \mathrm{k}_{11}^{2}, \delta_{2}^{2}=2 \mathrm{k}_{\mathrm{t} 22} / \mathrm{k}_{22}^{2}$

$$
\begin{aligned}
& r_{1}=k_{11} / k_{12}, x_{2}=k_{22} / k_{21} \\
& \phi=\frac{k_{t 12}}{2\left(k_{t 11} k_{t 22}\right)^{0.5}}
\end{aligned}
$$

If all collisions are equally effective

$$
\phi=1 \text { (refs.7c,47b) }
$$

where $\delta_{1}^{2}=k_{t 11} / k_{11}^{2}, \delta_{2}^{2}=k_{t 22} / k_{22}^{2}$
If all collisions are equally effective

$$
b=1 \text { (refs. } 42,106,107)
$$

Thus the equations derived with the American Convention or the British Convention may be readily interchanged by the following relationships: ${ }^{12 c}$

$$
\begin{aligned}
& 2 k_{t c}\left(\text { American) } \equiv k_{t c}(\text { British) }\right. \\
& 2 k_{t d}\left(\text { American) } \equiv k_{t d}(\text { British) }\right.
\end{aligned}
$$

Note that $\delta^{2}$ has same numerical value in the two conventions. 
II. Some Remarks About the Rotating Sector Technique

The Set-up. The following schematic diagram shows the set-up used in this study:

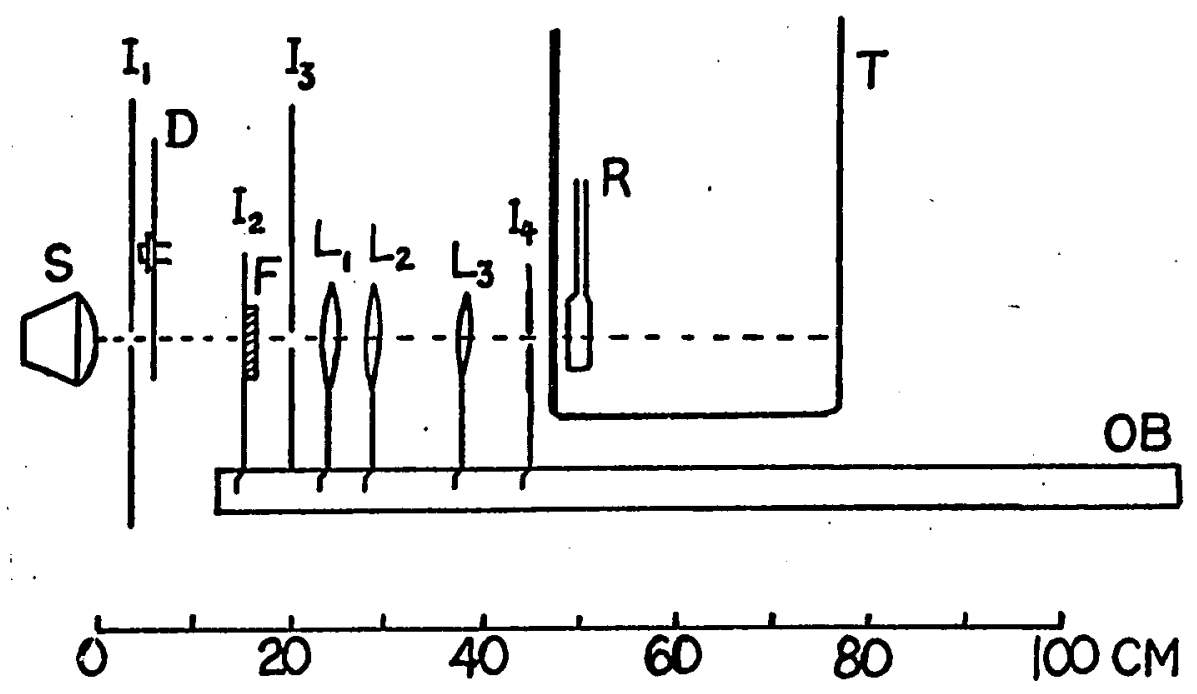

Notations from left to right:

S: The light source is a 100-watt General Electric Ultraviolet Mercury lamp supplied with power system (E.H. Sargent \& Co. Catalog No. s-44260). The power system should be kept in a basket containing Dry-Ice to reduce the heat produced by the system. The lamp could be kept cooling by a regular blower.

$I_{1}$ : An iris with a circle opening $\mathrm{ca} .4 \mathrm{~cm}$ in diameter. The portion close to the light source is made of aluminum foil.

D: The sector disc with adjustable opening made by Bausch \& Lomb Optical Co., Rochester, N.Y. The motor used, Bodine model 805SBK46, was made by Bodine Electric Co., Chicago, I11. The 
speed reducer APCOR mode1 No.2401 was made by Geartronicu Corporation, North Billerica, Mass, The disc, the motor and the speed reducer were all mounted on the same heavy steel plate to insure the reproducibility of the disc rotation.

$I_{2}$ : An iris with adjustable opening. (ca. $4 \mathrm{~cm}$ in diameter was used In this study).

F: A filter, Corning C. S. 0-52, made by Corning Glass Works, Parkersburg, W. Va, This filter was fixed on $I_{2}$.

$I_{3}$ : An iris with circle opening ca. $4 \mathrm{~cm}$ in diameter.

$I_{1}, I_{2}:$ Glass lenses supplied by Edmund Scientific Co., Barrington,

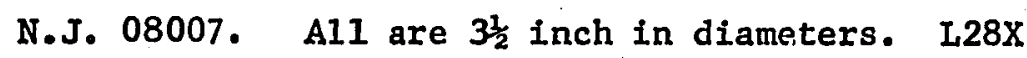

$I_{3}$ : A Mercury reading glass lens, 3 inch in diameter.

$I_{4}$ : An iris with adjustable circle opening. An opening with $\mathrm{ca} .4 \mathrm{~cm}$ in diameter was used in this study.

T: A thermostat bath, wrapped with aluminum foil (or kept in a box). R: A reaction cel1.

OB: An aluminum bench of 1 meter long (Ealing Corporation, Cambridge, Mass. catalog No. 22-681).

Note that $I_{2}, F, I_{1}, I_{2}, I_{3}, I_{4}$ were all fixed on $0 B$. All parts in this set-up should be fixed including the source $S$, the cell $R$, etc. This is important for obtaining the reproducible rates.

\section{A Sample Calculation of Average Radical Lifetime. The dark}

rate of polymerization for PFS is 0.11 x $10^{-6} \mathrm{M} \mathrm{sec}-1$ at [ACHN] = $3.00 \times 10^{-3} \mathrm{M}$. The corresponding rate under steady light is $5.50 \times 10^{-6} \mathrm{M}$ $\sec ^{-1}$ (see Table 15). Therefore, the thermal correction factor, 
$z=$ dark rate/steady light rate $=0.02$. The differences between the theoretical and experimental curves (for $z=0.02$ and $r=2$ ) as measured from Figure 20 are as. follows for pure PFS:

$\begin{array}{lc}\underline{R}_{\mathrm{P}} / \mathrm{R}_{\mathrm{Ps}} & \text { Difference }(=\log \tau) \\ 0.565 & 0.29 \\ 0.519 & 0.26 \\ 0.465 & 0.24 \\ 0.428 & 0.26\end{array}$

Average $\log T=0.263, T=1.83$ sec. Note that in a11 experiments In Table 15, the points lying near midway between the limits of the theoretical curve were chosen for the calculation of the average lifetime. The accuracies were 5-20\% By measuring the lifetime at various rates of polymerization, the accuracy of the determination of the rate constants could be improved. ${ }^{10}$ A plot of rate against reciprocal lifetime will give a straight line from the slope of which the ratio $2 k_{t} / k_{p}$ can be computed (see Equation 22). 


\section{THE KINETICS OF DIRADICAL POLYMERIZATION}

The Over-a11 Rate and the Activation Energies. The bimolecular diradical mechanism proposed by Flory 57 a for the thermal polymerization of styrene is as follows:

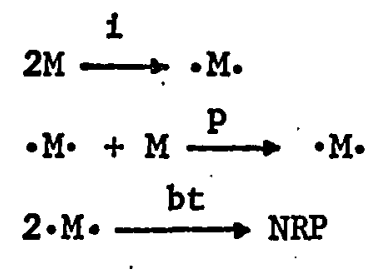

If the rate of termination is assumed to be bimolecular as in the case of monoradical-inftiated polymerization, then it fcllows from the steady state condition $R_{1}=R_{t}$ that $k_{i}[M]^{2}=2 k_{b t}[\cdot M \cdot]^{2}$ and the rate of polymerization is then given by

$$
R_{p}=k_{p}[\cdot M \cdot][M]=k_{p}\left(k_{i} / 2 k_{b t}\right)^{\frac{1}{2}}[M]^{2} \quad \text { (iv) }
$$

This mechanism leads to a second-order rate for thermal polymerization of PF'S in agreement with experiment. If, on the other hand, the termination is a first-order process (e.g., intramolecular coupling), step (iii) will be replaced by step (v):

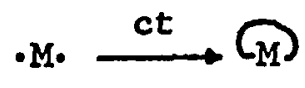

At steady state $k_{i}[M]^{2}=k_{c t}[\cdot M \cdot]$, and the rate of polymerization is given by

$$
R_{P}=k_{p}[\cdot M \cdot][M]=k_{p} k_{i} / k_{c t}[M]^{3}
$$


Thus a first-order termination process would raise the over-all order for the polymerization to 3 . If the termination is entirely by transfer reaction, the step (iii) will be replaced by step (vii):

$$
\cdot M \cdot+M \frac{\operatorname{tr,M}}{\text { slow }} 2 M \cdot \underset{\text { fast }}{\longrightarrow} \mathrm{NRP}
$$

At steady state $k_{i}[M]^{2}=k_{t r, M}[\cdot M \cdot][M]$ and the over-ail rate of polymerization is given by

$$
R_{P}=k_{p}[\cdot M \cdot][M]=k_{P} k_{1} / k_{t r, M}[M]^{2}
$$

Thus the over-all rate is second order in monomer a1so. However, the activation energy equation derived from Equation (viii) will be $E_{t h}=E_{p}+E_{i, t h}-E_{t r, M}$ which is different from $E_{t h}=E_{p}+\left(E_{i, t h}-E_{b t}\right) / 2$ derived from Equation (iv). The actual termination mechanism for the thermal polymerization of PFS may be a combination of Equations (iii) and ( $v i i)$ instead of the combination of (iii) and (v) so that the over-all rate may be second order in PFS in agreement with experiment. The Relationship Between the Over-all Rate and the Degree of Polymertzation. In the presence of solvent, the following step may be added:

$$
\cdot M \cdot+S \stackrel{\operatorname{tr}, S}{\longrightarrow} \operatorname{NRP} \quad(i x)
$$

It follows from Equations (i) - (iii), (vii) and (ix) that the degree 
of polymerization may be given by

$$
\overline{\mathbf{P}}=\frac{-\mathrm{d}[\mathrm{M}] / \mathrm{dt}}{\mathrm{d}[\mathrm{P}] / \mathrm{dt}}=\frac{\mathrm{k}_{\mathrm{p}}[\cdot \mathrm{M} \cdot][\mathrm{M}]}{k_{b t}[\cdot \mathrm{M} \cdot]^{2}+k_{t r, M}[\cdot M \cdot][M]+k_{t r, S}[\cdot M \cdot][S]}
$$

ox

$$
\frac{1}{\overline{\mathbf{p}}}=\frac{\mathrm{k}_{\mathrm{bt}}}{\mathrm{k}_{\mathrm{p}}[\mathrm{M}]}\left(\frac{\mathrm{R}_{\mathrm{i}}}{2 \mathrm{k}_{\mathrm{bt}}}\right)^{\frac{1}{2}}+\mathrm{C}_{\mathrm{M}}+\mathrm{C}_{\mathrm{S}} \frac{[\mathrm{S}]}{[\mathrm{M}]}
$$

where $C_{M}=k_{t r, M} / k_{p}, C_{S}=k_{t r, s} / k_{p}$

Since $R_{P}=k_{p}[M]\left(R_{1} / 2 k_{b t}\right)^{\frac{1}{2}}$ and assuming $\delta^{2}=2 k_{b t} / k_{p}^{2}$,

$$
\frac{1}{\bar{P}}=\frac{\delta^{2}}{2[M]^{2}} R_{P}+C_{M}+C_{S} \frac{[S]}{[M]} \quad(x)
$$

Thus the relationship between $R_{P}$ and $\bar{P}$ for Flory diradical polymerization is the same as that of monoradical-initated polymerization (see Equation 13). 
Tzu-Lee Huang was born in Tsingkiang, Fukien, China on October 12, 1938. He was educated in Tze-Yang Elementary School in Tsingkiang and Ta-Tung Public School in Taichung, Taiwan. He was admitted to Provincial Fist Middle School in Taichung in September of 1949 and graduated in July of 1956. He entered Provincial ChungHsing University in July of 1956 and received the Bachelor of Science degree in July of 1960. He was commissioned as a second lieutenant in The Chinese Army and completed his military service in October of 1961. After a short period teaching in the Taichung Middle School system, he returned to Chung-Hsing University as an assistant instructor of chemistry in March of 1962.

He entered the graduate school of the Louisiana State University in September of 1964, and was awarded a teaching assistantship for 1964-1967, and a research assistantship, 1968 to present, under the support of a U.S. Army grant.

He is currently a candidate for the degree of Doctor of Philosophy at the Louisiana State University, Baton Rouge, Louisiana. 
Candidate: Tzu-Lee Huang

Major Field: Chemistry

Title of Thesis: The Kinetics of Polymerization of Pentafluorostyrene

Approved:

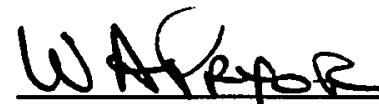

Major Prolessor and Chairman

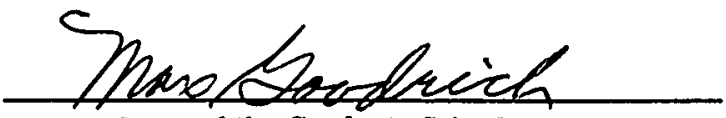

Dean of the Graduate School

EXAMINING COMMITTEE:

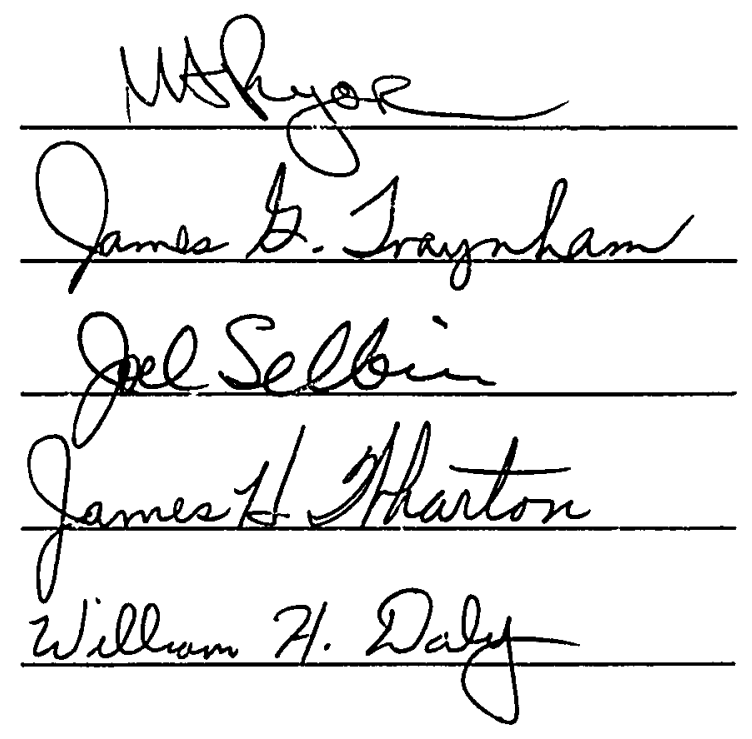

Date of Examination:

$\operatorname{March} 18,1970$ 